\title{
Recent progress in gasoline surrogate fuels
}

\author{
S.Mani Sarathy ${ }^{\mathrm{a}, *}$, Aamir Farooq $^{\mathrm{a}}$, Gautam T. Kalghatgi ${ }^{\mathrm{b}}$ \\ ${ }^{a}$ King Abdullah University of Science and Technology, Clean Combustion Research Center, Thuwal, Saudi Arabia \\ ${ }^{\mathrm{b}}$ Fuel Technology Team, Research and Development Center, Saudi Aramco, Dhahran, Saudi Arabia
}

\section{A R T I C L E I N F O}

\section{Article History:}

Received 1 April 2017

Accepted 25 September 2017

Available online xxx

\begin{abstract}
A B S T R A C T
Petroleum-derived gasoline is currently the most widely used fuel for transportation propulsion. The design and operation of gasoline fuels is governed by specific physical and chemical kinetic fuel properties. These must be thoroughly understood in order to improve sustainable gasoline fuel technologies in the face of economical, technological, and societal challenges. For this reason, surrogate mixtures are formulated to emulate the thermophysical, thermochemical, and chemical kinetic properties of the real fuel, so that fundamental experiments and predictive simulations can be conducted. Early studies on gasoline combustion typically adopted single component or binary mixtures (n-heptane/isooctane) as surrogates. However, the last decade has seen rapid progress in the formulation and utilization of ternary mixtures ( $\mathrm{n}$-heptane/isooctane/toluene), as well as multicomponent mixtures that span the entire carbon number range of gasoline fuels $\left(C_{4}-C_{10}\right)$. The increased use of oxygenated fuels (ethanol, butanol, MTBE, etc.) as blending components/additives has also motivated studies on their addition to gasoline fuels. This comprehensive review presents the available experimental and chemical kinetic studies which have been performed to better understand the combustion properties of gasoline fuels and their surrogates. Focus is on the development and use of surrogate fuels that emulate real fuel properties governing the design and operation of engines. A detailed analysis is presented for the various classes of compounds used in formulating gasoline surrogate fuels, including n-paraffins, isoparaffins, olefins, naphthenes, and aromatics. Chemical kinetic models for individual molecules and mixtures of molecules to emulate gasoline surrogate fuels are presented. Despite the recent progress in gasoline surrogate fuel combustion research, there are still major gaps remaining; these are critically discussed, as well as their implications on fuel formulation and engine design. (c) 2017 Elsevier Ltd. All rights reserved.
\end{abstract}

\section{Contents}

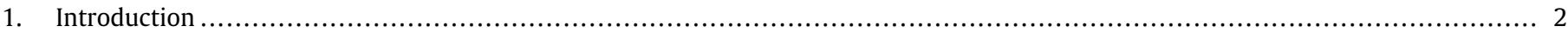

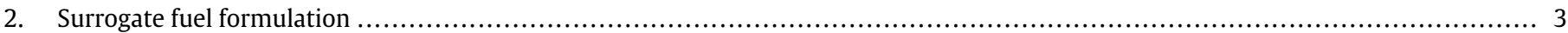

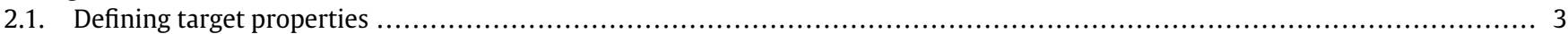

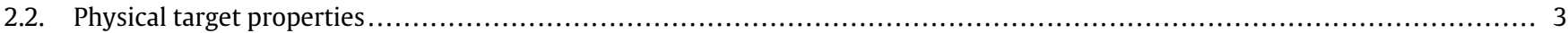

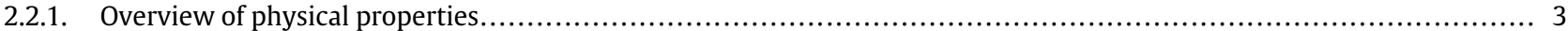

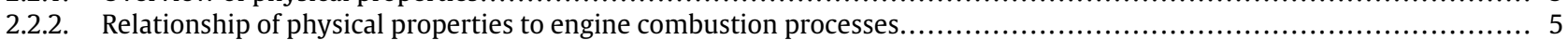

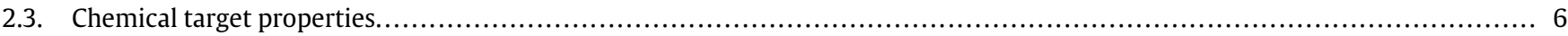

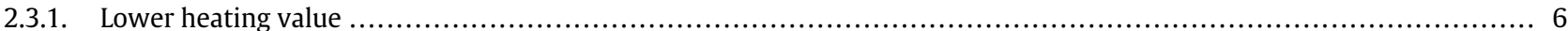

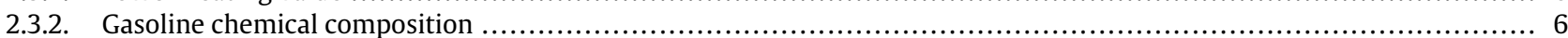

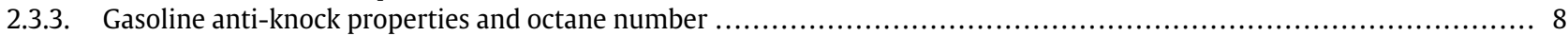

2.3.4. Relationship of chemical properties to engine combustion processes..................................................... 8

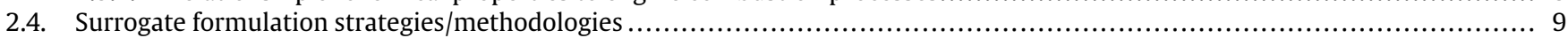

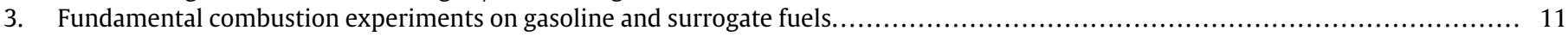

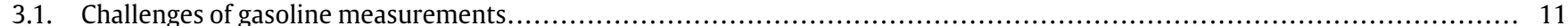

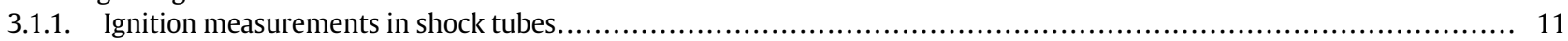

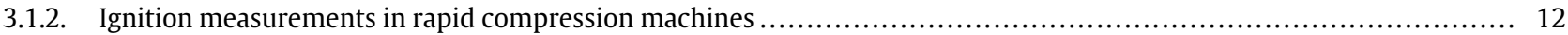

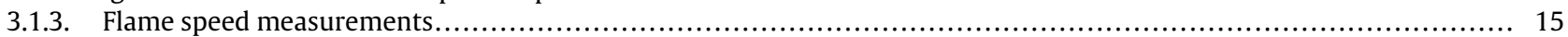

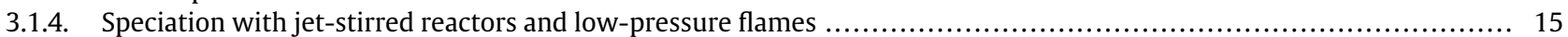

\footnotetext{
* Corresponding author.

E-mail address: mani.sarathy@kaust.edu.sa (S.M. Sarathy).
} 


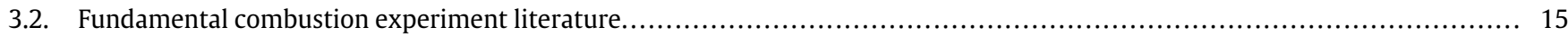

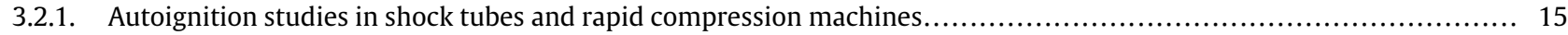

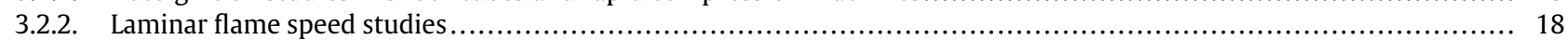

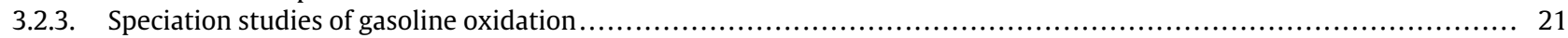

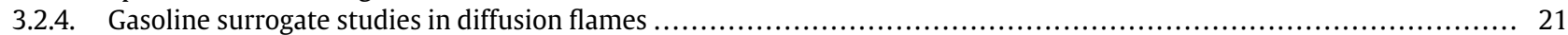

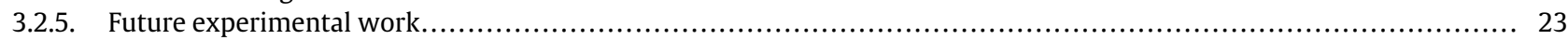

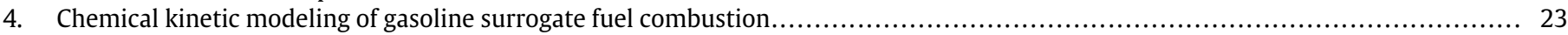

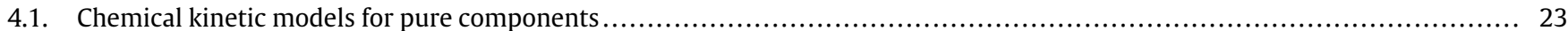

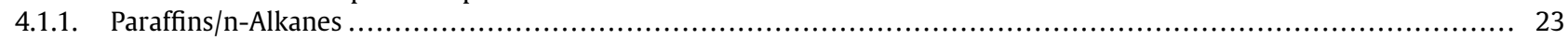

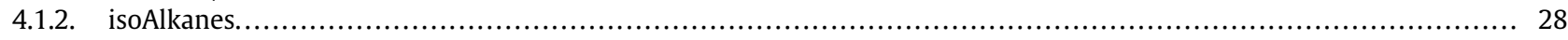

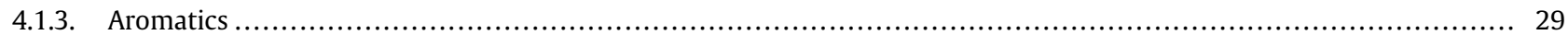

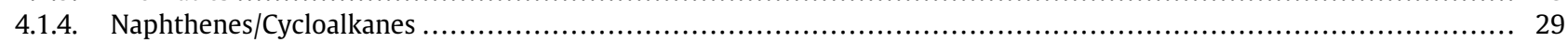

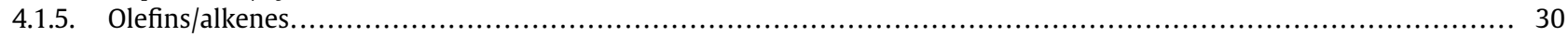

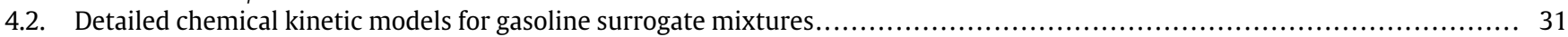

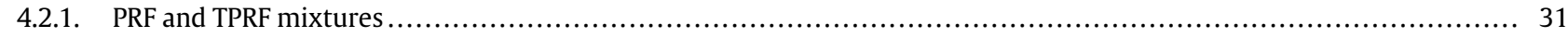

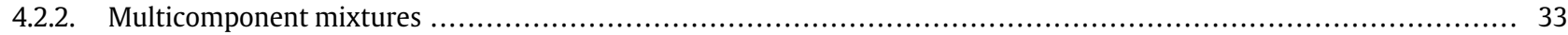

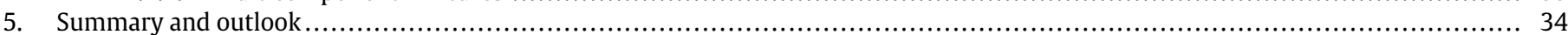

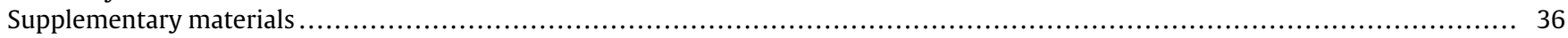

\section{Introduction}

Transport is an essential part of modern society, accounting for around $20 \%$ of the world's energy use [1]. Currently, about $95 \%$ of the energy used for transport is provided by liquid fuels made by refining petroleum. Nearly $40 \%$ of global transport energy is used in passenger cars, which are essentially ( $\sim 80 \%)$ powered by spark ignition (SI) engines running on gasoline [2]; although in Europe diesel engines have a much larger share of the passenger car market. At around 25 million barrels of oil equivalent [3], the daily global demand for gasoline exceeds 4.8 billion liters.

The outlook for transport energy, the prime movers for change in transport technology, alternatives to conventional engines and fuels [4-6], and implications for combustion science in these developments $[7,8]$ have been discussed. There are many forces for change in the transport sector, including increasing demand from a growing and prosperous population, concerns about local and global emissions, energy security and consumer demands and preferences. The importance of each of these varies in different countries at different times. Nevertheless, as in all energy sectors, efficiency is the primary requirement for the engines that drive transport. Engine efficiency is directly related to fuel economy and $\mathrm{CO}_{2}$ emissions. There is also increasing pressure to minimize tailpipe emissions of unburned hydrocarbons (HC), carbon monoxide (CO), nitrogen oxides (NOx) and particulate matter (PM). Nanoparticles are of particular concern for public health.

Reconciling these often conflicting demands for the development of future transport power systems is a tremendous challenge, one which could be better met if new fuel/engine systems are co-operatively developed. Reliable computational models that can predict engine performance and emissions will be of great benefit to development; such models will need to handle mixture formation, combustion, and abnormal combustion, such as engine knock and emissions, which limit efficiency. Fuel composition and properties can affect performance and emissions in current engines [9] and may be of greater importance in new combustion systems that use fuel properties as an additional control parameter. However, practical fuels are mixtures of hundreds of hydrocarbons, and simplified surrogate fuels are needed to represent them [10-12] in computational models. Surrogate fuels contain a limited number of pure components blended together to match a target practical fuel's combustion and emission characteristics. It is currently impossible for a single surrogate to represent all aspects of fuel behavior that are of interest in engines, and different surrogates will be needed to model different phenomena. For instance, the surrogate fuel to model vaporization and mixture formation is likely to be quite different from a surrogate to model autoignition behavior. However, as kinetic models become available for more components and computational resources increase in speed, future surrogates could reproduce all real fuel characteristics.

The path towards cleaner burning and higher efficiency gasoline engine technologies is illustrated in Fig. 1. This review focuses on the development of surrogate fuels for gasoline, which is an integral part of achieving the aforementioned goal. SI engines operate on gasoline fuels comprising petroleum hydrocarbons obtained from fossil resources. The chemical composition of gasoline varies with time and location, so methods of characterizing important chemical and physical properties are needed. Section 2 discusses target fuel properties and strategies for the formulation of surrogate fuels. When formulating surrogates, it is important to understand the relationship between specific fuel properties and engine performance (e. g., efficiency and emissions), so these are also discussed in Section 2. Once surrogates are formulated, fundamental combustion experiments comparing them with their target gasoline fuels are useful for refining the formulation and studying relationships between fuel composition and combustion performance. Section 3 of this paper covers fundamental combustion experiments on gasoline and surrogate fuels, including measurements of ignition delay time, laminar flame speed, and product species formation. Simulating the combustion of gasoline using surrogate fuel chemical kinetic models is needed to perform computer-aided engineering and design. Therefore, Section 4 of this paper focuses on chemical kinetic models for gasoline surrogates and model validation against fundamental combustion experiments. Such models are essential for predicting various combustion phenomenon, such as knock in SI engines and combustion in homogeneous charge compression ignition ( $\mathrm{HCCI}$ engines. Section 5 provides concluding remarks and an outlook towards future research in gasoline surrogate fuel development.

\section{Surrogate fuel formulation}

\subsection{Defining target properties}

An appropriate surrogate fuel mixture can accurately emulate specific target properties of a gasoline fuel under investigation. A surrogate that does not fall within standard gasoline specifications would not be useful for studying fuel/engine interactions. The U.S. standard specifications for SI engine fuels are given by ASTM D481417 , and properties vary depending on state and season [13]. Rand and Verstuyft [14] provide a good reference for various fuel specifications and their practical uses. Gasoline properties are measured following standard test methods; Table 1 provides an overview of 


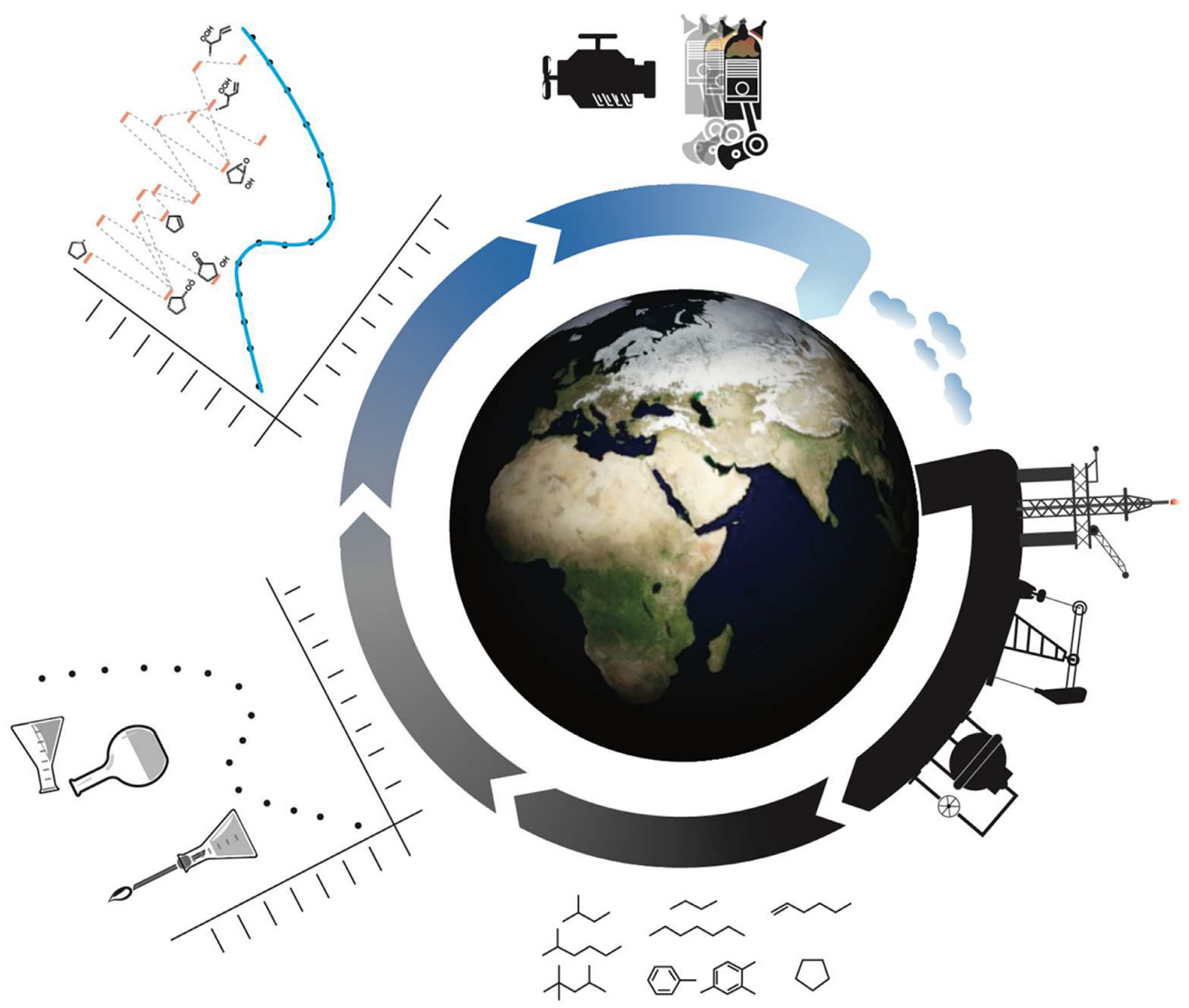

Fig. 1. Design process for developing optimal gasoline fuel-engine technologies with high efficiency and low environmental impact.

important ASTM methods. When formulating a surrogate, target properties are judiciously selected, with an understanding of how they impact engine combustion and operating characteristics. Because each property impacts the combustion process, the relationship between the target property and combustion performance must be considered. Target properties are classified into physical and

Table 1

Summary of relevant ASTM standards for gasoline fuels.

\begin{tabular}{lll}
\hline ASTM Code & Description & Reference \\
\hline D4814 & $\begin{array}{l}\text { Standard specification for automotive spark igni- } \\
\text { tion engine fuel }\end{array}$ & {$[13]$} \\
D2699 & Research octane number (RON) & {$[15]$} \\
D2700 & Motor octane number (MON) & {$[16]$} \\
D4953, D5191 & Vapor pressure & {$[17,18]$} \\
D86 & Distillation & {$[19]$} \\
D4052 & Density & {$[20]$} \\
D240 & Heat of combustion and lower heating value & {$[21]$} \\
& $\quad$ LHV) & {$[22,23]$} \\
D6730, D1319 & Detailed hydrocarbon analysis (DHA) & {$[24]$} \\
D5291 & Carbon and Hydrogen content (H/C) & {$[25,26]$} \\
D4815, D5599 & Oxygenate content & {$[27]$} \\
D5580 & Aromatic content & {$[28]$} \\
D6550 & Olefin content & \\
\hline
\end{tabular}

chemical properties. For example, physical properties, such as fuel volatility, impact spray formation, which in turn influences combustion performance; chemical target properties such as octane number impact the knock-limited operating conditions.

The selection of target properties is closely related to the engine application in which the gasoline fuel is used. Although gasoline fuels are used in both $\mathrm{SI}$ and $\mathrm{CI}$ engine applications, the combustion process in each is significantly different. Even within a specific technology, combustion processes may change, depending on specific engine operating conditions such as speed and load, or if abnormal conditions occur (e.g., pre-ignition, knock, etc.). Therefore, it is important to determine which target properties should be matched by a surrogate, and if all-or possibly only a subset-of target properties should be emulated.

This section presents a summary of important target properties and explains their role in various combustion processes. Table 2 presents typical properties of gasoline fuels from various sources, as well as the properties of some important additives (e.g., oxygenates). Both physical and chemical (thermodynamic and chemical kinetic) target properties will be discussed in the following sections. Finally, strategies for formulating surrogate mixtures by considering which targets should be emulated are discussed. 
Table 2

Typical properties of gasoline fuels.

\begin{tabular}{lllll}
\hline Properties & EURO VI & CARB LEV III E10 & FACE G & FACE F \\
\hline RON & 97.5 & 91.0 & 96.8 & 94.4 \\
MON & 86.6 & 83.4 & 85.8 & 88.8 \\
AKI (antiknock index; & 92.05 & 87.2 & 91.3 & 91.6 \\
$\quad$ [RON+MON]/2) & & & & \\
S & 10.9 & 7.6 & 11.0 & 5.6 \\
Specific gravity & 0.749 & 0.748 & 0.760 & 0.707 \\
Lower heating value (MJ/kg) & 42.4 & 41.8 & 43.1 & 44.3 \\
H/C (mole/mole) & 1.78 & 1.98 & 1.83 & 2.13 \\
Carbon (wt\%) & 85.62 & 82.60 & 86.70 & 84.96 \\
Hydrogen (wt\%) & 12.66 & 13.74 & 13.3 & 15.04 \\
Oxygen (wt\%) & 1.73 & 3.7 & $\mathrm{~N} / \mathrm{A}$ & $\mathrm{N} / \mathrm{A}$ \\
Ethanol (vol\%) & 4.7 & 10.0 & $\mathrm{~N} / \mathrm{A}$ & $\mathrm{N} / \mathrm{A}$ \\
MTBE (vol\%) & $\mathrm{N} / \mathrm{A}$ & $\mathrm{N} / \mathrm{A}$ & $\mathrm{N} / \mathrm{A}$ & $\mathrm{N} / \mathrm{A}$ \\
Aromatics (vol\%) & 30.5 & 22.5 & 33.5 & 5.8 \\
Olefins (vol\%) & 8.2 & 5.7 & 7.8 & 8.6 \\
Vapor pressure (kPa) & 59.8 & 49.6 & 49.6 & 53.8 \\
Distillation profile & & & & \\
Volume recovered (\%) & $\mathrm{T}(\mathrm{K})$ & $\mathrm{T}(\mathrm{K})$ & $\mathrm{T}(\mathrm{K})$ & $\mathrm{T}(\mathrm{K})$ \\
10 & 321 & 332 & 350 & 346 \\
50 & 373 & 375 & 411 & 370 \\
90 & 434 & 431 & 451 & 391 \\
\hline
\end{tabular}

\subsection{Physical target properties}

The physical properties of gasoline determine important enginerelated performance measures. A typical certificate of analysis for gasoline fuel in North America and Europe provides details on specific gravity or density of the fuel at ambient conditions, vapor pressure, and distillation profile, as shown in Table 2. Other important physical properties include viscosity and surface tension, but these are not typically provided in a certificate of analysis, so they should be measured separately. Physical properties such as viscosity play a more significant role in gasoline direct injection (GDI) technology, where fuel sprays strongly impact in-cylinder combustion, as opposed to port fuel injection (PFI).

\subsubsection{Overview of physical properties}

The volatile characteristics of gasoline describe how easily the fuel vaporizes under various conditions. Physical properties related to volatility determine how liquid fuel droplets are converted to gasphase species, where the combustion process occurs. Volatility characteristics strongly affect engine performance under various weather conditions: cold winter conditions require a highly volatile fuel to start the engine, while in summer lower volatility is desirable to prevent emission of volatile organic compounds (VOC). Vapor pressure and distillation profile are two important properties used to measure volatility.

Fuel vapor pressure is exerted by the vapor under thermodynamic equilibrium in the condensed liquid phase; it is an important parameter governing fuel evaporation and affecting cold start, emissions, and combustion efficiency. In the past, carbureted engines could only be started with highly volatile fuels, but modern engines with PFI or GDI do not have this requirement. The vapor pressure of market gasoline varies depending on seasonal temperature conditions. Lower volatility fuels are used at higher temperatures to minimize vapor lock and fuel vapor emissions, while higher volatility is desirable under colder conditions. Typical gasoline vapor pressure ranges from $48-103 \mathrm{kPa}$; it is measured in a closed chamber at $37.8{ }^{\circ} \mathrm{C}(310.95 \mathrm{~K})$ and ambient pressure of one atmosphere (101.325 kPa). In the U.S., dry vapor pressure equivalent (DVPE) is typically measured by ASTM D5191 (the mini method), or ASTM D4953 (dry method) for gasoline-oxygenate blends, while in Europe the DVPE is measured by EN 13016.
The distillation profile (or distillation curve) of gasoline measures the amount of fuel distilled as the temperature varies. Hundreds of hydrocarbon and oxygenated components, of different molecular weight and molecular structure, are contained in gasoline. The boiling points of the various hydrocarbons in the mixture varies, so the gasoline mixture is distilled over a range of temperatures. Compounds with lower boiling points are distilled first, higher boiling point compounds distill later. This distillation profile impacts gasoline engine performance.

The front end of the distillation curve determines the initial volatility of the mixture, which impacts cold start performance and evaporative losses. Butane is typically added to gasoline under cold weather conditions to help raise front end volatility. The mid-range and tail-end of the distillation curve impacts acceleration, power output, fuel economy, and unburned hydrocarbon emissions. The distillation profile is measured by ASTM D86 methodology, in which $100 \mathrm{~mL}$ of fuel is heated in a flask at a controlled rate; as the fuel evaporates, the gas passes through a condenser tube and the condensate is recovered. Temperature is measured by a thermocouple placed above the sample liquid, so that it measures the gas-phase temperature. The temperature corresponding to various volumes of fuel recovered in the condensate is recorded (e.g., T at $10 \mathrm{vol} \%$ recovered, T50, T90, etc.).

A major drawback of the ASTM D86 methodology is that it does not measure the temperature under thermodynamically vapor-liquid equilibrium (VLE) conditions. The rate of heating and condensation, as well as the temperature measurement location, are subject to significant uncertainty. This reduces experimental precision and prevents the modeling of the experiment using thermodynamic equations of state. To resolve these issues, Bruno et al. [29-32] developed the advanced distillation curve (ADC) method, which measures true thermodynamic VLE state points with significantly improved accuracy. The ADC method's improved ability to accurately measure VLE conditions, compared to the ASTM D86 method, makes it possible to numerically predict the fuel's distillation properties using a mixture model [33].

Fig. 2 shows an example of ADC measurements for six FACE (Fuels for Advanced Combustion Engines), as measured by Burger et al. [32]. Recently, Ferris and Rothamer [34] modified an ASTM D86 distillation apparatus to determine experimental equilibrium distillation curves (EEDC). Fig. 3 from Ferris and Rothamer [34] shows typical uncertainty resulting from traditional D86 measurements of gasoline fuel, in which temperature measured in the vapor phase (D86 vapor) is much lower than the equilibrium condition. Simply measuring the liquid temperature in the sample (D86 Liquid) provides a much closer agreement to the equilibrium measurement method (i.e. EEDC). These improved distillation methods are beneficial because they make it possible to simulate complex fluid behavior using thermodynamic vapor-liquid equilibrium relations [33,35].

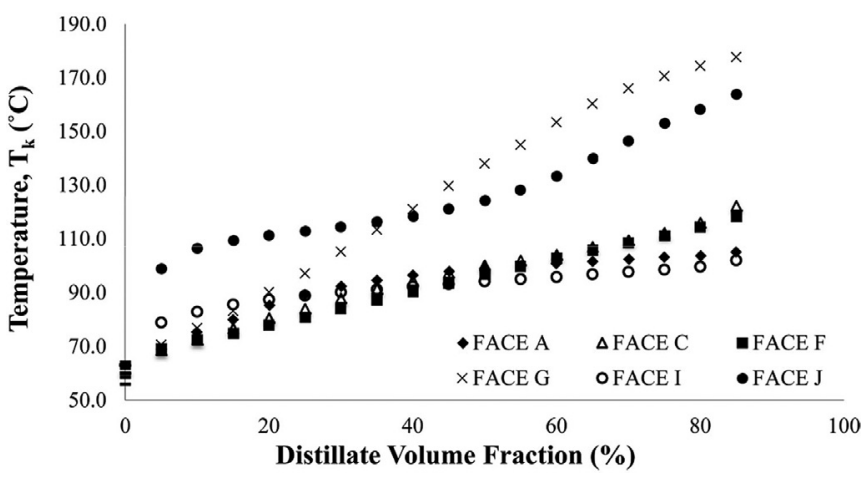

Fig. 2. Distillation curves for FACE gasolines measured by the ADC method of Burger et al. [32]. Reproduced with permission from The American Chemical Society. 


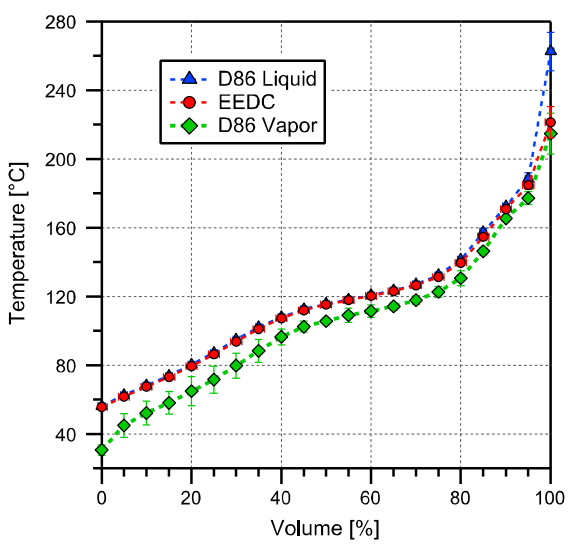

Fig. 3. Experimentally measured equilibrium (EEDC), D86 vapor, and D86 liquid distillation curves for a certification gasoline by Ferris and Rothamer [34]. Reproduced with permission from Elsevier Publishing.

Vapor pressure and distillation profile requirements for gasoline fuels in automotive engines are specified according to ASTM D4814 in the U.S. market and EN 228 in the European market. Various categories, with their own ranges for vapor pressure and distillation profile, are provided to meet various seasonal and performance measure requirements. In the ASTM specification, vapor pressure ranges from $54 \mathrm{kPa}$ for Class AA gasoline to $103 \mathrm{kPa}$ for Class $\mathrm{E}$ gasoline. T10, T50, and T90 for Class AA gasolines are $70{ }^{\circ} \mathrm{C}(343 \mathrm{~K})$, $77-121^{\circ} \mathrm{C}(350-394 \mathrm{~K})$, and $190^{\circ} \mathrm{C}(463 \mathrm{~K})$, respectively. For Class $\mathrm{E}$ gasolines, T10, T50, and $\mathrm{T} 90$ are $50{ }^{\circ} \mathrm{C}(32 \mathrm{~K}), 77-110{ }^{\circ} \mathrm{C}$ (350-383 K), and $185^{\circ} \mathrm{C}(458 \mathrm{~K})$, respectively [36]. A recent study by CONCAWE [37] showed that volatility requirements may be relaxed with the introduction of modern engine hardware, such as GDI technology, which reduces the effects of gasoline volatility on regulated emissions and driveability.

The specific gravity and viscosity of gasoline fuels are important physical properties that may impact fuel spray formation and breakup processes. Specific gravity (the ratio of fuel density to water density) is a dimensionless quantity. The density is measured by
ASTM D4052 in North America or EN 12185 in Europe. The typical range of specific gravity in the ASTM D4814 or EN 228 specifications is between 0.72 and 0.77 , which is to ensure sufficient energy density. Viscosity requirements for gasoline fuels are not mentioned in ASTM D4814 and EN 228 specifications for SI fuels, and measurement and reporting of these values is not required. Gasoline viscosity has less influence on spray processes in PFI and GDI engines due to the use of hollow cone injectors with wide spray angles and relatively low injection pressures.

\subsubsection{Relationship of physical properties to engine combustion processes}

The previous section highlighted several important physical properties of gasoline. It is necessary to understand how these properties affect various engine combustion processes in order to know which properties are important for a surrogate fuel to emulate. This section summarizes recent literature relating various fuel physical properties with engine combustion processes and performance measures.

It has been noted that volatility and distillation profile characteristics affect engine cold-start performance and emissions. Volatility primarily affects fuel evaporation rate, and thus, the air/fuel ratio in the combustion chamber. The main processes affecting mixture preparation in PFI SI engines are shown in Fig. 4 [38]. The processes are extremely complex and include both droplet evaporation prior to entering the combustion chambers and the entrainment of liquid droplets into the bulk flow. Wall wetting by larger droplets impinging on the inlet port or intake valve is also important. The dynamics and evolution of these processes are controlled by their fuel volatility characteristics, temperature, engine design and operating conditions. Skippon and Norton [38] investigated many of the effects of gasoline volatility on engine performance. They showed that when the engine is fully warmed up, all fuels are completely vaporized in the inlet port, regardless of their T50 or T90. However, under cold start conditions, only $20-30 \%$ of the fuel is vaporized in the inlet port, making wall wetting significant. T50 has a significant impact on how much fuel is vaporized under cold-start conditions, while the T90 is less relevant. However, as the engine warms up, T90 impacts vapor phase composition.

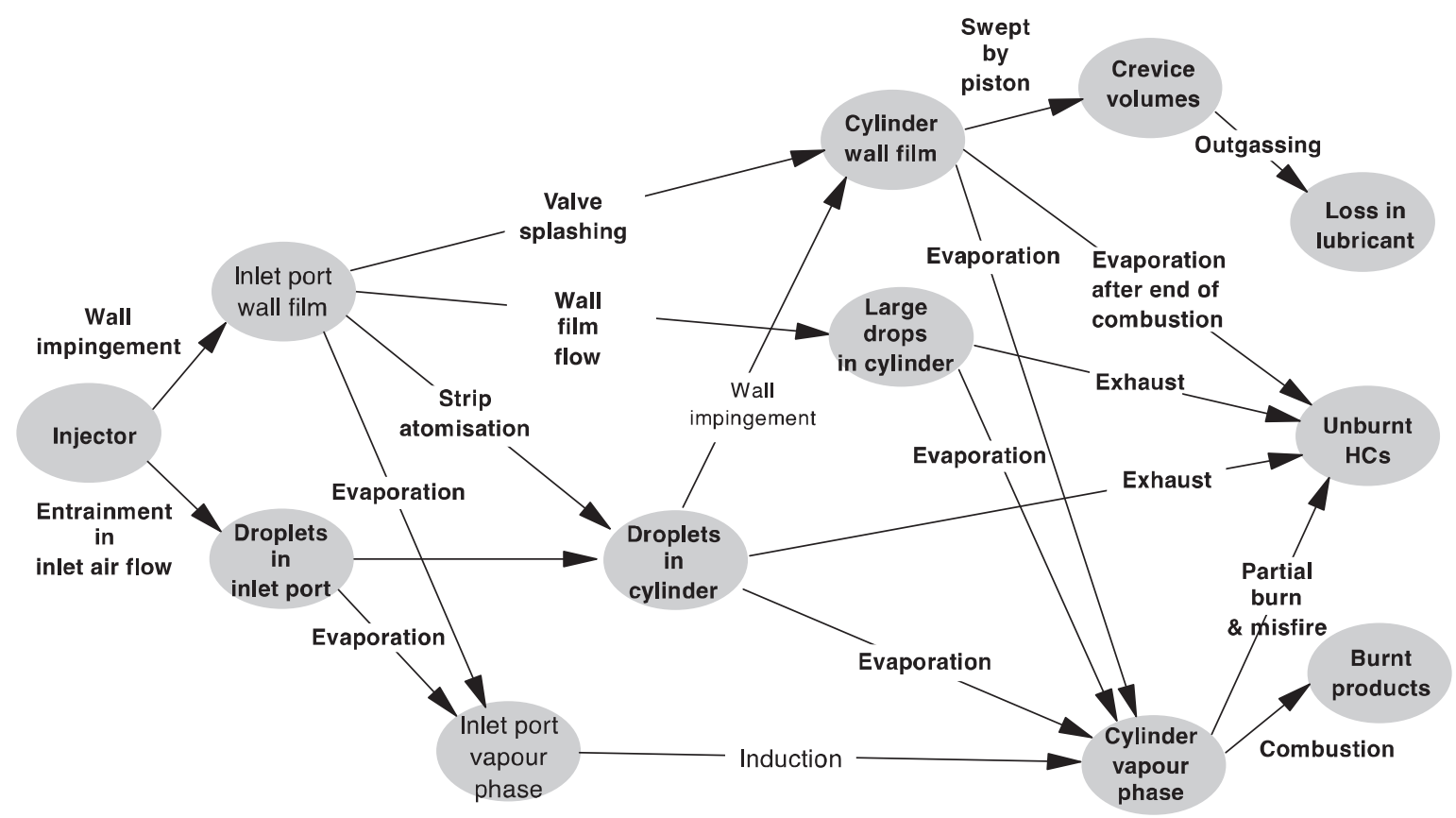

Fig. 4. Important processes affecting in-cylinder mixture formation in PFI SI engines. Reproduced from Skippon and Norton [38] with permission from SAE International. 
A detailed study of PFI engines by Takei et al. [39] showed that fuel volatility has a significant impact on $\mathrm{HC}$ emissions. Gasoline fuels with a high T50 result in leaner air/fuel rations in the cylinder due to poor vaporization of the fuel, causing lean misfiring and increasing $\mathrm{HC}$ emissions. If the T50 is too low however, the air/fuel ratio becomes rich and results in rich misfire and increased HC emissions. Ryan and Matheaus [40], performed HCCI engine measurements with gasolines of different volatilities. They showed that less volatile fuels inhibit the fuel/air mixing process, so that perfectly -or even partially mixed-fuel/air mixtures did not occur before the start of reaction. Incomplete fuel evaporation in HCCI engines results in fuel droplets that undergo diffusion combustion in the cylinder, increasing both soot and $\mathrm{NO}_{x}$ emissions. In principle, the high volatility of gasoline-like fuels are desirable in HCCI and other compression ignition engine concepts, where sufficient premixing of fuel and air is required prior to combustion [41-47].

In GDI engines, the distribution of the fuel spray has a significant impact on the in-cylinder combustion process due to the short time available for fuel/air mixing. The effects of fuel volatility and engine operating conditions on GDI fuel spray were investigated by VanDerWege and Hochgreb [48]. Their experiments used planar laserinduced fluorescence to image sprays ensuing from a pressure-swirl fuel injector in an optically-accessible direct injection spark ignition (DISI) engine. They showed that the higher volatility components in multi-component fuel mixtures evaporate quickly when fuel temperature is high, resulting in disruption of the spray structure and formation of a vapor core within the spray core. Fuel volatility also impacted spray penetration length and spray width.

Using Schlieren and Mie scattering techniques, Li et al. [49] also studied the effects of fuel volatility on GDI spray characteristics at high pressures and high temperatures. They tested two surrogate fuel mixtures comprising various amounts of n-pentane, isooctane, and n-decane, as well as a fully formulated gasoline fuel [49]. Their results showed that higher fuel temperature increased evaporation and decreased liquid and vapor penetration distances. Furthermore, fuel mixtures with a larger fraction of heavier components had lower volatility, and therefore lowered evaporation and increased liquid and vapor penetration.

Davy et al. [50] and Zigan et al. [51] showed that flash boiling influenced by fuel composition and volatility characteristics affects mean droplet diameter and mixture formation in DISI engines, thereby affecting combustion and emissions. The volatility of gasoline alters with the addition of ethanol due to non-ideal mixing behavior. Ethanol blending is known to cause higher volatility in gasoline-ethanol mixtures, while also introducing discontinuities in the distillation profile. Changes in T50 and T90 due to ethanol blending often motivate researchers to modify the gasoline blendstock by adding higher boiling point hydrocarbons in order to remain within ASTM D4814 limits. However, a recent study by Anderson et al. [52] showed that studies which evaluate the effects of ethanol blending on engine performance and emissions obscure the results, due to the mixing of higher hydrocarbons; for this reason, such modifications to the gasoline blendstock should be avoided.

Low speed pre-ignition (LSPI) and superknock phenomena in GDI engines has also been shown to be related to fuel volatility. One common hypothesis is that LSPI is caused by fuel impinging on combustion chamber walls, which interacts with oil on the liner and results in oil-fuel droplets detaching from the surface. These oilfuel droplets serve as reactive hot spots that result in pre-ignition. Mayer et al. [53] showed that increasing fuel volatility significantly reduces the tendency for pre-ignition. They explained that less volatile fuels increase wall wetting and enter the piston crevice volume, thereby enhancing the detachment of oil droplets by local fuel dilution. Their experiments were further confirmed by proving that $\mathrm{HC}$ emissions increase with decreasing fuel volatility, which also correlated with the pre-ignition tendency.

\subsection{Chemical target properties}

Chemical properties of gasoline affect the combustion process because fuel/air oxidation is controlled by the fuel's molecular structure. As mentioned previously, gasoline is a complex mixture of hundreds of hydrocarbons, as well as oxygenated additives. A gasoline certificate of analysis typically provides information on fuel octane numbers, carbon content, hydrogen content, oxygen content, $\mathrm{H} / \mathrm{C}$ ratio, aromatic content, olefinic content, and lower heating value (LHV), all of which are determined by various ASTM or EN standard methods. In addition to these typical chemical properties, more detailed information on gasoline chemical composition can be obtained by detailed hydrocarbon analysis (DHA), including the distribution of PIONA (paraffins, isoparaffins, olefins, naphthenes, aromatics), and even individual hydrocarbon structures. Laminar flame speed is another chemically-related target property that is not typically reported for market fuels, but may be measured using various methods.

The chemical composition of the fuel ultimately affects combustion related target properties such as RON, MON, laminar flame speed, and LHV. However, it is currently difficult to include the full spectrum of hydrocarbons in a gasoline surrogate mixture, primarily due to the present lack of chemical kinetic models for most species (as discussed in Section 4). Nevertheless, it is plausible that as kinetic models become available for hundreds of hydrocarbons, future gasoline surrogate mixtures would include a large number of components that accurately emulate all properties of the target gasoline.

\subsubsection{Lower heating value}

The LHV of gasoline is a gauge of its energy content, which is measured as the heat produced by combusting a prescribed amount of fuel in stoichiometric proportions with air under certain initial temperature and pressure conditions. For this reason, LHV is also commonly referred to as heat of combustion, and is directly related to the chemical composition of the gasoline fuel. LHV is measured by ASTM D240, using a bomb calorimeter, and is typically reported on a mass basis, according to SI units (MJ/kg). On a mass basis, the LHV is similar for fuels with similar molecular structure. For example, all paraffinic hydrocarbons from $C_{5}$ to $C_{16}$ have LHV in the range of $\sim 44-46 \mathrm{MJ} / \mathrm{kg}$, while aromatics have LHV near $40-41 \mathrm{MJ} / \mathrm{kg}$. This relationship between molecular structure and LHV is shown in Fig. 5 [54], in which the LHV is linearly proportional to the $\mathrm{H} / \mathrm{C}$ ratio of a complex real fuel mixture.

Gasoline fuels are typically sold on a per unit volume basis, so it is often useful to understand the amount of energy per unit volume (e. g., MJ/L). This has an impact on vehicle fuel economy, which is

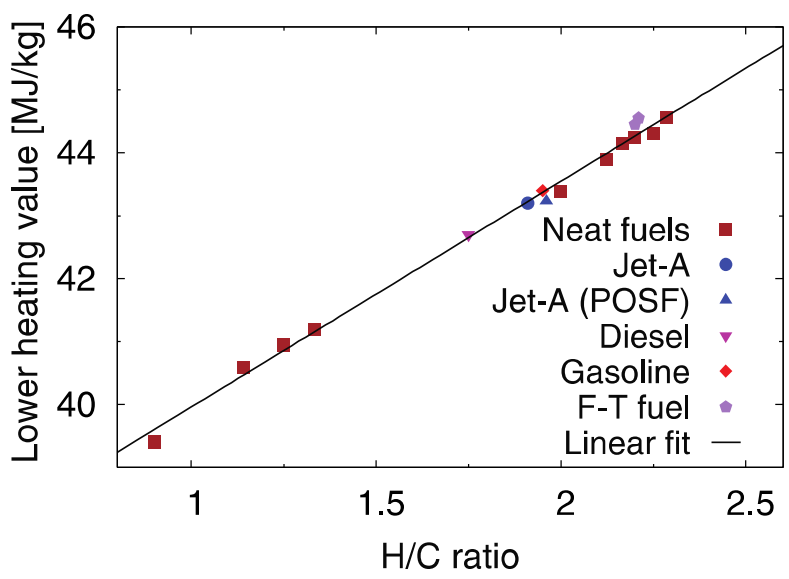

Fig. 5. Correlation between LHV and $\mathrm{H} / \mathrm{C}$ ratio. Reproduced from Narayanaswamy et al. [54], with permission from Elsevier Publishing. 
measured in units of $\mathrm{L} / 100 \mathrm{~km}$ (or miles per gallon), because distance travelled per unit of fuel is directly related to the volumetric energy density of the fuel. Converting LHV to volumetric energy density requires multiplying by the liquid density of the fuel, which varies greatly with its molecular structure. Low molecular weight hydrocarbons have lower liquid density, therefore their volumetric energy density is notably lower than higher molecular weight hydrocarbons. The addition of oxygenates (e.g., ethanol) to gasoline decreases LHV (mass basis) because fuel-bound oxygen does not burn to generate heat (i.e., oxygen has no heating value). Therefore, the volumetric energy density of oxygenated fuels is also lower than pure hydrocarbon fuels, lowering oxygenated fuel economy. In general, the reduction in LHV is proportional to the mass percent of oxygen in the fuel.

\subsubsection{Gasoline chemical composition}

One important property of gasoline is its chemical composition, which determines all subsequent chemical properties (octane numbers, $\mathrm{H} / \mathrm{C}$ ratio, $\mathrm{LHV}$, etc.) and physical properties (distillation curve, density, etc.). The PIONA range of typical gasoline fuels is shown in Fig. 6, along with representative molecular structures for each PIONA class. Gasoline is distilled from crude oil, and the initial cut comprises $\mathrm{C}_{4}$ to $\mathrm{C}_{10}$ n-paraffins, isoparaffins, naphthenes (cycloparaffins), and aromatics. Various refinery processes are used to upgrade crude distillation products into fuels that meet gasoline specifications; these processes include alkylation, catalytic condensation, isomerization, and catalytic reforming [55], all of which are aimed at creating highoctane quality molecules in the gasoline molecular weight range.

Normal paraffins have the lowest octane quality of all gasoline hydrocarbons, and are not typically found in large quantities in market fuels. Iso-paraffins are generally found in larger quantities due to their higher octane numbers. Paraffins range in carbon numbers from $C_{4}$ to $C_{8}$. Low molecular weight paraffins, such as n-butanes and isobutanes, are blended into gasoline to meet front-end distillation requirements for cold-start under winter conditions. Other common paraffins include $\mathrm{n}$ - and isopentane and various isomers of hexane, heptane, and octane with multiple methyl substitutions. Octane number increases with the increased degree of methyl substitutions [56,57], so higher molecular weight paraffins $\left(C_{7}-C_{8}\right)$ in gasoline typically have one to three methyl substitutions. The mixture of $n$ - and isoparaffins is highly variable, and because of the large number of possible isomeric species, no specific paraffinic structure is present at more than a few percent. For example, the widely used primary reference fuel surrogates, n-heptane and isooctane, are only present in small quantities (less than 1\%) in real gasoline fuels.

The naphthenic content of gasoline is limited to below 20 vol\%, since these compounds have low octane quality and are easily converted to aromatics via reforming. Typical naphthenes found in gasoline are in the $C_{5}$ to $C_{8}$ range, and include species such as cyclopentane, cyclohexane, methyl cyclopentane, methyl cyclohexane, and dimethyl cyclohexane isomers. Cyclopentane has the highest octane number among the cycloalkanes.

Olefins (alkenes) are also found in limited quantities due to their poor oxidative stability, which reduces the storage life of gasoline fuels. Furthermore, olefins are often useful precursors for other value added chemicals (e.g., polymers). Typical olefins range from $C_{5}$ to $C_{8}$ and include linear and branched pentene and hexene isomers. Due to the presence of double bonds in the molecular structure, they have high octane numbers; but they also display high octane sensitivity.

Aromatics are the highest molecular-weight hydrocarbons in gasoline fuels, falling in the $C_{6}$ to $C_{9}$ carbon number range. The end of the gasoline distillation profile is typically comprised of high molecular weight alkylbenzenes. Aromatics have high octane numbers, but they are typically limited to below 30-35 vol\%, due to their propensity to increase soot (particulate matter) emissions. Furthermore, benzene is a known carcinogen, so its concentration in
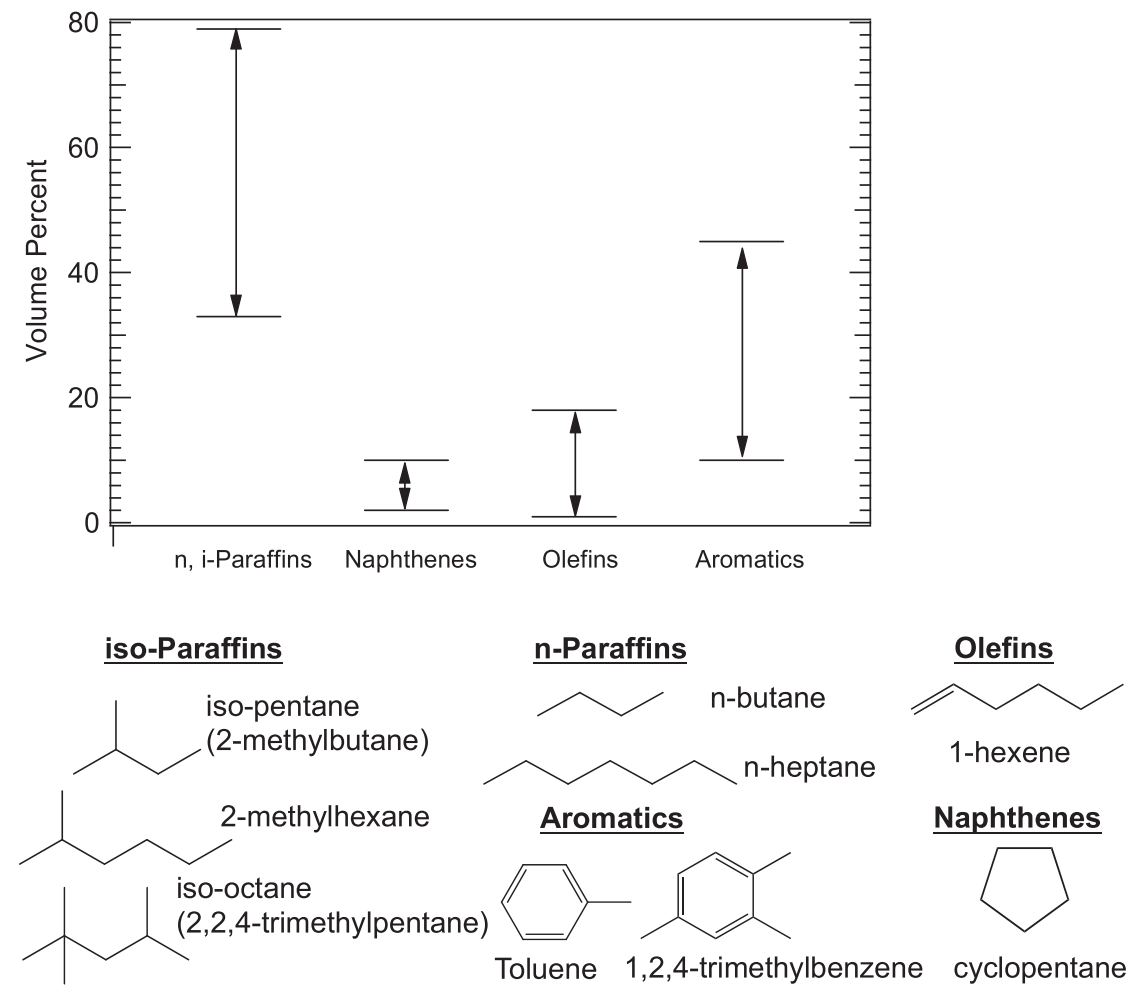

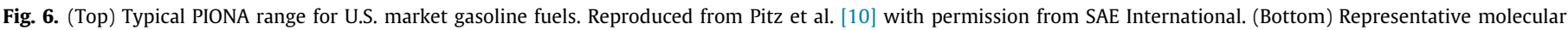
structures in gasoline fuels. Reproduced from Sarathy et al. [58] with permission from Elsevier Publishing. 
gasoline is limited to below one vol\%. For these reasons, the aromatic hydrocarbons in gasoline fuel are limited to toluene, m-xylene, oxylene, ( $p$-xylene is a valuable commodity chemical, not blended into gasoline), ethylbenzene, and various trimethyl benzene isomers. Toluene is the most predominant aromatic found in gasoline, followed by the xylene isomers.

In addition to hydrocarbon components, gasoline fuels may also contain various oxygenated additives. Traditionally, oxygenates such as methyl t-butyl ether (MTBE), ethyl t-butyl ether (ETBE), tamyl methyl ether (TAME), diisopropyl ether (DIPE), methanol, ethanol, and t-butanol have been added to gasoline to improve its antiknock quality. The use of MTBE as an octane enhancer is prohibited in North America, but many Asian countries still use it. Ethanol is by far the most widely used oxygenate additive for gasoline fuels, and may be blended up to 85 vol\% (E85) into gasoline fuels; the most commonly found blends contain ten vol\% (E10) in North America and five vol\% (E5) in Europe. Recently, interest in renewable fuels has motivated research on blending other oxygenates, such as propanol and butanol isomers [59,60], pentanol isomers [61-64], cyclic oxygenates (e.g., furans and alkyl furans) [65-67], aromatic oxygenates and esters derived from levulinic acid (e.g., ethyl levulinate, methyl levulinate, etc.) [68,69].

The exact chemical composition of gasoline fuels can be determined by ASTM D6730, which utilizes high resolution gas chromatography (GC). This DHA test method determines the individual hydrocarbon components in SI engine fuels, including mixtures containing oxygenates, with boiling ranges up to $225^{\circ} \mathrm{C}(498 \mathrm{~K})$. The D6730 method is accurate for mixtures containing up to $25 \mathrm{wt} \%$ olefins, which makes it acceptable for most practical gasoline fuels. However, mixtures containing higher olefin content, or olefins larger than $C_{7}$, require a separate multidimensional GC method (e.g., ASTM D1319) to obtain accurate olefin percentages.

A detailed analysis of individual components in gasoline fuels is usually unavailable, or not required by ASTM standards. Typically, gasoline suppliers only provide information on the aromatic, olefinic, oxygenate (ethanol or MTBE), carbon, hydrogen and oxygen contents, and $\mathrm{H} / \mathrm{C}$ ratio, as shown in Table 2 . Normally, this information, together with the octane rating, is sufficient to develop a surrogate fuel with a reasonable level of chemical fidelity. Carbon and hydrogen content are important for determining the $\mathrm{H} / \mathrm{C}$ ratio, and these are measured using ASTM D5291 methodology. Oxygen content and the concentration of oxygenated additives are measured by ASTM D4815, which is suitable for determining MTBE, ETBE, TAME, DIPE, t-amyl alcohol, and $\mathrm{C}_{1}$ to $\mathrm{C}_{4}$ alcohols, and/or D5599 for other oxygenates. The aromatic content is measured by ASTM D5580, which utilizes gas chromatography to quantify benzene, toluene, ethylbenzene, xylene isomers, and $C_{9}$ and heavier aromatics. The total olefinic content is measured by ASTM D6550, which is based on supercritical-fluid chromatography.

\subsubsection{Gasoline anti-knock properties and octane number}

Perhaps the most important chemical property of gasoline fuel is its antiknock quality, which is determined by the ability of the fuel/ air mixture to resist autoignition. Knock occurs because of autoignition of the unburned fuel/air mixture in the end-gas, ahead of the advancing flame front in a SI engine; the presence of knock limits engine efficiency $[8,16]$. The knocking tendency of a fuel/air mixture depends on the pressure and temperature evolution with time and on the anti-knock quality of the fuel. The anti-knock, or octane quality, is traditionally measured by the research and motor octane numbers, RON and MON. The MON test is run at $900 \mathrm{rpm}$ with an intake temperature of $149^{\circ} \mathrm{C}$; the RON test is run at an engine speed of $600 \mathrm{rpm}$ and an intake temperature of $52{ }^{\circ} \mathrm{C}$ in a single-cylinder CFR engine. These tests are run using procedures set in ASTM D2699 for RON and ASTM D2770 for MON. All practical fuels have RON higher than MON, and the difference between RON and MON is known as octane sensitivity (S).

If a target surrogate is intended to mimic only autoignition phasing in engines running under premixed conditions (where different fuels are subjected to the same pressure and temperature evolution), it should match both RON and MON of the target gasoline. A toluene/ PRF (TPRF) mixture can be found to match any target RON and MON [70], and chemical kinetic calculations on such a surrogate can predict knock onset in knocking engines [70,71]. However, TPRF surrogates for high octane sensitivity gasolines (e.g., above seven) have toluene fractions which exceed 30\%. Such surrogates with high aromatic fractions do not accurately represent the hydrocarbon distribution in practical gasoline fuels.

\subsubsection{Relationship of chemical properties to engine combustion processes}

Several important chemical properties of gasoline were highlighted in the previous sections. Chemical properties inherently affect combustion processes in an engine because the molecular structure impacts reactivity. However, it is necessary to ascertain the importance of chemical properties on various engine processes and to determine what level of chemical fidelity is needed for a surrogate to emulate a real gasoline fuel. The following section summarizes recent literature relating various fuel chemical properties to engine combustion processes and performance measures. The effects of fuel chemical properties on deposit formation are not discussed in detail as this is primarily related to fuel sulfur content, olefin content, aromatic content, and presence of detergents [72,73]. Increasing fuel aromatic and olefin content has a statistically significant effect on promoting deposit formation [74].

The efficiency, and hence $\mathrm{CO}_{2}$ emissions, of SI engines depends strongly on octane requirements, which determine the knock limited operating range. Higher octane fuels enable earlier spark timing, which can improve combustion efficiency and power output at higher compression ratios. Di Iorio et al. [75] showed that blending oxygenates, such as ethanol, MTBE, and ETBE, increase the octane number, thereby improving combustion performance. This results in decreased $\mathrm{HC}$ and carbon monoxide (CO) emissions, as well as lower particulate matter emissions in oxygenated fuels due to the displacing of aromatics [76-78]. Machado et al. [79] conducted a careful study of gasoline fuel composition on the SI engine calibration and performance, with a specific focus on the relationship between octane number and composition. The content of aromatics, n-paraffins, and isoparaffins was varied in a gasoline base fuel containing anhydrous ethanol, and the effect of each blending component on engine combustion was assessed. The authors found that n-paraffins are suitable blending components for engine conditions that are not sensitive to knock because they permit higher stoichiometric fuel/ air ratios and higher $\mathrm{H} / \mathrm{C}$ ratios, which increases combustion efficiency and decreases fuel consumption. However, when the engine is operated at conditions sensitive to knock, aromatics and isoparaffins can be blended to produce a higher octane rating fuel. isoParaffins are superior to aromatics due to their higher stoichiometric fuel/ air ratio and higher $\mathrm{H} / \mathrm{C}$ ratios, which improves combustion efficiency and reduces particulate matter emissions. The authors demonstrated the need for flexible engine control systems that can optimize engine performance based on the fuel used [79]. This fuel blending concept has led to recent interest in octane-on-demand (OOD) [80-82], which offers the potential to vary fuel composition, and hence its octane number, depending on the engine operating requirements.

The chemical composition of gasoline fuel has a direct impact on engine emissions. A comprehensive study by Hochhauser et al. [83] investigated the effects of aromatic, olefin, and MTBE content on vehicle emissions. It was shown that the addition of MTBE reduces HC and CO emissions. It is well accepted that oxygenated additives, 
such as ethers and alcohols [60,84], improve combustion efficiency, thereby reducing particulate matter (i.e., soot), HC, CO emissions. In modern vehicles, increasing the aromatic content increases hydrocarbon and particulate emissions [78] while lowering oxides of nitrogen (NOx). However, the addition of oxygenated aromatics (e.g., 2-phenylethanol, anisole, etc.) can improve the soot-NOx tradeoff [85-87]. Increasing olefin content corresponds to lower NOx emissions and higher hydrocarbon emissions $[83,88]$.

Modern DISI engines are shown to be sensitive to fuel composition and antiknock quality. As mentioned previously, modern DISI engines have negative $K$ values [89], so fuels with lower MON values (i.e., higher S) extend the knock-limited operating range. Davies et al. [90] studied the fuel effects on DISI combustion with a focus on octane appetite; they showed that higher sensitivity fuels (high RON and low MON) perform better in modern engines. Furthermore, high sensitivity fuels were shown to have higher burning velocity, thereby improving fuel efficiency and cyclic variability. They also noted that higher burning velocity fuels may be more prone to preignition, and hence superknock [90].

Machado et al. [91] showed that various TPRF (toluene/n-heptane/isooctane) surrogate mixtures, each blended with $25 \mathrm{vol} \%$ ethanol, behaved differently in a multi-cylinder DISI engine due to variations in their antiknock index (AKI) values and stoichiometric $\mathrm{A} / \mathrm{F}$ ratios. A reference gasoline with an AKI of 89.2 was tested alongside ten different surrogates at a range of speed and load operating points. Their results showed that TPRF/ethanol mixtures with AKI values and stoichiometric $\mathrm{A} / \mathrm{F}$ ratios close to the reference gasoline could match engine torque, fuel consumption, and specific fuel consumption across the entire operating range.

A recent study by Ahmed et al. [92] assessed the impact of gasoline chemical properties and composition of DISI engine combustion, performance, and emissions. The study was unique in that two wellcharacterized non-oxygenated gasolines with similar AKI, but varying $S$, were experimentally investigated at various load points and spark timings with early injection timings. The goal was to determine whether fuels with similar knocking characteristics in a standard cooperative fuel research (CFR) engine (i.e., similar AKI) behave differently in DISI engines. The authors showed that gasoline with higher aromatic content resulted in higher hydrocarbon and soot emissions [92]. Interestingly, they also noted that if the fuel octane number is held constant, a gasoline fuel with lower heat capacity (e. g., constant pressure, $C_{p}$ ) will result in higher end-gas temperatures, making it more prone to knock. Furthermore, the fuel burn duration was found to be dependent on fuel composition (e.g., $\mathrm{H} / \mathrm{C}$ ratio), as well as thermodynamic properties of the fuel, which affect in-cylinder temperature and pressure. Thus, in DISI engines heat capacity is an important chemical property to consider during surrogate fuel formulation, as this determines the conditions at which combustion occurs.

The previous discussion focused on the impact of gasoline chemical properties on SI engine combustion and emissions. However, gasoline-like fuels may also be utilized in low temperature combustion (LTC) engine strategies such as $\mathrm{HCCI}, \mathrm{PCCl}$, etc. The combustion process in LTC engines is notably different, and therefore fuel chemical properties have different effects than in SI engines. Most notably, to obtain the desired onset of heat release and combustion phasing, an appropriate ignition quality is required in $\mathrm{HCCl}$ engines. An ignition quality metric for $\mathrm{HCCl}$ engines has received attention in the literature $[8,40,93,94]$, and is naturally linked to the chemical properties of the fuel. In PCCI and PPC engines, where fuel is injected late in the cycle to achieve stratification, both fuel chemical properties (e.g., ignition quality) and physical properties (e.g., spray formation, vaporization, etc.) are important.

Shibata et al. [93] proved that the evolution of low temperature heat release (LTHR) plays a critical role in operation of $\mathrm{HCCl}$ engines. Paraffinic fuels were shown to have appreciable LTHR, while aromatics did not display LTHR behavior. Olefins and naphthenes (cycloalkanes) display minor LTHR but behave more like LTHR inhibitors than LTHR promoters, when compared to paraffins. The authors linked a fuel's measured HCCI engine high temperature heat release (HTHR) characteristics to its conventional RON and MON metrics, obtained in an SI engine. They showed that RON correlates with the HTHR characteristics under engine conditions when the fuel combustion displays minor LTHR characteristics. However, MON was shown to correlate with HTHR characteristics under conditions without LTHR [93].

The effect of fuel composition on $\mathrm{HCCI}$ engine combustion was investigated by Truedsson et al. [95,96] by investigating various PRF mixtures and mixtures of n-heptane, isooctane, toluene, and ethanol. Their aim was to develop an HCCI autoignition index to rank fuels, similar to the RON and MON metric for SI engines. The autoignition temperature and magnitude of LTHR were identified as relevant metrics of ranking ignition quality of fuels in $\mathrm{HCCI}$ engines. The authors demonstrated that increasing n-heptane concentration increases LTHR and decreases AIT, while toluene increases AIT and acts as an LTHR inhibitor. Ethanol was also shown to increase the AIT and suppress LTHR. These findings indicate that chemical composition (e.g., paraffin, aromatic, alcohol) has similar qualitative effects in HCCI engine autoignition and SI engine knock. However, quantitatively, the HCCI ranking of fuel autoignition is not directly correlated with SI engine RON and MON ratings. This indicates that the effect of chemical composition depends strongly on engine operating conditions (e.g., temperature, pressure, and equivalence ratio).

To further understand fuel composition effects on autoignition quality, Lacey et al. [94] studied the effects of refinery stream gasoline blends in an HCCI engine. They tested 17 gasoline fuels with ethanol content ranging from $0 \%$ to $100 \%$, and mixtures with various amounts of aromatics, olefins, and saturates (paraffins/isoparaffins). A broad range of RON, MON, and S were captured in the blends. They showed that $\mathrm{HCCl}$ combustion phasing is strongly dependent on the RON and MON of the fuel, as well as its composition (i.e., fraction of aromatics, olefins, saturates, and ethanol). They defined a revised form of the octane index (i.e., $\mathrm{OI}_{\mathrm{JKZ}}$, where JKZ denotes the authors' initials [94]) to describe fuel ignition characteristics under various engine conditions. The $\mathrm{OI}_{\mathrm{IKZ}}=\mathrm{RON}-\mathrm{K}^{*} \mathrm{~S}+\kappa^{*}$ (aromatics $)^{2 *}$ (olefins + saturates $)+\varepsilon *\left(\right.$ aromatics*ethanol), where $K^{\prime}, \kappa$, and $\varepsilon$, are constants that depend on engine operating conditions [94]. The authors showed that $\mathrm{OI}_{\mathrm{JKZ}}$, which depends on fuel composition, can accurately describe ignition characteristics of fuel in an HCCI engine.

The effects of fuel composition on $\mathrm{HCCl}$ engine emissions were also tested by Truedsson et al. [97] with a specific focus on NOx, CO, and HC emissions. In general, emissions are low in HCCI applications; nevertheless, higher RON PRF mixtures were shown to yield greater NOx emissions because of the higher in-cylinder temperatures achieved. Adding ethanol or toluene to a high octane mixture reduced $\mathrm{NOx}$ emissions. Increasing the PRF octane number decreased HC emissions, due to higher in-cylinder temperature and less fuel trapped in the crevices. The addition of toluene was found to increase $\mathrm{HC}$ emissions, while ethanol reduced $\mathrm{HC}$ emissions by promoting fuel oxidation. $\mathrm{CO}$ emissions were not found to be directly linked to fuel composition, rather, in-cylinder temperature inhomogeneity (leading to cold spots) was found to be the primary reason why $\mathrm{CO}$ was not being oxidized to $\mathrm{CO}_{2}$.

The importance of fuel chemical properties in LTC engines depends on injection timing. In HCCI combustion, fuel is injected very early, with plenty of time to vaporize and mix before burning; therefore, the combustion process is primarily determined by fuel chemical properties. In PCCI or PPC operating modes, the fuel is injected late in the cycle, so there is less time for fuel vaporization and mixing. As a result, the combustion process is affected by both chemical and physical properties. Aronsson et al. [98] investigated the effect of fuel properties on LTHR in HCCI and PPC engines. They 
showed that increasing isooctane concentration increased LTHR in the PPC mode, while decreasing LTHR in the HCCI mode. Ethanol and toluene additions increased the fraction of LTHR when operating under the PPC mode, but it decreased LTHR under HCCI combustion operating conditions. Their results showed that fuel chemical properties strongly impact $\mathrm{HCCl}$ engine operation, but are less important at later injection times, corresponding to PPC.

The previous section on physical properties discussed the effect of volatility on LSPI in DISI engines. Chemical properties can also impact LSPI because they impact the fuel octane rating and burning rate. Amann et al. [99] investigated fuel composition effects on LSPI in high performance SI engines. Four fuels with varying aromatic and oxygenate (ethanol) content, but similar RON, MON, and AKI, were tested. They discovered that fuel composition strongly affects the frequency and magnitude of LSPI. Increasing the level of aromatics was found to increase LSPI frequency, while increasing oxygenate content and decreasing aromatic content decreased LSPI frequency. Unexpectedly, they also showed that-despite having similar RON and MON as the other test fuels-low aromatic gasoline showed an increased propensity for conventional end-gas knock/ autoignition in the DISI engine. This was attributed to the low aromatic gasoline displaying LTHR prior to the main heat release event.

\subsection{Surrogate formulation strategies/methodologies}

To this point, discussion has focused on important physical and chemical properties of gasoline fuels and their impact on engine combustion processes. A surrogate fuel mixture, comprising a limited number of components, can be formulated to match various physical and chemical target properties of the real gasoline fuel. This section described various approaches for formulating gasoline surrogate fuels. The methodology of formulation for surrogates of diesel and aviation fuels is also relevant to the present study, as the general approach is similar. The reader is referred to notable works on formulation of diesel and aviation fuel surrogates [12,33,67,100-107]

The target properties to be matched, and their link to the engine combustion processes to be replicated by the surrogate, are the first issues to be addressed. For example, if only spray droplet formation and vaporization are to be captured, a surrogate that matches a limited set of physical properties of the real fuel may be sufficient, neglecting any chemical properties as targets. The most important property to be replicated for gasoline fuels is autoignition behavior; this is true for both $\mathrm{SI}$ and $\mathrm{Cl}$ engines operating on gasoline-like fuels. To predict autoignition phasing (if the $\mathrm{P} / \mathrm{T}$ trajectory with time is the same as followed by the gasoline), the RON and MON of the surrogate should be the same as that of the gasoline. A toluene, heptane, isooctane mixture can always be found to match a given RON and MON. Other properties to match with those of the gasoline, such as carbon/hydrogen ratios, have also been suggested [10], although the importance or actual necessity of doing so has not been demonstrated in engine tests. Physical properties such as volatility, viscosity and heat of vaporization must be replicated if the surrogate is to model spray and mixture formation, e.g., in gasoline compression ignition (GCI) engines. Knowledge of laminar burning velocity could be useful in judging the possibility of pre-ignition; it could also be useful for predicting flame development rates in SI engines. Fuel effects on flame development, though likely to be small, might be of interest as engine designers seek ever greater efficiency. However, this will require additional information about turbulence in the engine and its effect on the laminar flame.

Obviously, the surrogate will become more complex, since it has more properties to match. In fact, it is probably not possible to match both physical and chemical properties fully and maintain the complexity of the surrogate at a manageable level. Ultimately, it is a matter of judgement. Equally important is that the accuracy of any computational prediction will also depend on the computational model used. Even if the surrogate matches the gasoline properties well; if the computational model-for example, chemical kinetics or mixing-is not adequate, then the predictions of the model will not be accurate. Also, the complexity of the surrogate (for chemical kinetics for instance) will also affect the complexity of the chemical kinetic model and detract from its usefulness. In GCI combustion for example, the focus might be to design a complementary mix for complex spray and turbulent flow models; a simple kinetic model with chemistry for a small number of surrogate components is needed to integrate with the flow models.

Pitz et al. [10] stated that gasoline surrogates should be formulated to match the target real fuel properties and HCCI engine performance characteristics; the important fuel property targets are LHV and $\mathrm{H} / \mathrm{C}$ ratio. $\mathrm{LHV}$ should be matched within $+/-5 \%$ of the reference gasoline so that fuel flow to the engine is similar, in order to maintain a similar fuel energy input. Real gasoline fuels have $\mathrm{H} / \mathrm{C}$ ratios between 1.6 and 2.0, therefore surrogate fuel mixtures should be in the same range. Targeting the $\mathrm{H} / \mathrm{C}$ ratio is important because air/fuel ratio depends on this value. If the $\mathrm{H} / \mathrm{C}$ ratio is well matched by a surrogate fuel, then air flow to the engine will be similar between the real gasoline fuel and its surrogate. The important engine properties to match are combustion phasing of $10 \%$ mass fraction burned (CA10) and 50\% mass fraction burned (CA50). The CA10 is normally related to the onset and magnitude of LTHR; a surrogate that matches the CA10 of a target gasoline fuel essentially matches its low temperature chemical reactivity. CA50 is the most important combustion parameter in an $\mathrm{HCCl}$ engine because it ultimately determines engine performance and emissions. A surrogate mixture that matches the RON and MON of a target gasoline will have the same CA50 in an HCCI engine [108,109].

A general methodology for gasoline surrogate fuel formulation for HCCI engines was presented by Puduppakkam et al. [110]. First, a palette of surrogate fuel components was selected, which contained molecules representative of the various chemical class in real gasoline fuels. The surrogate components were then blended in proportions needed to match various target properties of the real fuel, keeping combustion targets in mind. If combustion simulations were to be performed, then chemical kinetic models needed to be assembled for the surrogate fuel components. The authors outlined target properties that should be matched, including the molecular structure, distillation curve, octane numbers, LHV, and $\mathrm{H} / \mathrm{C}$ ratio. Matching the molecular composition helped to match various physical properties of the fuel. Matching several points along the distillation curve (e.g., T10, T50, T90) ensured that the surrogate matched the spray characteristics of the real gasoline. As noted previously, matching octane numbers is necessary to capture the combustion phasing and knocking characteristics. LHV determines the cumulative heat release upon combustion, while the $\mathrm{H} / \mathrm{C}$ ratio determines emission characteristics, so these properties should be matched in a surrogate fuel. Puduppakkam et al. [110] outlined a computational methodology (Fig. 7), to formulate a surrogate that matched defined target properties. The methodology minimizes an objective function to optimize a surrogate formulation that matched distillation curve, LHV, $\mathrm{H} / \mathrm{C}$ ratio, RON, and MON value. The methodology is flexible in that various targets properties may be included or removed (e.g., $\mathrm{O} / \mathrm{C}$ ratio may be added for oxygenated fuels).

Su et al. [111] outlined a similar approach for the development of surrogate fuels for transportation fuels, including gasoline. The target properties of interest included physical properties, such as density, LHV, volatility, and viscosity, and chemical properties, such as $\mathrm{H} / \mathrm{C}$ ratio and ignition quality (i.e., RON). They used an optimization algorithm to determine the surrogate mixtures that best matched the target properties. Each target property was also given a weighing factor to quantify its importance, as well as error tolerances for convergence checking. The methodology was used to formulate a 


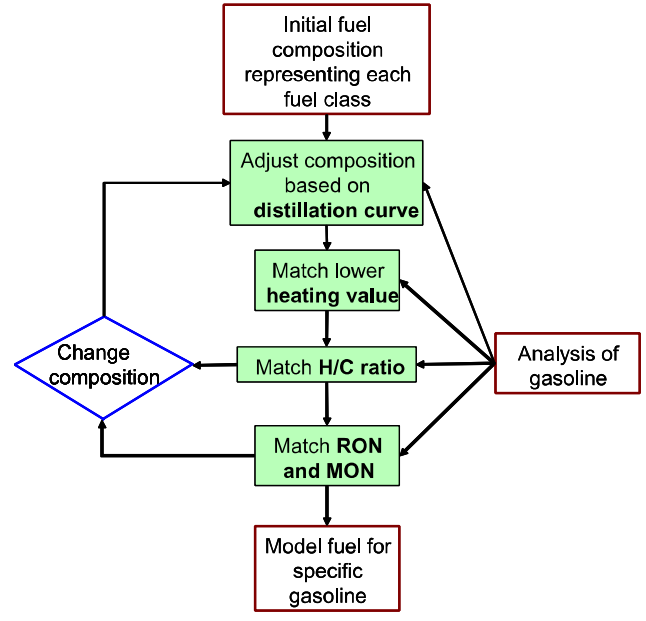

Fig. 7. Flow chart for surrogate fuel formulation from Puduppakkam et al. [110]. Reproduced with permission from SAE International.

surrogate that accurately reproduced the combustion behavior of a target fuel under LTC engine conditions.

A unique approach to gasoline surrogate formulation was presented by Mehl et al. at Lawrence Livermore National Laboratory [112]. Like the previous approaches, a palette of surrogate species was first defined, together with target properties to be matched. The target properties included gasoline paraffin content, aromatic content, olefin content, $\mathrm{H} / \mathrm{C}$ ratio, $\mathrm{RON}$, and MON. The authors presented a novel methodology to determine the RON and MON for a proposed surrogate mixture. The methodology performed chemical kinetic simulations under homogeneous batch reactor conditions to predict the ignition delay time of a surrogate mixture. A mapping of ignition delay times for various mixtures with known RON and MON was then utilized to determine the RON and MON of the proposed surrogate mixture [112]. This methodology for predicting RON and MON is accurate, but it requires high fidelity chemical kinetic models. Badra et al. [113] demonstrated that ignition delay time simulations which considered the actual volume-time history of the fuel/air mixture in the CFR engine could better predict measured RON and MON values of toluene/n-heptane/isooctane surrogate mixtures.

A common theme in surrogate formulation methodologies is the attempt to match multiple target properties with a combination of species in a palette. This requires predicting, without actually measuring, the properties of various candidate surrogate mixtures to find one that best matches the properties of the target fuel. Pera and Knop [114,115] showed that $\mathrm{H} / \mathrm{C}$ ratio, O/C ratio, LHV, molecular weight, RON, and MON could be calculated using simple linear molar blending rules. Morgan et al. [116] showed that non-linear blending rules more accurately predict RON and MON, and similar results have also been shown for ethanol blending with gasoline surrogates $[117,118]$. Physical properties, such as volatility characteristics (i.e., distillation curve), are more difficult to estimate because they are not additive. Slavinskaya et al. [119] and Huber et al. [33] have shown that the distillation characteristics of mixtures requires calculating vapor-liquid equilibrium. This can be achieved by selecting an appropriate equation of state and mixing rules for estimating the properties of mixtures. Similar thermo-transport models [120-124] have been shown to be useful for predicting gasoline droplet heating and evaporation characteristics and formulating surrogates. Ahmed et al. [125] and Abianeh et al. [126] later demonstrated that various estimation methods for target properties could be introduced into an optimization algorithm that formulates a surrogate capable of matching multiple target properties with a minimum of error.

In summary, this section offers a general outline for formulation of a surrogate mixture to match a gasoline fuel of interest. It is imperative to first determine which physical and chemical properties should be chosen as target properties, as well as their relationship to the combustion technology and the operating conditions of interest. Once the target gasoline properties are selected, a surrogate fuel can be formulated from a mixture of palette components. The optimal mixture of components is best determined using a computational algorithm that assigns a weight to each target property and then solves an objective function to minimize the error against all the target properties. Subsequent sections will discuss experimental and computational studies performed on gasoline surrogate mixtures and relate them to investigations performed on real gasoline fuels.

\section{Fundamental combustion experiments on gasoline and surrogate fuels}

Gasoline fuels are primarily used in spark ignition engines and in advanced low-temperature combustion counterparts. Fuel combustion in internal combustion engines is complex and may comprise fuel injection, spray, vaporization, fuel-air mixing, heat and mass transfer, ignition and combustion. Targeted engine experiments may be carried out on real gasoline and proposed surrogate mixtures to assess how well the surrogate captures real fuel behavior, such as heat release rate, combustion phasing and emissions. Such experiments are typically performed at selected engine operating conditions, and therefore, may not cover the entire spectrum of practical scenarios to which the fuel will be subjected. Also, depending on the engine operating mode, the observed trends may be affected by physical as well as chemical properties of the real fuel and surrogate mixture. Lastly, engine experimental data cannot be directly used to develop and validate detailed chemical and physical models for the surrogate mixtures.

Fundamental combustion experiments carried out in welldesigned chemical reactors and/or canonical flames may provide valuable data that can be used to (i) understand trends and comparisons among various fuels and fuel surrogates, (ii) build detailed chemical models to propose optimal surrogates, and (iii) describe fuel behavior over wide ranges of engine operating conditions. Such fundamental experiments may be able to decouple the physical and chemical aspects of fuel behavior and are ideal for understanding the effects of the chemical structure on fuel autoignition and emissions, for example. When the focus is solely on fuel chemistry, the experiments are designed so that chemical kinetic processes govern the fuel oxidation, while physical/mixing processes play a negligible role.

There are two key goals in performing and presenting fundamental combustion experiments on gasolines and surrogates: (a) to demonstrate, in well-controlled experimental conditions, that the surrogate matches the combustion behavior of the target gasoline, and (b) to provide data that can be used to develop and validate detailed chemical kinetic models of gasoline surrogates. If a surrogate successfully emulates, for example, the autoignition behavior of real fuel in a shock tube (ST) and a rapid compression machine (RCM), will such a surrogate also reproduce the knock timing or heat release rate of real fuel in an engine? The answer rests on two important points: the experimental conditions tested in ST / RCM must overlap with the engine operating conditions, and the ignition process in the engine must be dominated by fuel chemistry. In the first consideration, the temperatures $(500-2000 \mathrm{~K})$, pressures $(1-60 \mathrm{bar})$ and equivalence ratios $(0.2-4)$ covered in modern ST / RCM facilities do overlap appreciably with engine operating conditions. Secondly, the ignition process in HCCI engines, for example, is indeed dominated by fuel chemistry [127]. Likewise, the knock timing in SI engines is predominantly controlled by the autoignition behavior of the end gas, as illustrated in a recent review paper by Zhi et al. [128].

Researchers have developed and used a variety of fundamental experiments to understand the combustion chemistry of various fuels. Each reactor/experiment provides data on specific aspects of 
the chemical kinetic behavior of the fuel, and each experimental apparatus has its sweet spots and its limitations. Therefore, data obtained from the so-called ideal reactors should not be universally categorized as ideal, and care must be exercised in using these data for building chemical kinetic models and for understanding fuel chemistry.

Before the literature data on gasoline and gasoline surrogates is presented, it is important to briefly describe the advantages and challenges associated with various kinds of fundamental devices in which these data are obtained. Specifically, the additional complexities faced when working with distillate fuels and fuel mixtures will be discussed and compared to single-component fuels.

\subsection{Challenges of gasoline measurements}

\subsubsection{Ignition measurements in shock tubes}

Fuel autoignition quality is critical in determining the operating regime of SI engines. This is typically measured in terms of the research and motor octane numbers (RON, MON), with the help of ASTM standard tests carried out in CFR engines. These octane numbers cannot be directly used to build or validate chemical kinetic models; however, it has previously been shown [112] that homogeneous ignition delay times may be correlated with the octane ratings. As an illustration of this relationship, Fig. 8 [113] plots ignition delay times as a function of RON and MON of a number of threecomponent TPRF (n-heptane / isooctane / toluene) fuels. It can be clearly seen that there is a strong correlation between RON/MON and homogeneous ignition delay times at the specific conditions chosen carefully by Mehl et al. [112].

The homogeneous ignition delay time (also known as the induction time) is defined as the time it takes for a homogeneous fuel/air mixture at a specific temperature and pressure to explode, resulting in rapid increase of temperature/pressure and heat release. Although ignition delay time is a global indicator of fuel oxidation behavior, it
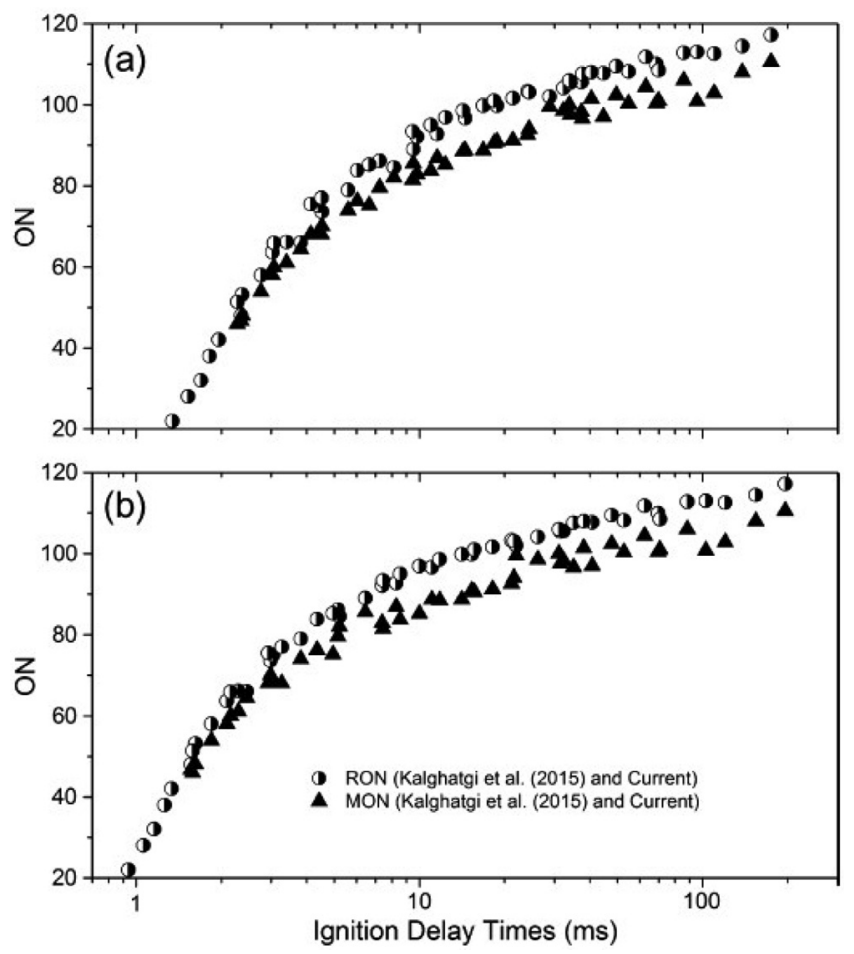

Fig. 8. Calculated ignition delay times for stoichiometric TPRF/air mixtures versus RON and MON at (a) $835 \mathrm{~K}$ and 20 bar, (b) $825 \mathrm{~K}$ and 20 bar. Figure adapted from Badra et al. [113] with permission from Elsevier Publishing. is strongly influenced by the underlying elementary reactions, and thus it provides a very stringent target for kinetic model development and validation.

The shock tube stands as the ideal homogeneous batch reactor for measuring ignition delay times as a function of temperature, pressure and mixture fraction. A shock wave heats and pressurizes the fuel/air mixture almost instantly and the environment behind the reflected shock wave is adequately modeled as a zero-dimensional (homogeneous) reactor. Shock tubes have historically been used to measure high temperature ignition delay times, which tend to be of the order of a few microseconds to a couple of milliseconds. Over these times, the shock tubes behave almost ideally where the pressure behind the reflected shock waves remains nearly constant.

Some of the challenges encountered during the measurement of ignition delay times of gasoline fuels are examined here briefly.

a) Long ignition delay times: Most commercial gasolines have relatively high RON (91-97), and boosted engines are expected to utilize fuels with even higher octane ratings. The addition of ethanol and use of knock inhibitors (e.g., MTBE) results in high octane gasolines with relatively long ignition delay times, particularly at low temperatures and in the NTC region. It is very important to characterize the fuel reactivity at low temperatures and NTC to accurately describe the LTHR and ITHR, which are critical in the design of modern low-temperature combustion (LTC) engines.

Typically, shock tubes were used to measure only high temperature ignition delays, as accessible test times were limited to $<2 \mathrm{~ms}$. Recently however, longer driver sections and driver gas tailoring have enabled much longer test times [2]. Although the driver gas tailoring theory is well-established [129], in practice, achieving long test times requires considerable effort and experimentation. Additionally, the gradual increase of pressure (dP/ dt) behind reflected shock waves becomes significant when measuring long ignition delay times, particularly for small diameter shock tubes. It is very important to carefully characterize the $\mathrm{dP} / \mathrm{dt}$ for each shock tube and provide the value for the specific experiments being reported. It should also be noted that $\mathrm{dP} / \mathrm{dt}$ might not be the same for tailored and non-tailored experiments. Fig. 9 shows that long test times may be achieved by adding $\mathrm{N}_{2}$ or $\mathrm{CO}_{2}$ to $\mathrm{He}$ in the driver section of the shock tube. Sometimes a buffer gas [4] must be added between the driver and driven gases to avoid pressure bumps at the contact surface. Varying compositions of driver gases and buffer gas are needed for specific test times and temperatures. It can be very difficult to avoid over- or under-tailoring, as demonstrated in Fig. 9b, by the contact surface expansion.

Finally, it has recently been observed that shock tube ignition delay data might be affected by pre-ignition and flame propagation over long test times [130]. Fig. 10 shows various ignition types observed for low temperature oxidation of n-hexane and n-heptane. The intermediate temperature cases (Fig. 10b) show a marked, gradual rise of pressure, reminiscent of flame propagation, before the main ignition event. Such pre-ignition energy release can artificially shorten the otherwise homogeneous ignition delay times; therefore, care must be exercised in using long ignition delay shock tube data which might be shortened by non-ideal effects such as the $\mathrm{dP} / \mathrm{dt}$ and the pre-ignition.

b) Fuel vaporization: Since gasoline fuel is comprised of hundreds of compounds with varying boiling points, it is important to have an efficient strategy for fuel vaporization. The liquid fuel should be injected into a heated chamber, such as a mixing vessel, where the temperature of the vessel is high enough to ensure vaporization of all gasoline components. Depending on the high carbon content of the gasoline and aromatic fraction, a vessel temperature in the range of $80-150 \mathrm{C}$ might suffice. Fuel 

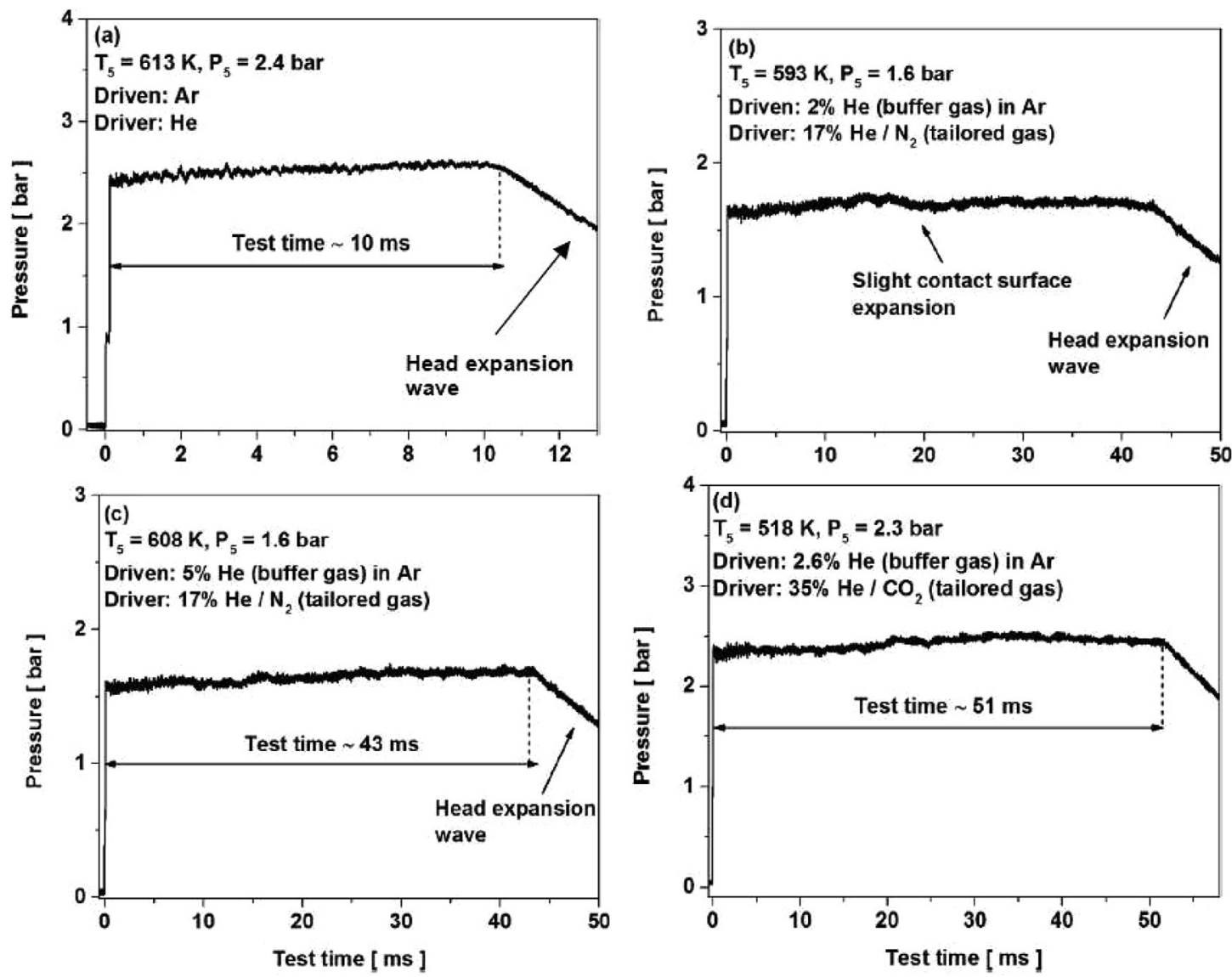

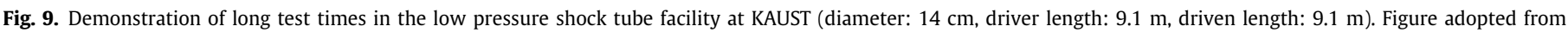
Tamour Javed $\mathrm{PhD}$ Thesis [131].

vaporization may be verified by sampling fuel from the mixing vessel and comparing the GC (gas chromatograph) spectrum with that of the liquid fuel. At these high mixing temperatures, there is a small but finite likelihood that some fuel components could undergo decomposition. This can also be checked by sampling the fuel mixture from the mixing vessel at varying residence times. Lastly, the heavy fuel components could condense if there are any cold spots within the mixing vessel or mixing manifold, or the (usually long) line connecting the vessel with the shock tube driven section. Some molecules can also adsorb to metallic surfaces. Passivating the vessel and shock tube walls with the fuel can help reduce adsorption losses. Fuel loss by condensation or adsorption may be quantified either with a laser absorption diagnostic (e.g., using a $3.39 \mu \mathrm{m}$ HeNe laser in the shock tube), or by sampling the fuel mixture from the shock tube and running GC or FTIR (Fourier Transform Infrared Spectrometer) tests.

c) Thermodynamic properties: The calculation of reflected shock temperature and pressure necessitates the measurement of incident shock velocity and knowledge of the thermodynamic properties of the fuel mixture. This requires knowing the detailed composition (DHA: detailed hydrocarbon analysis) of the gasoline. Thereafter, a thermodynamic surrogate that mimics the thermal properties of the gasoline can be set up.

d) Compositional changes: It is well known that gasoline fuels may undergo compositional changes if stored for long periods and/ or improperly stored. For example, if the container is not sealed well, some of the lighter components may evaporate. Over a long storage period, oxygen reactions in the head space of the storage container may also degrade the gasoline. Whenever possible, it is best to store the fuel in refrigerated conditions. Compositional analysis of the fuel should be performed at the time of procurement/production and at the time of experimental usage to determine if there have been changes to the composition.

\subsubsection{Ignition measurements in rapid compression machines}

Rapid compression machines (RCMs) are generally used to measure long ignition delay times which are not accessible by shock tubes. This is particularly important for high octane gasolines where ignition delay times may exceed $5 \mathrm{~ms}$ for initial temperatures lower than $\sim 900 \mathrm{~K}$ for initial pressures ranging $10-20$ bar. Therefore, to effectively study the fuel NTC behavior, the RCM ignition delay data play a critical role. Also, the differences among various fuels are amplified in the NTC and low-temperature regions.

The challenges encountered in RCM measurements of gasoline ignition delay times are very similar to those mentioned for shock tubes. Some additional considerations are as follows:

a) As a general rule, it is not advisable to use RCMs for measuring ignition delay times less than $\sim 5$ ms. This is because, for such relatively short ignition delay times, considerable chemical reactions occur during the piston compression phase. Although the compression stroke can be modeled during reactive simulations, as illustrated in Fig. 11, assigning a specific initial temperature to such ignition delay experiments becomes ambiguous.

b) Fuel adsorption could be a bigger concern in RCM experiments as the combustion chamber has relatively high surface-to-volume ratio. Therefore, sampling of the fuel mixture from the RCM combustion chamber may be used to confirm the fuel/air mixture composition. 

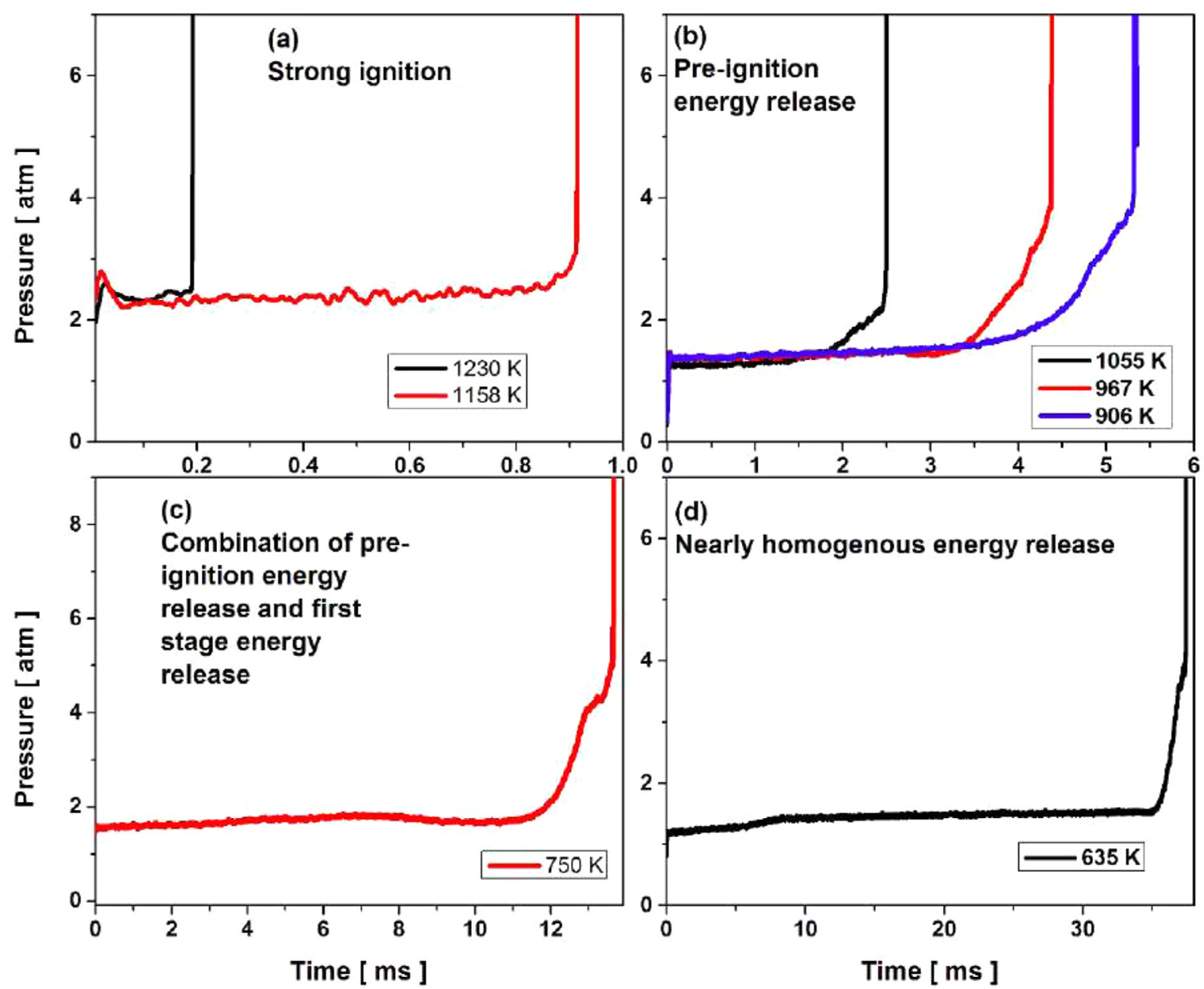

(d)

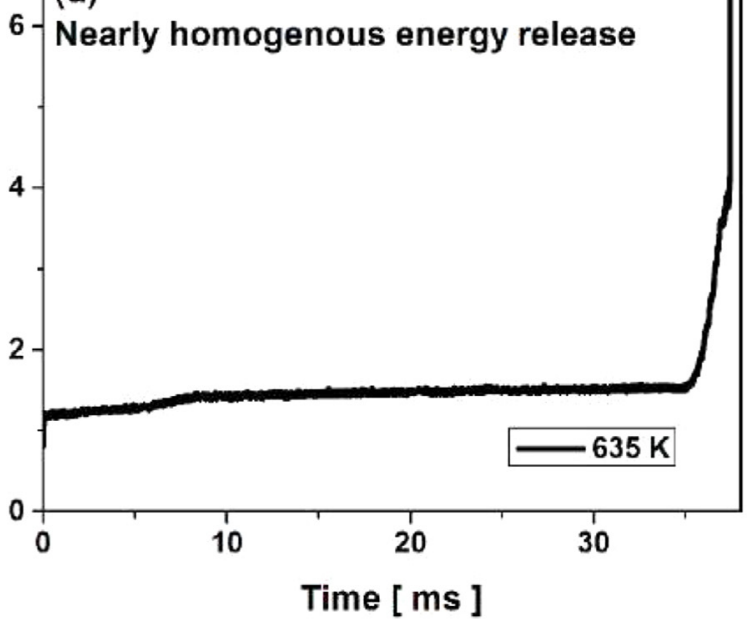

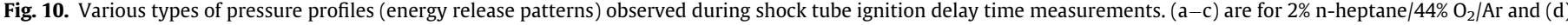
is for $5 \% \mathrm{n}$-hexane $/ 47.5 \% \mathrm{O}_{2} / \mathrm{Ar}$. Figure adopted from Javed et al. [132] with permission from Taylor \& Francis.

c) Reactive simulations of RCM ignition delay experiments for gasoline fuels are performed using a chemical kinetic surrogate. Thermal properties of the kinetic surrogate may be different than thermal properties of the real fuel, or an adequate thermal surrogate of the fuel. This would result in a different end-of-

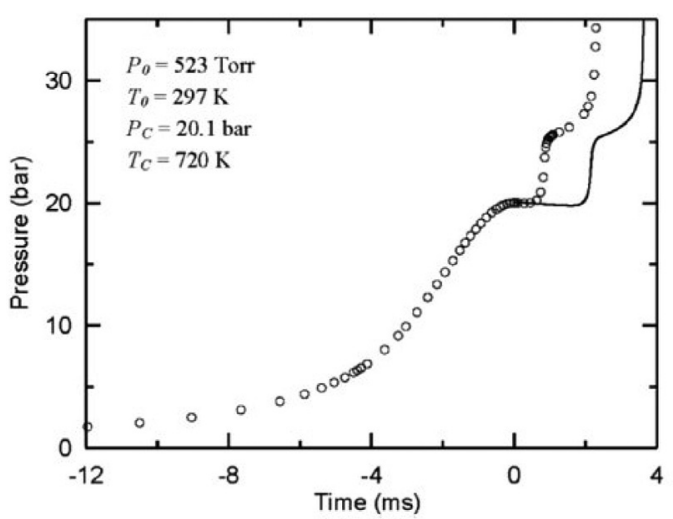

Fig. 11. Effect of compression stroke on the first stage and overall ignition delay time. Open symbols represent reactive calculations performed considering the RCM compression stroke. Solid line simulation is obtained by initializing the reactive calculations at the end of compression stroke. Figure adopted from Sung and Curran [133] with permission from Elsevier Publishing. compression (EOC) temperature than is experimentally observed. The optimal solution would be a surrogate that matches both the thermodynamic and kinetic behavior of the real fuel.

d) For RCM experiments, EOC temperatures can be varied by changing the initial temperature and/or the composition of the bath gas by mixing $\mathrm{N}_{2}$ with $\mathrm{Ar}$ or $\mathrm{CO}_{2}$. Variation in bath gas composition may affect third body reaction rates, which should be modeled carefully while simulating RCM experiments.

e) Due to the long test times accessible with RCMs, it is possible to differentiate various fuels in the NTC and low-temperature regions. However, it should be considered that ignition can potentially start in the cold boundary layer, particularly when measuring ignition delay times in the NTC region. This behavior may be detected by analyzing the pressure traces carefully for evidence of pre-ignition and flame propagation prior to the bulk homogeneous ignition.

f) Heat transfer losses in rapid compression machines are modeled by employing a varying volume time-history derived from nonreactive pressure trace measurement. This approach works reasonably well for single stage ignition. For two-stage ignition phenomenon, heat release during the first stage may alter the overall heat loss characteristics considerably over those modeled using non-reactive experiments. For example, this could result in over-prediction of ignition delay times compared to 


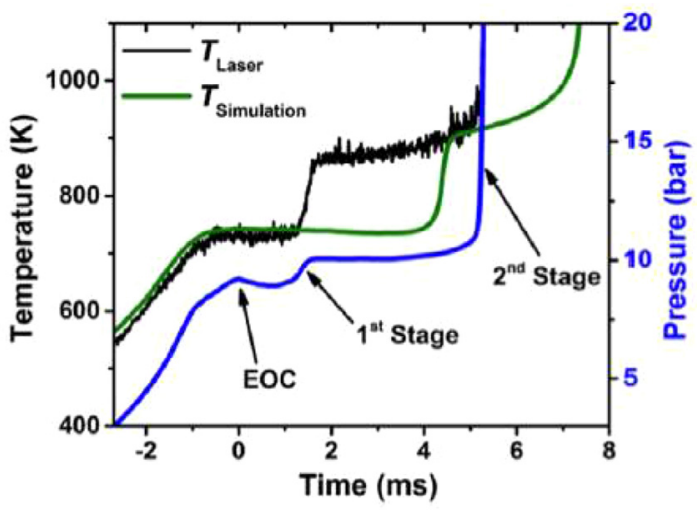

Fig. 12. Temperature measurement in a rapid compression machine using chirpedlaser absorption spectroscopy. Simulated temperature is obtained by running a zerodimensional reactive simulation. $\mathrm{P}_{\mathrm{c}}=9.21 \mathrm{bar}, \mathrm{T}_{\mathrm{c}}=742 \mathrm{~K}, 2.56 \% \mathrm{n}$-pentane $/ 20.46 \%$ $\mathrm{O}_{2} / 75.98 \% \mathrm{~N}_{2} / 1 \% \mathrm{CO}$. Figure adopted from Nasir and Farooq [134] with permission from Elsevier Publishing.

the measured data. Nasir and Farooq [134] presented a novel temperature measurement in a rapid compression machine (Fig. 12). The temperature measured by laser absorption for first stage heat release was lower than predicted by the zero-dimensional simulation. The higher predicted temperature during the first stage also expedited the second stage ignition in the simulation. Among various solutions proposed to model two-stage ignition, simulating the two-stage ignition process with a multizone model provided a good compromise compared to full CFD simulation [135]. However, such multi-zone models are not universal and must be adjusted to the specific RCM; also, multizone models increase computational cost significantly compared to the zero-dimensional kinetic simulations.

g) Finally, it should be mentioned that RCMs used in the literature vary in their design and geometry; heat loss characteristics and crevice confinement are very different from one machine to another. This makes comparison of ignition delay data across various machines difficult. Meaningful comparisons can only be made with the help of simulations that consider respective heat losses in individual machines.

\subsubsection{Flame speed measurements}

Flame speed is critical to modeling flame propagation in SI engines and is an important validation goal for the high-temperature chemical kinetic mechanism. Although the flame propagation in real engines is turbulent, laminar flame speed measurements in ideal reactors provide the data needed to constrain the reaction models. It is important to understand flame speed variation as a function of equivalence ratio, initial temperature and initial pressure. Various kinds of reactors/apparatus are used for flame speed measurements.

The challenges encountered during flame speed measurements of gasoline fuels are somewhat dependent on the experimental methodology used for flame speed determination. The reader is referred to a recent review by Egolfopoulos et al. [136] in which the challenges and uncertainties associated with various laminar flame experiments are exhaustively discussed. Some pertinent points are mentioned below:

a) In general, adequate fuel vaporization is important for liquid fuels, and particularly for multi-component liquid fuels such as gasoline. For example, it is important to use heated tube between the evaporator and the burner; Sileghem et al. [137] reported that fuel condensation in non-heated tubes can lead to over-estimation of burning velocities, particularly for rich mixtures. On the other hand, over-heating of the fuel stream, or hot spots, can lead to premature fuel decomposition, especially for large molecules.

b) Liquid fuels are usually introduced via syringe pumps, or liquid flow regulators, which must be properly calibrated and should have dependable accuracy to avoid serious uncertainties in the equivalence ratio. This is usually not an issue for gaseous fuels as the mass flow controllers tend to be of greater accuracy.

c) For stagnation flames, such as the counterflow configuration, discrepancies exist in the extrapolation of measured flame speed to zero strain rate $(\mathrm{K})$ using either linear or non-linear extrapolation methods (these uncertainties tend to be bigger for larger molecules relevant to gasoline surrogates [136]). These issues arise from differential diffusion effects for mixtures of large molecular weight fuels, particularly under rich conditions.

d) For spherically expanding flames, partial pressure methodology is used to fill the chamber for each experimental run. It is very important that pressure transducers of appropriate range are used and that these transducers are well-calibrated. For multicomponent liquid fuels, as discussed earlier, the heating and vaporization requirements can be quite stringent and care must be taken to avoid hot/cold spots. It may also be advisable to sample the reactant mixture and confirm the composition by GC/MS techniques. Finally, issues similar to the extrapolation complexities in stagnation flames also affect data interpretation from spherically expanding flames.

e) The heat-flux method provides an advantage in that the flame speed is obtained via interpolation rather than extrapolation. However, this method is also affected by several uncertainties such as boundary conditions at the burner surface, flame instability, flame-wall interactions leading to loss of radicals, temperature and flow velocity measurements.

\subsubsection{Speciation with jet-stirred reactors and low-pressure flames}

A jet-stirred reactor (JSR) and/or low-pressure flame, coupled with GC-MS, FTIR or TOF-MS may be used to measure intermediate species and products of fuel oxidation. Such speciation data are useful for validating the detailed chemistry of the surrogate models being developed for the gasoline. Recently, there have been wideranging studies utilizing synchrotron-based vacuum ultraviolet (UV) photon ionization; this methodology has resulted in a wealth of valuable speciation data which have greatly increased understanding of intermediate fuel chemistry. Some key experimental speciation challenges are discussed briefly:

a) Similar to other fundamental combustion experiments on gasoline fuels, adequate vaporization and avoidance of fuel condensation is very important, particularly for gasolines with a relatively high boiling point.

b) For low-pressure flames, measurement of flame temperature as a function of height above the burner is critical for the usefulness of the data. Thermocouples [138], laser-induced fluorescence (LIF) [139] and laser absorption methods [140] have been utilized to measure the flame temperature profile. However, all of these methods have inherent uncertainties and limitations, and the uncertainties on the measured temperature lead to challenges in adequately modeling the speciation data.

c) A sampling probe may lead to significant distortions and nonidealities in the otherwise unperturbed flame. These non-idealities and uncertainties were addressed previously [136,141,142], and must be taken into consideration when using speciation data for model development and validation.

d) Additional challenges arise during the analyses of the raw experimental data. The intermediates/products are formed from various gasoline components and are quite complex. Also, the peaks of the fuel components and their fragments interfere with 
analysis of the intermediates/products. The uncertainty of product quantification becomes greater compared with single-component fuel speciation experiments.

\subsection{Fundamental combustion experiment literature}

\subsubsection{Autoignition studies in shock tubes and rapid compression machines}

Despite the importance and practical implications of gasoline fuels, ignition delay time measurements of distillate gasolines are scarce in the literature. Primarily, three types of gasoline fuels have been studied in homogeneous reactors of shock tube and rapid compression machines. RD387 gasoline was used in several previous studies $[15,143,144]$, and represents the non-oxygenated, regular grade gasoline used in the U.S. with an average octane number, $(\mathrm{RON}+\mathrm{MON}) / 2$, of 87 and an $\mathrm{H} / \mathrm{C}$ ratio of 1.85 . Two recent studies $[145,146]$ have used oxygenated RON 95 gasolines. The third type of gasoline fuels being investigated are the FACE (fuels for advanced combustion engines) gasolines.

One of the first ignition delay time studies on distillate gasoline (RD387) was carried out by Gauthier et al. [143]. Ignition delay times were measured behind reflected shock waves over a broad range of conditions; $15-60$ bar, $900-1300 \mathrm{~K}, 0.5-2.1 \phi$. The effect of exhaust gas recirculation (EGR) on ignition delay times was also examined by adding $20-30 \%$ of synthetic EGR mixture composed of $\mathrm{CO}_{2}, \mathrm{H}_{2} \mathrm{O}, \mathrm{O}_{2}$ and $\mathrm{N}_{2}$. The entire NTC behavior was not observed due to the lack of experimental data at lower temperatures, which would have required longer shock tube test times. An interesting feature of the work was the comparison of the gasoline ignition delay times with experimentally measured ignition delays of two ternary surrogates of n-heptane/isooctane/toluene. The surrogates and the gasoline matched well over the experimental conditions of their study, as shown in Fig. 13. However, the differences between surrogates and real fuels are expected to be pronounced at lower temperatures, which were not covered in the work of Gauthier et al. [143]. A curious feature of the work was the use of two surrogates which matched in their volumetric and molar fractions, respectively. We hypothesize that the authors' goal was to match the gasoline composition in molar ratios of $63 / 20 / 17 \%$ (surrogate B) for isooctane/toluene/n-heptane, but made the surrogate in volumetric 63/20/17\% fractions (surrogate A) in error.

The lack of low-temperature data in the work of Gauthier et al. [143] motivated Kukkadapu et al. [144,147,148] to study RD387 autoignition in a rapid compression machine over $650-900 \mathrm{~K}$ and

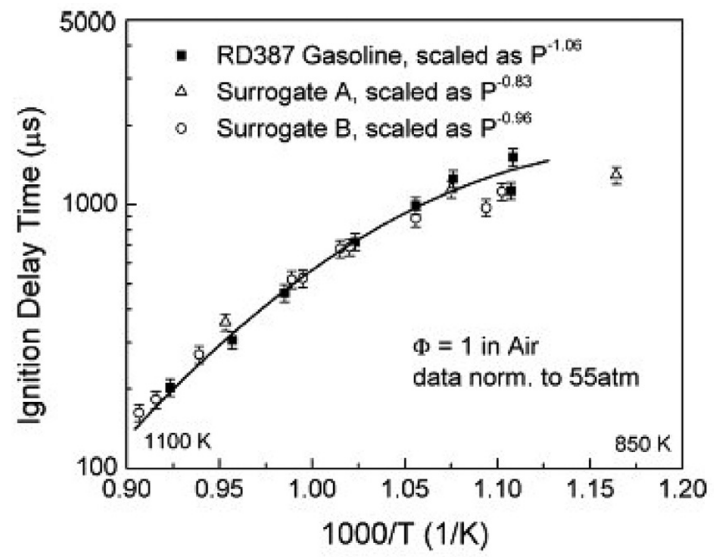

Fig. 13. Ignition delay times of RD387 gasoline and two TPRF surrogates ( $A$ and $B$ ). $P=$ 45-60 bar. Solid line represents quadratic fit to gasoline data. Figure adopted from [143] with permission from Elsevier Publishing.

pressures of 20 and 40 bar. The RD387 used in this study had a slightly different $\mathrm{H} / \mathrm{C}$ ratio of 1.87 , but similar values of RON (91) and sensitivity (8.3) as the RD387 used by Gauthier et al. [143]. As seen in Fig. 14, the RCM measurements clearly showed the NTC behavior for gasoline ignition, which was not apparent in the shock tube study of Gauthier et al. [143]. Another important contribution of the RCM study was the measurement of first-stage ignition delays in addition to the overall (or total) ignition delay. The firststage ignition delays are highly valuable for understanding and predicting the fuel reactivity in the NTC and low-temperature regions. Through their RCM measurements, Kukkadapu et al. [144,147,148] found that the ternary surrogate of n-heptane/isooctane/toluene proposed in the work of Gauthier et al. [143] failed to capture the RD387 ignition at low temperatures. A newly proposed fourcomponent surrogate [149] comprised of n-heptane / isooctane / toluene / 2-pentene agreed better with the measured ignition delay times of the gasoline. Although Kukkadapu et al. [144,147,148] demonstrated the importance of multi-component surrogates for capturing low temperature autoignition behavior of gasoline fuels, it was not possible to generalize these results as their work focused only on one specific gasoline. Also, despite the better performance of the four-component surrogate, some disagreements with the gasoline ignition were still observed at lean fuel conditions in the rapid compression machine.
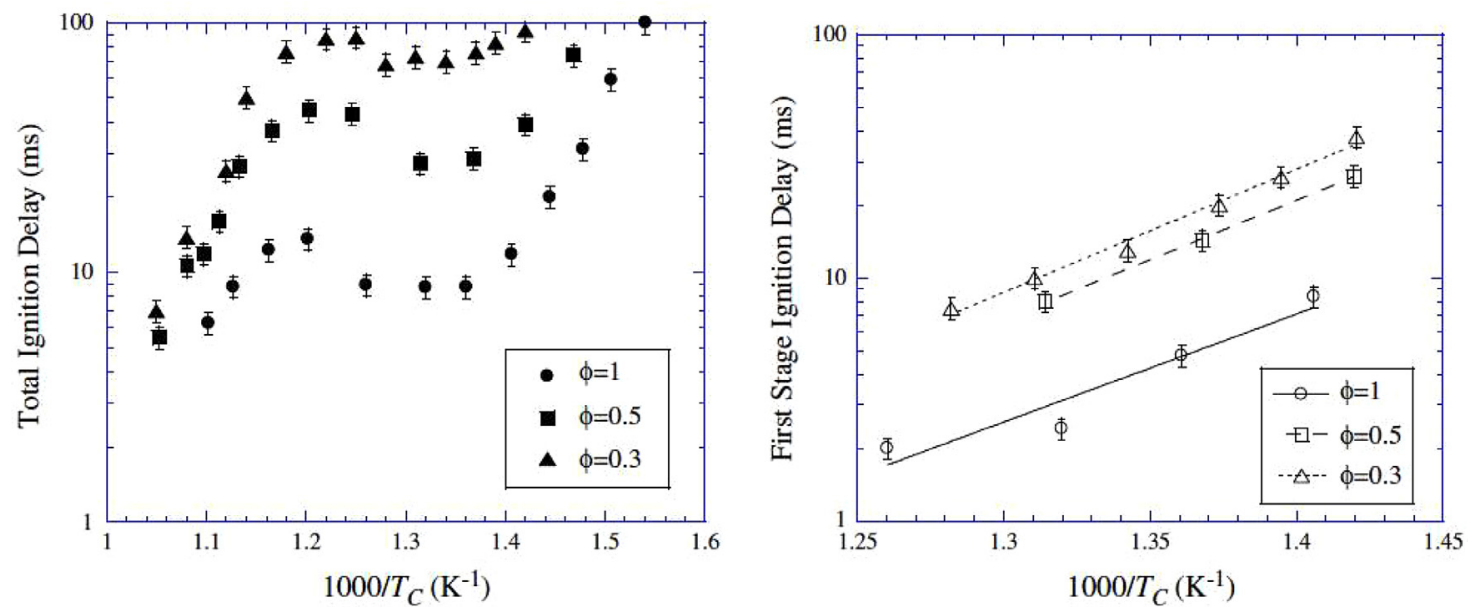

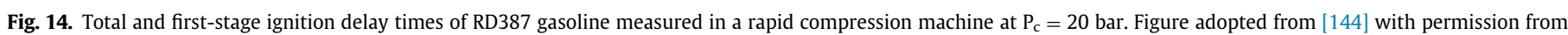
Elsevier Publishing. 
Chung et al. [145] focused on the two-stage ignition behavior while studying the autoignition of a RON 95 gasoline in a rapid compression machine. Pressure time-history profiles and ignition delay times of the gasoline were compared with pure components (isooctane, n-heptane, 1-heptene, 2-heptene, 3-heptene) as well as surrogate mixtures comprised of three components (n-heptane, isooctane, toluene) and seven components (n-heptane, isooctane, cyclohexane, toluene, cyclohexene, 1,3-cyclohexadiene, ethanol). It was argued that addition of cyclic alkenes to the surrogate mixture is important in emulating first stage and total ignition delay behavior of the gasoline.

Agbro et al. [146] recently studied the influence of $20 \%$ n-butanol addition to the autoignition of a reference RON 95 gasoline in a rapid compression machine at 20 bar and $678-858 \mathrm{~K}$. The addition of nbutanol resulted in longer ignition delay times at the low temperatures of the study, as expected. However, at temperatures higher than $800 \mathrm{~K}$, the gasoline/n-butanol blend exhibited slightly shorter ignition delay times than pure gasoline. Suitably formulated TPRF and TPRF/n-butanol surrogates were also tested experimentally and these, respectively, reproduced the autoignition behavior of gasoline and gasoline/n-butanol blend reasonably well.

Several autoignition studies of FACE gasolines have been carried out at KAUST, with collaborative contributions from various laboratories around the world. As discussed earlier, FACE gasolines comprise fuels with varying RON, MON, sensitivity and chemical composition; therefore, the use of these widely different gasolines can provide the data and knowledge needed to formulate a generalized surrogate formulation strategy.

The first autoignition study on FACE gasolines was carried out by Sarathy et al. [150] on FACE A and C, having similar octane numbers (RON and MON $\sim 84$ ) but varying compositions. It was shown that both gasolines exhibited comparable ignition delay times over the wide range of experimental conditions $(715-1500 \mathrm{~K}, 10-40 \mathrm{bar}$, $\phi=0.5$ and 1 ), and a PRF surrogate adequately captured the ignition requirements of these gasolines. Five- and six-component surrogates for FACE A and C, respectively, were formulated in this work, based on the DHA (detailed hydrocarbon analysis) of the two gasolines. These multi-component surrogates provided slightly better agreement than the PRF surrogate at the very low temperatures of the study.

Sarathy et al. [58] recently studied the autoignition and surrogate formulation for two high octane FACE gasolines, F and G. These two gasolines had very similar antiknock indices, $(\mathrm{RON}+\mathrm{MON}) / 2$, of 91.6 and 91.3. Apart from compositional differences, the two fuels had different octane sensitivities (FACE F: $R O N=94.4, \mathrm{~S}=5.6$; FACE $\mathrm{G}$ : RON $=96.8, \mathrm{~S}=11$ ). Ignition delay time measurements in shock tube and rapid compression machine showed that both gasolines were equally reactive at high temperatures $(\mathrm{T}>900 \mathrm{~K})$. At low temperatures, FACE F having lower RON was slightly more reactive than FACE G. On the other hand, FACE F having lower octane sensitivity displayed greater NTC behavior than FACE G. Experiments performed in the rapid compression machine also revealed the decrease of low-temperature heat release (LTHR) and increase of intermediate-temperature heat release (ITHR) with increasing octane sensitivity. These experimentally observed trends are shown in Fig. 15. It can also be clearly seen that FACE A and C, having RON of 84, have shorter ignition delay times in the NTC region and at low temperatures. Experimental ignition delay times were compared against two-component PRF, ternary TPRF, and multi-component surrogates. Autoignition of low-sensitivity $(S=5.6)$ FACE F was captured equally well by all three surrogate types; however, only the multicomponent surrogate performed well in reproducing the ignition behavior of high-sensitivity $(S=11)$ FACE G gasoline.

Javed et al. [151] recently carried out a shock tube and rapid compression machine ignition delay study on two low octane gasolines, FACE I and J, over $650-1200 \mathrm{~K}, 20-40$ bar and $\phi=0.5$ and 1 . These two gasolines have similar AKI of $\sim 70$ and similar octane sensitivities of $<3$. However, their compositions are quite different: FACE I being primarily paraffinic while FACE J contains about $30 \%$ (by mole) aromatics. The two fuels exhibited very similar ignition delay times over the wide range of experimental conditions. Experiments and simulations performed with PRF and multi-component surrogates showed that a PRF surrogate can adequately capture the reactivity of both gasolines, with the PRF surrogate being slightly more reactive at the low temperature conditions of the rapid compression machine.

Relevant to these low octane FACE gasolines are two recent studies carried out on Saudi Aramco light naphtha $(\mathrm{RON}=64.5, \mathrm{MON}=$ $63.5)$ and Haltermann straight run naphtha $(\mathrm{RON}=60, \mathrm{MON}=$ 58.3). Javed et al. [152] and AlAbbad et al. [153a] measured ignition delay times of these naphtha fuels in a shock tube and rapid compression machine over a wide range of experimental conditions. They also carried out experimental measurements of PRF and multicomponent surrogates for the two fuels. It was shown that PRF surrogates adequately captured the naphtha reactivity at high temperatures and in the NTC region. However, the PRF surrogates were more reactive at low temperature conditions, the differences being greater for higher fuel concentration cases ( $\phi=1$ and 2). Multi-component surrogates, formulated by matching the fuel octane numbers, $\mathrm{H} / \mathrm{C}$ ratio, carbon type and distillation curve, reproduced the fuel ignition behavior over the entire range of temperatures, as shown in Fig. 16.

Finally, Lee et al. [154] recently carried out a detailed study on the autoignition of two oxygenated certified gasolines, supplied by Haltermann $(\mathrm{RON}=91, \mathrm{MON}=83.4$, ethanol $=8 \mathrm{vol} \%)$ and Coryton $(\mathrm{RON}=97.5, \mathrm{MON}=86.6$, ethanol $=4 \mathrm{vol} \%)$. Experiments were performed over $650-1250 \mathrm{~K}$, pressures of 10-40 bar and equivalence ratios of $0.45,0.9$ and 1.8 . Fig. 17 shows that both gasolines exhibited similar ignition delay times at high temperatures $(\mathrm{T}>900 \mathrm{~K})$. At intermediate temperatures, the Haltermann gasoline, having lower RON and lower sensitivity, exhibited higher reactivity and greater NTC behavior than the Coryton gasolines. At the very low temperatures $(\mathrm{T}<700 \mathrm{~K})$, both fuels again exhibited similar ignition delay times. The differences between the two gasolines were more pronounced at lower pressures and higher equivalence ratios. Three different types of surrogates were formulated for each gasoline. These included three-component TPRF surrogates, four-component TPRF/ ethanol surrogates and eight-component surrogates. Surrogate performance was analyzed using detailed chemical kinetic simulations and partial experimental ignition delay measurements of the surrogates. At low temperatures, the TPRF surrogates were much less reactive than their corresponding gasolines. On the other hand, both four-component and eight-component surrogates adequately captured the ignition delay times of oxygenated gasolines over the wide range of experimental conditions.

Fig. 18 plots ignition delay times of eight gasoline fuels at initial pressure of 20 bar and a range of initial temperatures. Several interesting trends may be observed. At high temperatures, all gasolines have almost identical ignition delay times. The NTC region clearly manifests the dependence of ignition delay times on RON and sensitivity (RON - MON). The two low-octane FACE fuels, I and J, have the lowest ignition delay times in the NTC region. The two mid-octane FACE fuels, A and C, have longer ignition delay times. Finally, the high-octane gasolines (FACE F and G, Coryton and Haltermann) have the longest ignition delay times in the NTC region. These fuels also exhibit slower reactivity at the very low temperatures. Coryton and FACE G have the highest sensitivity $(\sim 11)$ among the high octane fuels and thus exhibit relatively less NTC behavior. On the other hand, FACE F has the lowest sensitivity (5.6) among this group of high-octane fuels and thus exhibits the steepest NTC character.

Apart from the handful of studies devoted to real gasoline fuels, there have been a relatively large number of experimental autoignition studies carried out on gasoline surrogates. These include studies 

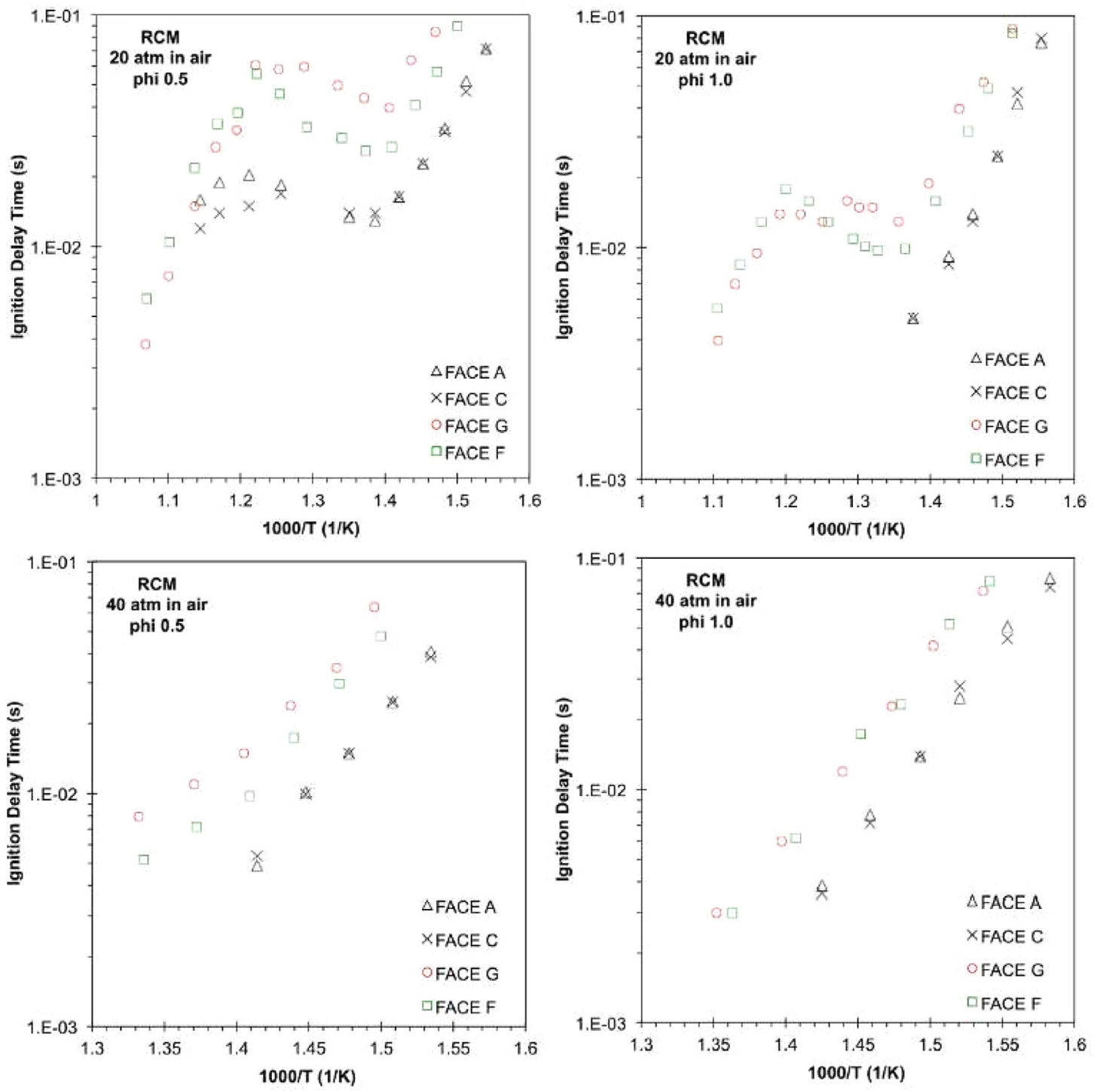

Fig. 15. - Ignition delay times of FACE F and G measured in a rapid compression machine. Figure adopted from [58] with permission from Elsevier Publishing.

on PRFs [34,155-157], TPRFs [158-160], n-heptane/toluene [40,161,162], isooctane/toluene [41,161], ethanol blends [163-165], and other multi-component blends [45,161,164,166-168]. These references and the relevant experimental details are listed in Table 3. These studies on gasoline surrogates have been very helpful in validating the chemical kinetic mechanisms of multi-component surrogate mixtures.

\subsubsection{Laminar flame speed studies}

Similar to ignition delay times, flame speed measurements of distillate gasolines are limited in the literature. One of the first measurements of gasoline flame speed were performed by Zhao et al. [169] on a research gasoline (CR-87) having an octane number of 87. Experiments were performed using the stagnation jet-wall flame configuration and particle image velocimetry (PIV), where laminar burning velocity was obtained by linear extrapolation of stretched flame speed to zero stretch speed. Measurements were carried out over a range of equivalence ratios (0.6-1.4), atmospheric pressure and initial temperatures of $353 \mathrm{~K}$ and $500 \mathrm{~K}$. Comparison of the measured data with previous PRF 90 laminar speeds showed that PRF could serve as a suitable surrogate for laminar flame speeds of CR-87 gasoline.
Jerzembeck et al. [170] measured laminar burning velocities of a commercial gasoline and a PRF 87 surrogate using the constant volume bomb and Schlieren method. The authors did not provide specifications for the gasoline; however, from comparisons with the PRF 87 surrogate, it may be assumed to have a RON of 87 . Flame speeds were measured at initial temperature of $373 \mathrm{~K}$, equivalence ratios ranging $0.7-1.2$ and initial pressures ranging $10-25$ bar. Overall, the results showed that PRF 87 can capture the burning velocities of the gasoline over the range of experimental conditions, with some deviations at rich conditions. A reduced high temperature PRF mechanism was also shown to perform satisfactorily for predicting laminar flame speeds.

Tian et al. [171] measured laminar burning velocities of European EN 228 gasoline (RON > 95) and compared the gasoline data with ethanol and 2,5-dimethyl furan (DMF) as alternative candidate fuels. These measurements were performed in a constant volume vessel using high speed Schlieren visualization. Experimental conditions spanned equivalence ratios of $0.6-2.0$ and initial temperatures of 323-373 K. As seen in Fig. 19, burning velocities of DMF matched with those of gasoline within $10 \%$; while ethanol burning velocities were larger by 30-40\%. Similar work performed by Dirrenberger et al. [172], using the heat flux method, showed that the burning velocities of a commercial 


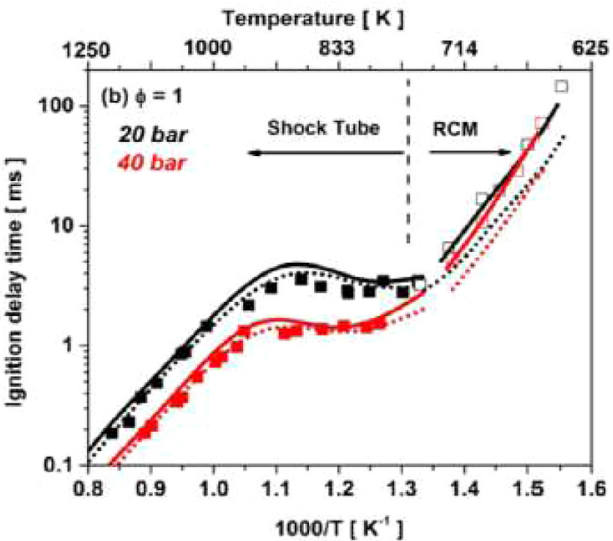

Fig. 16. Measured (symbols) and simulated (lines) ignition delay times of light naphtha. Solid lines represent simulations performed using a five-component surrogate. Dashed lines represent simulations performed with a two-component PRF 64.5 surrogate. Figure adopted from [152] with permission from Elsevier Publishing.

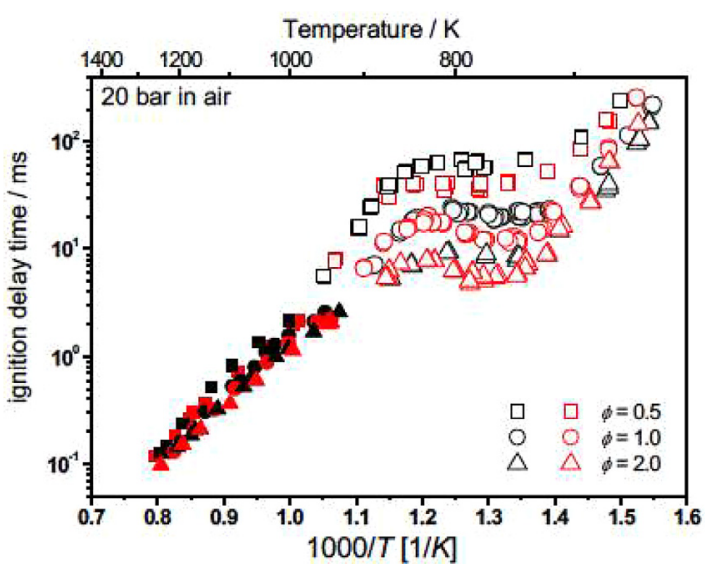

Fig. 17. Ignition delay times of Coryton gasoline (black) and Halterman gasoline (red) Filled points are shock tube and open points from RCM. Figure adopted from Lee et al. [154] with permission from Elsevier Publishing. (For interpretation of the references to color in this figure legend, the reader is referred to the web version of this article.)

oxygenated gasoline TAE7000 (RON 95.6) matched very well with a three-component TPRF (toluene/n-heptane/isooctane) surrogate over a wide range of equivalence ratios and initial temperature of $358 \mathrm{~K}$. They also showed that up to $15 \%$ of ethanol

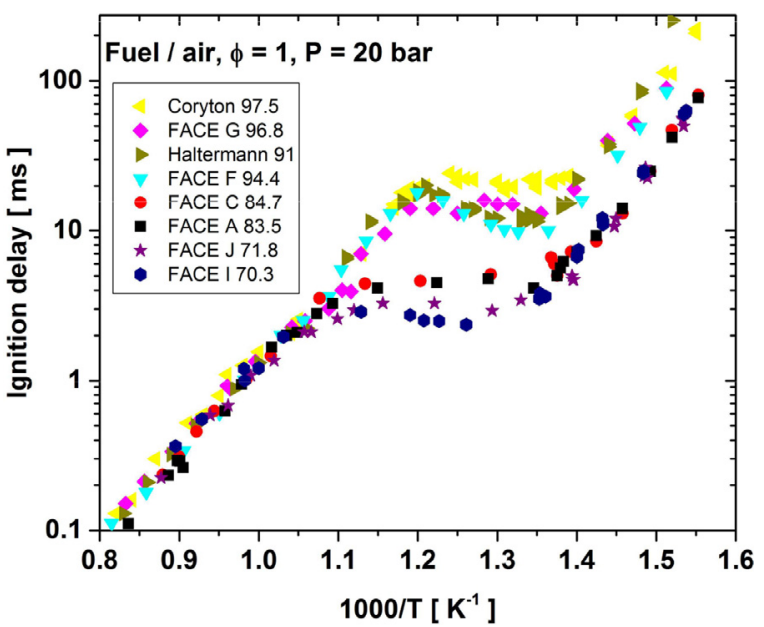

Fig. 18. Ignition delay times of various gasoline fuels measured in shock tube and rapid compression machine. (Fuel name followed by RON). addition to the gasoline had negligible influence on the burning velocities.

Sileghem et al. [137] utilized the heat flux method to report laminar burning velocities of a commercial non-oxygenated Exxon gasoline over equivalence ratios of $0.7-1.3$ and initial temperatures of 298-358 K. They formulated a three-component TPRF surrogate using the energy fraction mixing rule and showed that the surrogate matched the burning velocities of the gasoline very well over a wide range of initial temperatures and equivalence ratios, as illustrated in Fig. 20. Using the mixing rule, they also argued that a two-component PRF surrogate would only work well at lean conditions, and that toluene addition to the surrogate is necessary to emulate burning velocities of commercial gasolines containing many aromatic fractions.

Burning velocities of a wide range of ternary TPRF mixtures and three FACE gasolines $\mathrm{J}(\mathrm{RON}=70), \mathrm{C}(\mathrm{RON}=85)$ and $\mathrm{F}(\mathrm{RON}=95)$ were investigated by Mannaa et al. [173] at elevated pressures up to 6 bar, initial temperatures of $358 \mathrm{~K}$ and equivalence ratios of 0.8-1.6. Similar to Sileghem et al. [137], they showed that PRF surrogate can capture burning velocities of real gasoline only at lean conditions. For each gasoline, Mannaa et al. [173] formulated threecomponent TPRF surrogates to capture burning velocities over the wide range of their experimental conditions. In a later work, Mannaa et al. [174] studied the influence of ethanol addition (60 and $85 \mathrm{vol} \%$ ) to FACE C gasoline and its TPRF surrogate. They concluded that burning velocity enhancement from ethanol addition was similar in both the gasoline and TPRF surrogate.

Fig. 21 compares laminar burning velocities of gasoline fuels reported in various studies. These gasolines had varying RON and compositions. However, it may be argued that laminar burning velocities are more sensitive to gasoline composition and are negligibly affected by the RON. For example, the higher velocities measured by Dirrenberger et al. [172] may be attributed to the presence of oxygenates in the gasoline used in that study, but the non-availability of detailed composition (DHA) makes it difficult to compare burning velocities of different gasolines.

There have been several studies of laminar burning velocities on gasoline surrogate mixtures, such as PRFs [175-178], TPRFs [174,178], ethanol blends [177-179], and butanol blends [180,181]. These are listed in Table 3 and serve as benchmark studies for validating high-temperature kinetic mechanisms of multi-component mixtures.

\subsubsection{Speciation studies of gasoline oxidation}

Ignition delay times and laminar burning velocities are important global targets for the development and validation of chemical kinetic models of gasoline surrogates. However, time/spaceresolved measurements of combustion species (radicals, intermediates, products) can provide stringent targets for model validation. Such measurements have historically been performed for pure components and simple mixtures. Very few studies have measured species' profiles for distillate gasolines.

Chen et al. carried out a detailed speciation study on FACE A and C [182] and F [183] gasolines in a jet-stirred reactor (JSR) from high to low temperatures, pressure of 10 bar and equivalence ratios ranging $0.5-2$. Combustion species were sampled with a probe and analyzed using gas chromatography (GC) and Fourier transform infrared spectroscopy (FTIR). Measured species' profiles were compared with simulations using a simple PRF surrogate and two multi-component surrogates. As seen in Fig. 22, the simulated profiles from the three surrogates for FACE A and C are similar and do a reasonably good job of capturing the overall gasoline reactivity and two-stage oxidation behavior. Some disagreement was observed in the prediction of ethylene and propene, which may be attributed to the detailed chemistry of these alkenes. 
Table 3

Fundamental experimental studies of gasoline and gasoline surrogates.

\begin{tabular}{|c|c|c|c|}
\hline Reference & Fuels & Experimental device & $\mathrm{T}, \mathrm{P}$, mixture fraction \\
\hline \multicolumn{4}{|c|}{ Ignition Delay Time Studies } \\
\hline Gauthier et al. [143] & Gasoline RD 387, TPRF surrogates & Shock tube & $850-1280 \mathrm{~K}, 15-25$ and $45-60$ bar \\
\hline Kukkadapu et al. [144] & Gasoline RD 387 & Rapid compression machine & $647-955 \mathrm{~K}, 20$ and 40 bar \\
\hline Kukkadapu et al. [147] & Gasoline RD 387, TPRF surrogate, 4-component surrogate & Rapid compression machine & $650-900 \mathrm{~K}, 20$ and 40 bar \\
\hline Kukkadapu et al. [148] & TPRF surrogate, 4-component surrogate & Rapid compression machine & $665-950 \mathrm{~K}, 20$ and 40 bar \\
\hline Chung et al. [145] & Gasoline 95, 3-component surrogate, 7-component surrogate & Rapid compression machine & $670-1000 \mathrm{~K}, 25$ bar \\
\hline Agbro et al. [146] & $\begin{array}{l}\text { Gasoline } 95 \text {, Gasoline/butanol blend, TPRF surrogate, TPRF/ } \\
\text { butanol surrogate }\end{array}$ & Rapid compression machine & $678-858 \mathrm{~K}, 20 \mathrm{bar}$ \\
\hline Sarathy et al. [150] & FACE A gasoline, FACE C gasoline, PRF surrogate & Shock tube, rapid compression machine & $715-1500 \mathrm{~K}, 10,20$ and 40 bar \\
\hline Sarathy et al. [58] & FACE F gasoline, FACE G gasoline & Shock tube, rapid compression machine & $650-1270 \mathrm{~K}, 20$ and 40 bar \\
\hline Javed et al. [151] & FACE I gasoline, FACE J gasoline & Shock tube, rapid compression machine & $650-1200 \mathrm{~K}, 20$ and 40 bar \\
\hline Javed et al. [152] & Light naphtha, PRF surrogate, 5-component surrogate & Shock tube, rapid compression machine & $640-1250 \mathrm{~K}, 20$ and 40 bar \\
\hline AlAbbad et al. [153a] & $\begin{array}{l}\text { Straight run naphtha, PRF surrogate, TPRF surrogate, } \\
\text { 5-component surrogate }\end{array}$ & Shock tube, rapid compression machine & $650-1250 \mathrm{~K}, 20$ and 60 bar \\
\hline Lee et al. [154] & $\begin{array}{l}\text { Haltermann gasoline, Coryton gasoline, TPRF surrogate, } \\
\text { 4-component surrogate, 8-component surrogate }\end{array}$ & Shock tube, rapid compression machine & $650-1250 \mathrm{~K}, 10-40$ bar \\
\hline Vanhove et al. [161] & $\begin{array}{l}\text { n-heptane/toluene, isooctane/toluene, isooctane/1-hexene, } \\
\text { 1-hexene/toluene, isooctane/1-hexene/toluene }\end{array}$ & Rapid compression machine & $600-900 \mathrm{~K}, 4-16$ bar \\
\hline Fieweger et al. [155] & PRF 60, PRF 80, PRF 90 & Shock tube & $700-1250 \mathrm{~K}, 40$ bar \\
\hline Callahan et al. [156] & PRF 90, PRF 95, PRF 100 & $\begin{array}{l}\text { Rapid compression machine, } \\
\text { Flow reactor }\end{array}$ & $600-900 \mathrm{~K}, 20 \mathrm{bar}$ \\
\hline Tanaka et al. [157] & PRF 50, PRF 75, PRF 90 & Rapid compression machine & $750-850 \mathrm{~K}, 40 \mathrm{bar}$ \\
\hline AlAbbad et al. [153b] & PRF 70, PRF 80, PRF 91, PRF 95 & Shock tube & $750-1250 \mathrm{~K}, 20$ and 40 bar \\
\hline Javed et al. [158] & TPRF 70, TPRF 80, TPRF 91, TPRF 97.5 & Shock tube, rapid compression machine & $750-1250 \mathrm{~K}, 20$ and 40 bar \\
\hline Li et al. [160] & TPRF 87, TPRF 95 blends & Shock tube & $1100-1600 \mathrm{~K}, 10-20 \mathrm{bar}$ \\
\hline Cancino et al. [163] & $\begin{array}{l}\text { ethanol/isooctane, ethanol/isooctane/toluene/n-heptane/ } \\
\text { diisobutylene }\end{array}$ & Shock tube & $720-1220 \mathrm{~K}, 10-30 \mathrm{bar}$ \\
\hline Fikri et al. [164] & $\begin{array}{l}\text { n-heptane/isooctane/ ethanol, n-heptane /toluene /isooctane } \\
\text { /diisobutylene }\end{array}$ & Shock tube & $690-1200 \mathrm{~K}, 10-50$ bar \\
\hline Herzler et al. [162] & n-heptane/toluene & Shock tube & $620-1180 \mathrm{~K}, 10-50$ bar, \\
\hline Cancino et al. [165] & ethanol/isooctane/n-heptane/toluene & Shock tube & $690-1200 \mathrm{~K}, 10-50 \mathrm{bar}$ \\
\hline Hartmann et al. [208] & n-heptane/ toluene, isooctane/ toluene & Shock tube & $700-1200 \mathrm{~K}, 40 \mathrm{bar}$ \\
\hline Zhang et al. [293] & n-heptane/ butanol & Shock tube & $1200-1500 \mathrm{~K}, 2$ and 10 bar \\
\hline Yahyaoui et al. [166] & isooctane/toluene/1-hexene/ETBE & Shock tube, & $1390-1880 \mathrm{~K}, 2-10 \mathrm{bar}$ \\
\hline Yahyaoui et al. [167] & 1-hexene/toluene & Shock tube, & $1360-1860 \mathrm{~K}, 2-10 \mathrm{bar}$ \\
\hline Sakai et al. [159] & n-heptane/isooctane/toluene & Shock tube & $1200-1600 \mathrm{~K}, 2.5$ bar \\
\hline AlRamadan et al. [168] & 2-butanol/tert-butanol, TPRF/2-butanol/tert-butanol & Shock tube & $800-1200 \mathrm{~K}, 20$ and 40 bar \\
\hline \multicolumn{4}{|l|}{ Flame Speed Studies } \\
\hline Zhao et al. [169] & CR-87 gasoline & Stagnation jet-wall flame & $353 \mathrm{~K}$ and $500 \mathrm{~K}, 1$ bar, $\phi=0.6-1.4$ \\
\hline Jerzembeck et al. [170] & Commercial gasoline, PRF surrogate & Constant volume vessel & $373 \mathrm{~K}, 10$ and 25 bar, $\phi=0.8-1.2$ \\
\hline Tian et al. [171] & EN228 gasoline, dimethyl furan, ethanol & Constant volume vessel & $323 \mathrm{~K}$ and $373 \mathrm{~K}, 1$ bar, $\phi=0.6-2$ \\
\hline Dirrenberger et al. [172] & $\begin{array}{l}\text { TAE7000 gasoline, TAE7000 + 15\% ethanol, TPRF surrogate, } \\
\text { 4-compoenent surrogate }\end{array}$ & Perforated plate burner & $358 \mathrm{~K}, 1$ bar, $\phi=0.6-1.6$ \\
\hline Sileghem et al. [137] & Exxon 708,629 gasoline, TPRF surrogate & Flat flame burner & $298-358 \mathrm{~K}, 1$ bar, $\phi=0.7-1.3$ \\
\hline Mannaa et al. [173] & $\begin{array}{l}\text { FACE C gasoline, FACE F gasoline, FACE J gasoline, } \\
\text { PRF surrogates, TPRF surrogates }\end{array}$ & Constant volume vessel & $358 \mathrm{~K}, 1-6$ bar, $\phi=0.8-1.6$ \\
\hline Mannaa et al. [174] & $\begin{array}{l}\text { FACE C gasoline, FACE C gasoline + ethanol, TPRF surrogates, } \\
\text { four-component surrogates }\end{array}$ & Constant volume vessel & $358 \mathrm{~K}, 1-6$ bar, $\phi=0.8-1.6$ \\
\hline Huang et al. [175] & PRF 0, PRF 85, PRF 90, PRF 95, PRF 100 & Counter flow burner & $298 \mathrm{~K}, 1$ bar, $\phi=0.7-1.4$ \\
\hline Liao et al. [178] & $\begin{array}{l}\text { PRF 85, PRF 90, PRF 95, TPRF blends, ethanol/isooctane/ } \\
\text { n-heptane blends }\end{array}$ & Flat flame burner & $298-400 \mathrm{~K}, 1$ bar, $\phi=0.8-1.3$ \\
\hline Bradley et al. [176] & PRF 90 & Constant volume vessel & 358 and $450 \mathrm{~K}, 1-10$ bar, $\phi=0.8$ and 1 \\
\hline van Lipzig et al. [177] & $\begin{array}{l}\text { n-heptane/isooctane, n-heptane/ethanol, isooctane/ethanol, } \\
\text { n-heptane/isooctane/ethanol }\end{array}$ & Perforated plate burner & 298 and $338 \mathrm{~K}, 1$ bar, $\phi=0.6-1.3$ \\
\hline Gülder et al. [179] & isooctane/ethanol & Constant volume vessel & $350-600 \mathrm{~K}, 1$ bar, $\phi=0.75-1.4$ \\
\hline Broustail et al. [180] & Butanol/isooctane, ethanol/isooctane & Constant volume vessel & $350 \mathrm{~K}, 1$ bar, $\phi=0.8-1.4$ \\
\hline Broustail et al. [181] & Butanol/isooctane, ethanol/isooctane & Constant volume vessel & $423 \mathrm{~K}, 1-10$ bar, $\phi=0.7-1.4$ \\
\hline \multicolumn{4}{|l|}{ Speciation Studies } \\
\hline Chen et al. [182] & FACE A gasoline, FACE C gasoline & Jet-stirred reactor & $\begin{array}{l}530-1250 \mathrm{~K}, 10 \text { bar, } \phi=0.5-2 \\
\quad(183 \text { is Bingjie et al.) }\end{array}$ \\
\hline Chen et al. [183] & FACE F gasoline & Jet-stirred reactor & $530-1250 \mathrm{~K}, 10 \mathrm{bar}, \phi=0.5-2$ \\
\hline Selim et al. $[184,185]$ & FACE A gasoline, FACE C gasoline, PF 84 & Low-pressure laminar burner & 20 Torr, $\phi=1$ \\
\hline Javed et al. [186] & FACE A gasoline, FACE C gasoline, PRF 84 & Shock tube & $1350-1550 \mathrm{~K}, 2$ bar, $\phi=1$ \\
\hline Yahyaoui et al. [166] & isooctane/toluene/1-hexene/ETBE & Jet-stirred reactor & $750-1200 \mathrm{~K}, 10 \mathrm{bar}, \phi=1$ \\
\hline Yahyaoui et al. [167] & 1-hexene/toluene & Jet-stirred reactor & $750-1170 \mathrm{~K}, 10$ bar, $\phi=0.5-1.5$ \\
\hline Dagaut et al. [190] & 1-butanol/isooctane/toluene/1-hexene & Jet-stirred reactor & $770-1220 \mathrm{~K}, 10$ bar, $\phi=0.3-2$ \\
\hline Dagaut et al. [191] & Ethanol/isooctane/toluene/ 1-hexene & Jet-stirred reactor & $770-1220 \mathrm{~K}, 10$ bar, $\phi=0.3-2$ \\
\hline Dagaut et al. [193] & n-heptane/MTBE, n-heptane/ETBE & Jet-stirred reactor & $570-1150 \mathrm{~K}, 10 \mathrm{bar}, \phi=1$ \\
\hline Dagaut et al. [187] & PRF10, PRF 50, PRF 70, PRF 90 & Jet-stirred reactor & $550-1150 \mathrm{~K}, 10 \mathrm{bar}, \phi=1$ \\
\hline Dagaut et al. [192] & ethanol/n-heptane & Jet-stirred reactor & $530-1070 \mathrm{~K}, 10$ bar, $\phi=0.5$ and 1 \\
\hline Dubreuil et al. [188] & n-heptane/isooctane, n-heptane/toluene & Jet-stirred reactor & $550-1000 \mathrm{~K}, 10 \mathrm{bar}, \phi=0.2-0.7$ \\
\hline Wilke et al. [194] & n-heptane/alkenes, n-heptane/isooctane, n-heptane/MTBE & Flow reactor & $570-920 \mathrm{~K}, 1$ bar, $\phi=1$ \\
\hline
\end{tabular}


Table 3 (Continued)

\begin{tabular}{|c|c|c|c|}
\hline Reference & Fuels & Experimental device & $\mathrm{T}, \mathrm{P}$, mixture fraction \\
\hline Lenhert et al. [195] & 1-pentene/toluene/n-heptane/isooctane & Flow reactor & $600-800 \mathrm{~K}, 8$ bar, $\phi=0.5-1$ \\
\hline Hori et al. [189] & n-heptane/toluene & Micro-flow reactor & $300-1300 \mathrm{~K}, 1-5$ bar \\
\hline Togbe et al. [193] & Methanol/isooctane/toluene/1-hexene/ & Jet-stirred reactor & $770-1140 \mathrm{~K}, 10 \mathrm{bar}, \phi=0.35-2$ \\
\hline \multicolumn{4}{|c|}{ Diffusion Flame Studies } \\
\hline Marciq [198] & Gasoline, gasoline/ethanol blends & Coflow diffusion flame & 1 bar \\
\hline Khosousi et al. [199] & Gasoline, gasoline/ethanol blends & Coflow diffusion flame & 1 bar \\
\hline Lemaire et al. [200] & $\begin{array}{l}\text { Gasoline, gasoline/ethanol blends, gasoline surrogate/ethanol } \\
\text { blends }\end{array}$ & Turbulent spray flames & $1 \mathrm{bar}$ \\
\hline Bieleveld et al. [201] & $\begin{array}{l}\text { Gasoline 87, gasoline 91, PRF 87, PRF 91, n-heptane/ } \\
\text { isooctane/toluene/methylcyclohexane surrogate, }\end{array}$ & Counterflow diffusion flame & $1 \mathrm{bar}$ \\
\hline Choi et al. [202] & n-heptane/isooctane, n-heptane/toluene, isooctane/toluene & Counterflow diffusion flame & 1 bar \\
\hline Kashif et al. [203] & n-heptane/toluene, isooctane/toluene & Coflow diffusion flame & 1 bar \\
\hline
\end{tabular}

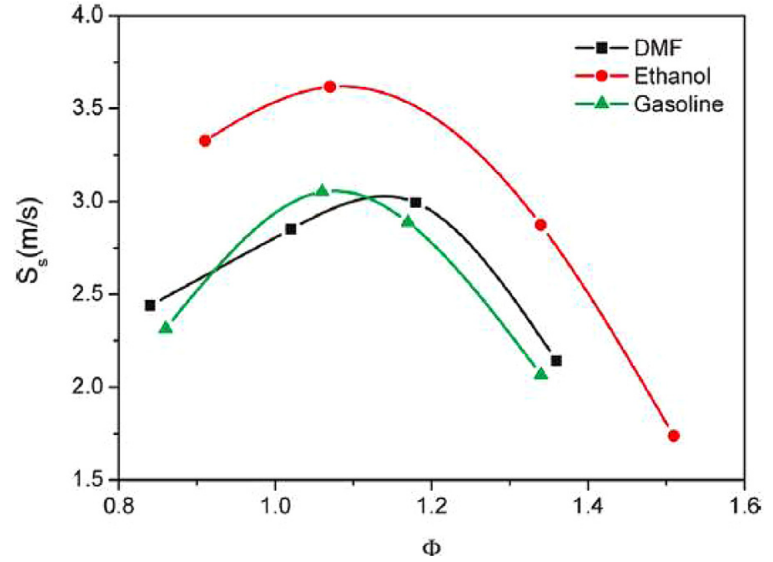

Fig. 19. Unstretched laminar flame speed at initial temperature of $323 \mathrm{~K}$ and initial pressure of 1 bar. Fig. adopted from [171] with permission from The American Chemical Society.

Selim et al. studied speciation of the same gasolines, FACE A and C [184], as well as PRF 84 [185], in a low-pressure (20 Torr) flame coupled to vacuum-ultraviolet synchrotron photoionization timeof-flight molecular beam mass spectrometry. The authors utilized a novel approach, comparing quantities of interest to discern the differences between the intermediate species profiles of both gasolines

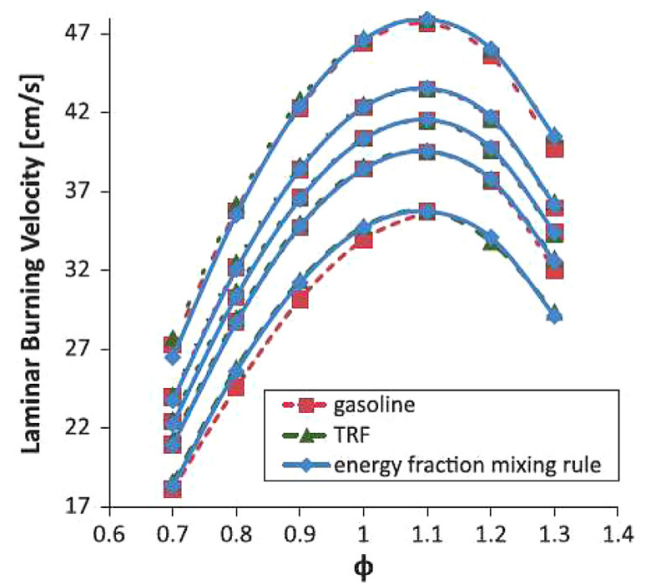

Fig. 20. Laminar burning velocities of non-oxygenated Exxon gasoline and TRF (toluene/isooctane/n-heptane) at initial temperatures of 298, 318, 328, 338 and 358 K. Predictions of the energy fraction mixing rule are also shown. Figure adopted from Sileghem et al. [137] with permission from Elsevier Publishing. and the chemical kinetic simulations of surrogate mixtures. In agreement with previous autoignition studies on FACE A and C [150], they concluded that PRF surrogates are suitable for capturing the detailed flame chemistry of alkane-rich gasolines.

Javed et al. [186] applied four simultaneous laser-based diagnostics in a shock tube study to measure species' profiles during the high temperature oxidation of FACE A, C and PRF 84 surrogate. As shown in Fig. 23, they observed that the two gasolines and their PRF surrogate produced very similar radical pool $(\mathrm{OH})$, intermediate species ( $\mathrm{CO})$ and products $\left(\mathrm{CO}_{2}, \mathrm{H}_{2 \mathrm{p}} \mathrm{O}\right)$, thereby explaining their nearly identical ignition delay times at high temperatures.

There have been several speciation studies on gasoline surrogate mixtures, such as PRFs [186-188], n-heptane/toluene [188,189], alcohol blends [190-193], and other multi-component mixtures $[72,166,167,194,195]$. These are listed in Table 3 and serve as good targets for validating the detailed kinetic mechanisms of multicomponent mixtures.

\subsubsection{Gasoline surrogate studies in diffusion flames}

Section 2 of this paper highlighted the role of fuel physical and chemical kinetic properties on PM (i.e., soot) formation in engines. For example, it was shown that the fuel volatility characteristics, aromatic content, oxygenate content, and antiknock quality all influence PM formation in engines. It is important for surrogate fuel simulations to emulate the soot formation characteristics of real fuels, in order to design gasoline engines with lower PM emissions. Soot in SI engines is typically formed due to insufficient fuel/air mixing or

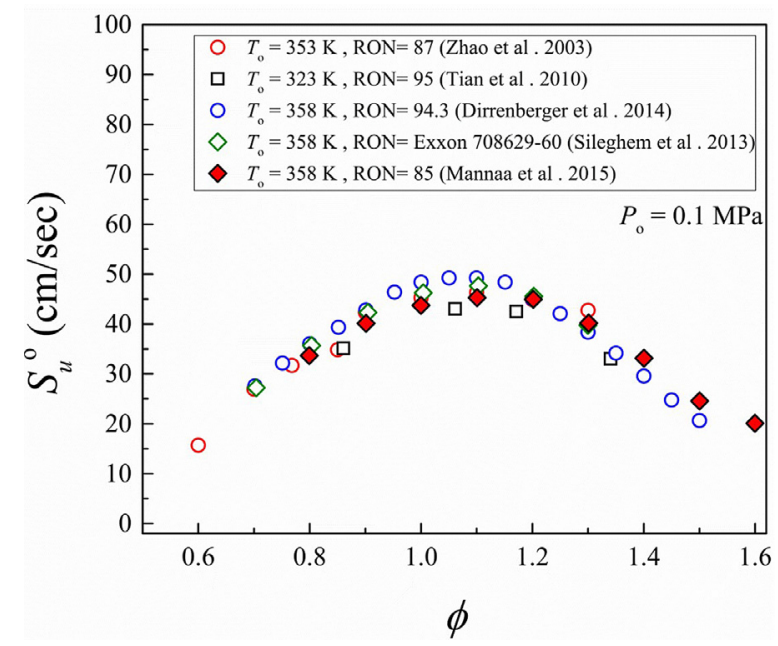

Fig. 21. Comparison of gasoline burning velocities reported in various studies. 

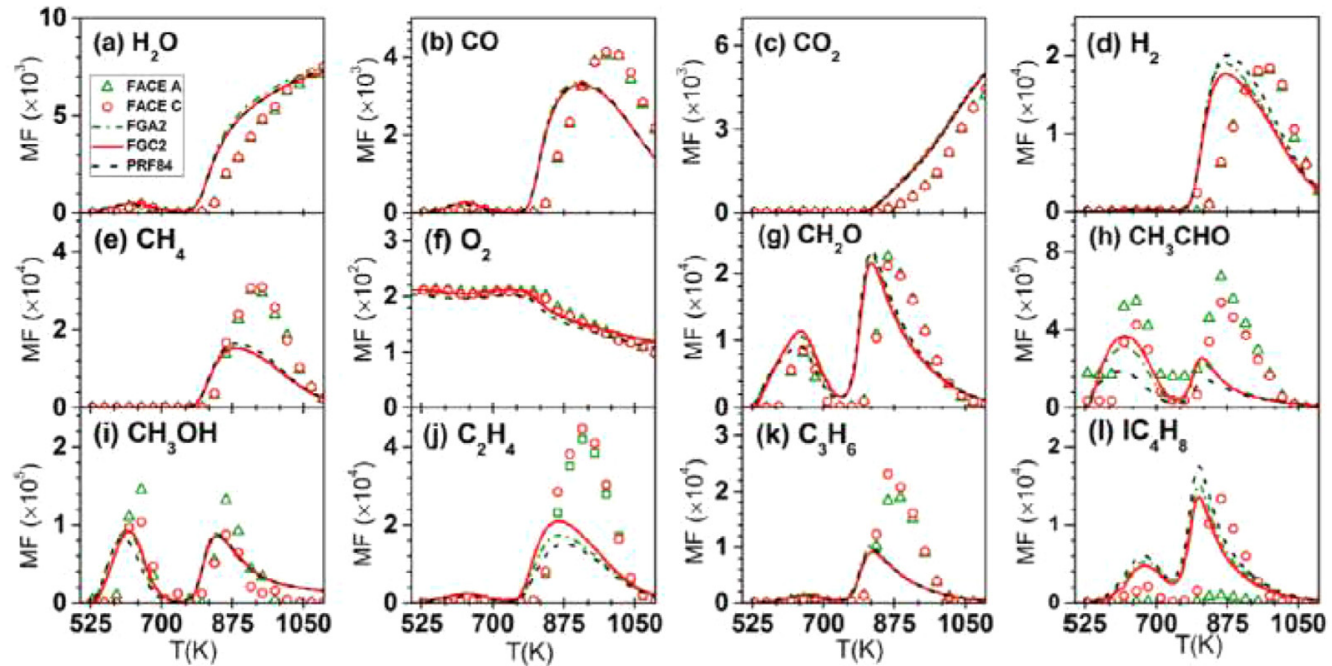

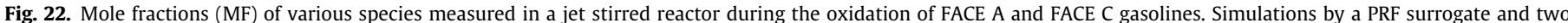
multi-component surrogates are also shown. Figure adopted from [182] with permission from Elsevier Publishing.

from fuel spray impinging on the wall and not completely vaporizing $[196,197]$. Both scenarios create rich pockets or diffusion flamelets where soot can be formed and not completely oxidized.

Diffusion flames are often used to study the tendency of a specific fuel to form soot particles. Since the addition of oxygenated species (such as ethanol) to hydrocarbons is expected to reduce soot formation, a few studies have been dedicated to carry out diffusion flame experiments of gasoline and ethanol blends. Marciq [198] performed coflow flame experiments on E0 (pure gasoline), E20 (20\% ethanol / $80 \%$ gasoline), E50 (50\% ethanol / 50\% gasoline) and E85 (85\% ethanol / $15 \%$ gasoline). Soot size distribution was measured as a function of height above the burner using scanning mobility particle sizer (SMPS). It was found that the addition of up to $50 \%$ ethanol to gasoline had little effect on flame properties. The E20 and E50 flames
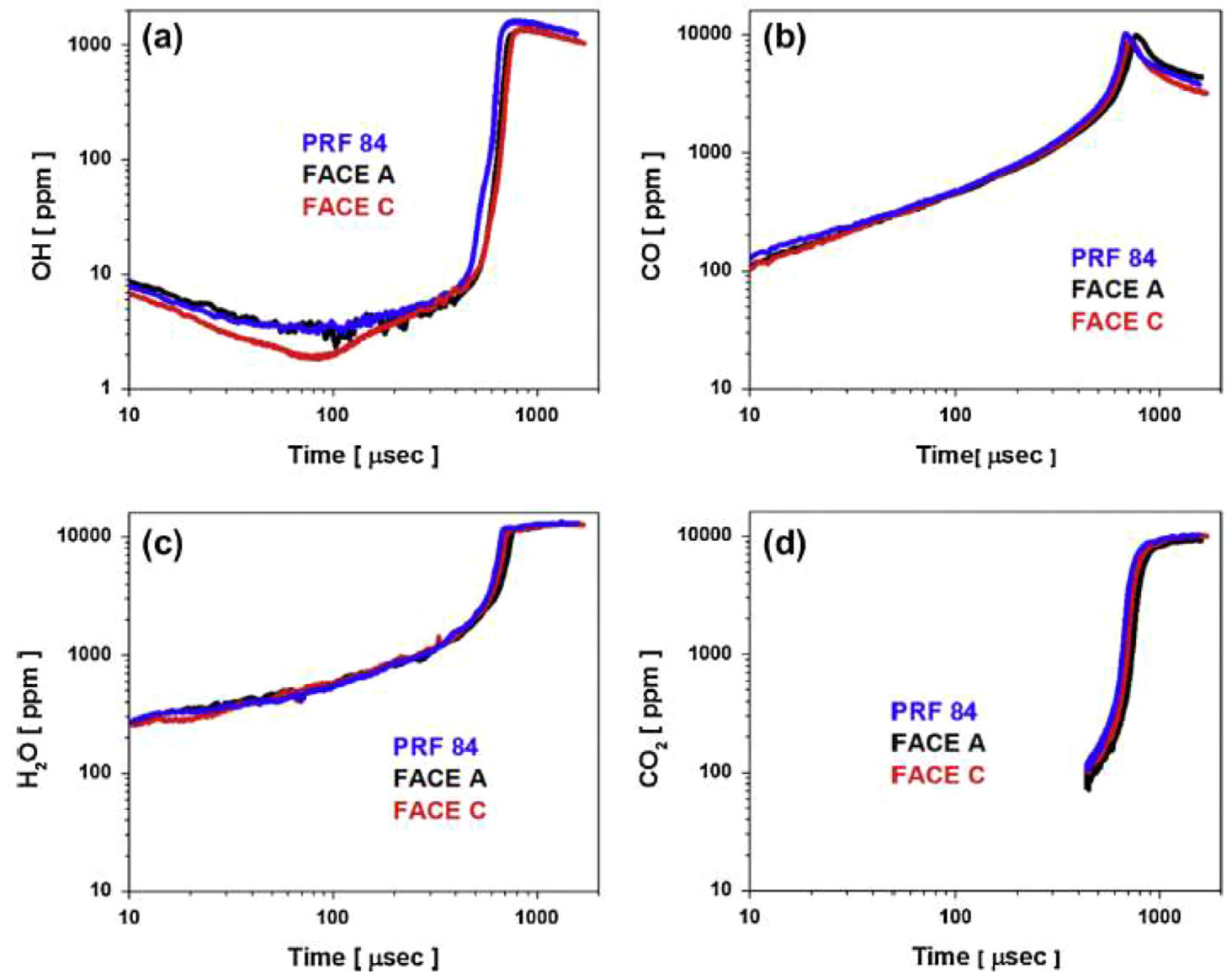

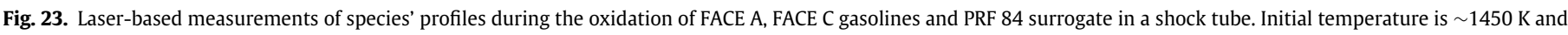
initial pressure is 2 bar. Figure adopted from [186] with permission from Elsevier Publishing. 


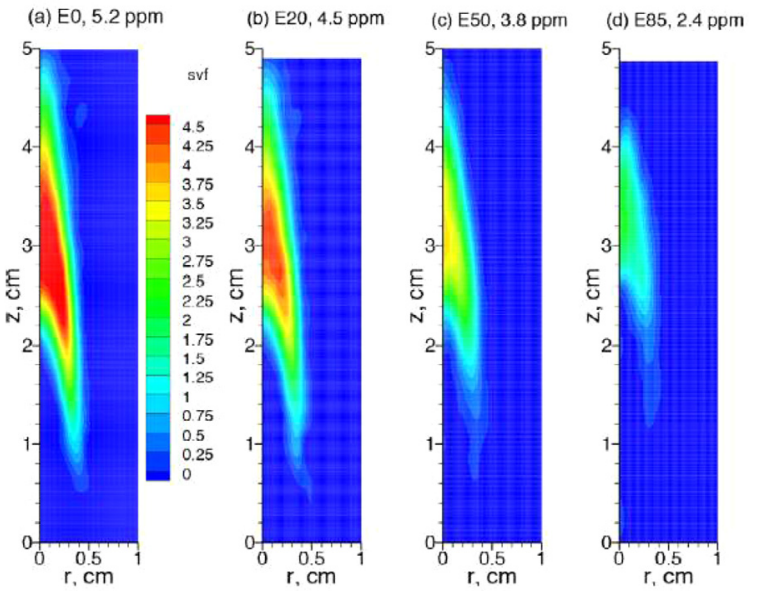

Fig. 24. Measured soot volume fraction distributions in the E0, E20, E50, and E85 flames. Peak soot volume fraction in each flame is indicated. Figure adopted from [199] with permission from Elsevier Publishing.

behaved almost the same as the E0 flame. However, the E85 flame resulted in 4-7 times reduction in nuclei mode mass and a reduction factor of about two in the size of soot agglomerates compared to the E0 flame.

Recently, Khosousi et al. [199] studied the same fuels as Marciq [198] in a similar configuration of coflow laminar diffusion flames. However, in contrast to Marciq [198], Khosousi et al. [199] heavily diluted the fuel stream with nitrogen to prevent the flames from smoking. They also measured radially-resolved soot volume fraction distributions by employing a two-dimensional line-of-sight attenuation (2D-LOSA) technique and an Abel inversion algorithm [199]. The measured volume fractions in Fig. 24 show decreasing amounts of soot with increasing ethanol fraction. However, the suppression of soot only becomes significant for $50 \%$ or more ethanol. A numerical model and gasoline surrogate proposed in the study predicted the experimentally observed trends.

Lemaire et al. [200] used a turbulent spray flame to study the influence of ethanol addition to gasoline on soot formation tendency. Spatially resolved measurements of soot volume fraction and polycyclic aromatic hydrocarbons (PAHS) were made by simultaneous applications of LII and LIF. They observed that $10-30 \%$ addition of ethanol to gasoline significantly reduced the concentration of soot precursors (PAH) and about $25-81 \%$ reduction in the total quantity of soot. Experiments performed with gasoline surrogates and surrogate/ethanol blends adequately reproduced the gasoline and gasoline/ethanol soot production trends. The results also indicated that the gasoline/ethanol soot oxidized faster than the pure gasoline soot.

Bieleveld et al. [201] employed a counterflow diffusion flame technique to study the extinction and autoignition of two gasolines (RON 87 and 91), PRF surrogates and multi-component surrogates comprising n-heptane / isooctane / toluene / methylcyclohexane. Experiments and calculations performed with a semi-detailed kinetic mechanism showed that the extinction/ignition characteristics of PRF 87 and PRF 91 were different from those of the corresponding gasolines. However, two multi-component surrogates were able to reproduce the combustion characteristics of the gasoline fuels. The results affirm that a simple PRF surrogate is not adequate to model the combustion and emission behavior of a fully blended gasoline.

Choi et al. [202] and Kashif et al. [203] utilized counterflow and coflow diffusion flames, respectively, to investigate sooting tendency of gasoline surrogates comprised of binary mixtures of n-heptane, isooctane and toluene.
A few other studies of gasoline and surrogates include the works of Liu et al. [204] on a RON 87 gasoline and blends of n-heptane/isooctane/toluene using sub-millimeter droplets, Farouk et al. [205] on PRF droplet burning, Baumgardner et al. [206] on PRF and n-heptane/n-butanol blends in a constant volume combustion device, and Naser et al. [207] on PRF and TRF (n-heptane/toluene) in an ignition quality tester.

\subsubsection{Future experimental work}

The literature presented demonstrates that there has been considerable work done on gasoline surrogate components and surrogate mixtures. However, research on gasoline fuels in fundamental combustion devices has been inadequate. Such work is necessary to build a sound basis for surrogate formulation strategies and kinetic mechanisms of gasoline surrogates. These experiments should encompass global reactivity data (ignition delay times, flame speeds, extinction, autoignition) as well as details of reactivity trends (species time-histories). The fuels chosen for experimentation should span a wide range of properties ( $\mathrm{RON}, \mathrm{MON}, \mathrm{H} / \mathrm{C}$ ratio, distillation range, oxygenation, composition) that would be expected in current and future energy conversion devices.

\section{Chemical kinetic modeling of gasoline surrogate fuel combustion}

The chemical kinetics of gasoline was previously discussed in the context of experimental work performed on surrogate mixtures and full boiling range refinery gasoline fuels. Numerical simulations can also aid understanding the effects of gasoline fuel composition on combustion properties and engine performance. These simulations rely on chemical kinetic models comprising a series of elementary reaction steps that describe the molecular-level transformations of reactants (i.e., fuel/air) to intermediate and product species, as well as thermal energy. Chemical kinetic models are capable of simulating reactions in the flame zone that result in heat release, the ignition characteristics of fuel/air mixtures, and the formation of major and minor pollutant species.

Gasoline fuels contain hundreds of different molecules, and developing such kinetic models for each individual component is unmanageable. Kinetic models are only available for surrogate fuel mixtures comprising a limited number of components. This section presents available chemical kinetic models for various pure hydrocarbon and oxygenated species that can be used in gasoline surrogate fuel mixtures. Kinetic models for surrogate mixtures are then presented, with insights into engine-relevant phenomenon that these models provide, such as flame propagation, engine knock, and pollutant formation mechanisms.

\subsection{Chemical kinetic models for pure components}

As described previously, gasoline fuel components can be divided into five main hydrocarbon classes (paraffins, isoparaffins, olefins, naphthenes, and aromatics) and oxygenates. The kinetic models for each individual component comprises a set reaction classes and rate coefficient estimations, which can be assigned manually or via automatic generation tools (e.g., NETGEN [209], EXGAS [210,211], Reaction Mechanism Generator [212-216], and Genesys [217]). The models are developed in a hierarchical manner because combustion proceeds via a series of elementary steps that fragments the parent fuel into smaller intermediate species, which subsequently react to form stable products. This concept is well represented by the Dooley et al.'s [218] schematic representation of real fuel combustion kinetic phenomena, as shown in Fig. 25. Complex fuels contain many chemical structures, but when burned, the intermediates produced contain much fewer distinct chemical functionalities. Reactions involving these chemical intermediates characterize the small 


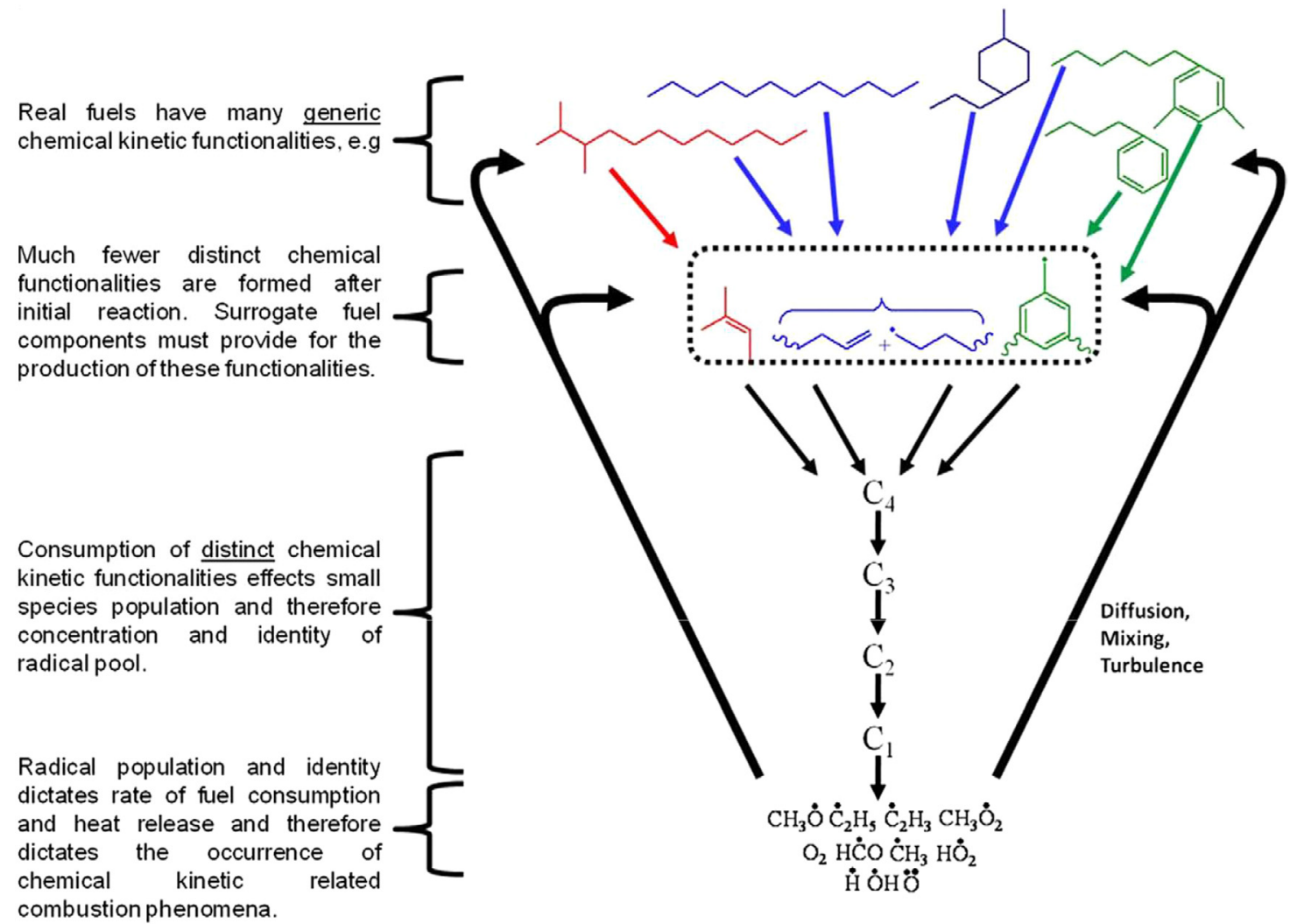

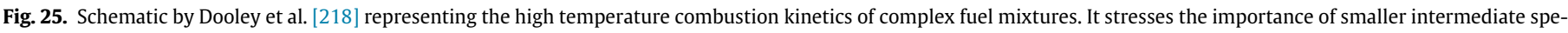
cies in the combustion of larger hydrocarbons. Figure reproduced from [218] with permission from Elsevier Publishing.

species radical pool, which governs important combustion processes (e.g., ignition delay, flame propagation, emissions formation). The schematic highlights the importance of having a common high fidelity small molecule reaction mechanism (or "core mechanism"), on top of which the reaction mechanism for larger hydrocarbons can be developed. These core mechanisms typically include detailed and well validated reaction mechanisms for oxidation and pyrolysis of hydrogen and $\mathrm{C}_{1}-\mathrm{C}_{4}$ hydrocarbon species. Popular core mechanisms for developing gasoline fuel surrogates models include NUI Galway's AramcoMech [219-222], Princeton Mechanism [223-226], San Diego Mechanism [227-229], Politecnico di Milano's CRECK mechanism [201,230], and Stanford's Foundational Fuel Chemistry Model (FFCM-1) [231]. The reactions for larger hydrocarbons are added to the core reaction mechanism. The following sub-sections summarize available kinetic models for larger hydrocarbons, which could be combined to create gasoline surrogate kinetic models.

Table 4 is an overview of the available kinetic models published since 2000. Table 4 presents information for various n-alkanes, isoalkanes, cycloalkanes, alkenes, aromatics, and oxygenated fuels that are typically found in gasoline. Molecular formula and boiling points are also presented for quick identification of surrogate components with desired physical properties. Table 4 focuses on comprehensive chemical kinetic models, which have been validated across a broad range of temperatures and pressures. Several comments on the validity range of the developed chemical kinetic models are given in Table 4. As clarified in the following section, the merging of hydrocarbon mechanisms requires a common core mechanism, so wherever possible, the core mechanism utilized in the model is highlighted.

\subsubsection{Paraffins/n-Alkanes}

n-Alkanes (or paraffins) are the most widely studied class of hydrocarbons in gasoline fuels. Previous significant reviews by
Simmie [232] and Battin-Leclerc [233] have highlighted many important aspects of $n$-alkane kinetic modeling. The fact that they have been widely studied, both experimentally and numerically, has resulted in high fidelity chemical kinetic models which are readily adopted into gasoline surrogate kinetic modeling studies. The high temperature oxidation kinetics of n-alkanes is well understood, as it is initiated by $\mathrm{H}$-atom abstraction from the fuel, and typically followed by scission of the $\mathrm{C}-\mathrm{C}$ bond $\beta$ to the radical site (i.e., $\beta$-scission), as shown in the red box in, left panel. The resulting products are a smaller alkyl radical and an alkene, of which the former undergoes further $\beta$-scission, and the latter is consumed by $\mathrm{H}$-atom abstraction. At very high temperatures (i.e., above $1250-1400 \mathrm{~K}$ ) or in the absence of oxygen, reactivity is initiated by unimolecular decomposition of the fuel to form two alkyl radicals (i.e., pyrolytic $\mathrm{C}-\mathrm{C}$ scission). Other important reactions include alkyl radical isomerizations, alkenyl radical decompositions, and retroene reactions. Detailed descriptions of the various high temperature reactions classes in n-alkane oxidation are presented in the literature $[232,234,235]$.

In general, the high temperature oxidation mechanism controls engine-relevant phenomenon such as premixed laminar flame speed, premixed flame extinction, and high temperature ignition delay (i.e., above $\sim 1000 \mathrm{~K}$ ). An interesting observation is that the high temperature oxidation behavior of n-alkanes typically found in transportation fuels are remarkably similar. This is best exemplified by the work of Ji et al. [236], in which the authors experimentally studied the premixed laminar flame speeds and extinction strain rates for $C_{5}-C_{12} n$-alkanes in air. The authors found that all n-alkanes larger than $C_{5}$ exhibit the same laminar flame speed and extinction strain rates, as shown in Fig. 26. The reason for the similarity is well captured by chemical kinetic models, and can be attributed to the fact that all large n-alkanes decompose at high temperatures to a similar pool of radical species (mainly $\mathrm{H}, \mathrm{CH}_{3}, \mathrm{C}_{2} \mathrm{H}_{5}$, and $\mathrm{C}_{3} \mathrm{H}_{7}$ ). The 
Table 4

Comprehensive chemical kinetic models for various gasoline surrogate components published since 2000 .

\begin{tabular}{|c|c|c|c|c|c|c|}
\hline Molecule & $\begin{array}{l}\text { Molecular } \\
\text { Formula }\end{array}$ & $\begin{array}{l}\text { MW } \\
(\mathrm{g} / \mathrm{mol})\end{array}$ & $\begin{array}{l}\text { Boiling } \\
\text { Point (K) }\end{array}$ & Reference, Year & $\begin{array}{l}\text { \# of Species and \# } \\
\text { of Reactions }\end{array}$ & Comments \\
\hline \multirow[t]{2}{*}{ n-butane } & \multirow[t]{2}{*}{$\mathrm{C} 4 \mathrm{H} 10$} & \multirow[t]{2}{*}{58.12} & \multirow[t]{2}{*}{272} & Healy et al., 2010 [246] & $\begin{array}{l}238 \text { species and } \\
1328 \text { reactions }\end{array}$ & $\begin{array}{l}\text { Validated against ignition delay times from } \\
690-1430 \mathrm{~K} \text {, up to } 45 \text { bar, and various equiva- } \\
\text { lence ratio }\end{array}$ \\
\hline & & & & Cord et al., 2012 [285] & NA & $\begin{array}{l}\text { Validated against species profiles at } 550-800 \mathrm{~K} \text {, } \\
1 \text { bar and phi }=1\end{array}$ \\
\hline iso-butane & $\mathrm{C} 4 \mathrm{H} 10$ & 58.12 & 261 & Healy et al., 2010 [286] & $\begin{array}{l}230 \text { species and } \\
1328 \text { reactions }\end{array}$ & $\begin{array}{l}\text { Validated against ignition delay times from } \\
590-1567 \mathrm{~K} \text { up to } 30 \text { bar and various equiva- } \\
\text { lence ratios }\end{array}$ \\
\hline \multirow[t]{3}{*}{ n-pentane } & \multirow[t]{3}{*}{$\mathrm{C} 5 \mathrm{H} 12$} & \multirow[t]{3}{*}{72.15} & \multirow[t]{3}{*}{309} & Bugler et al., 2016 [247,248] & NA & $\begin{array}{l}\text { Validated against ignition delay times (ST and } \\
\text { RCM) at } 643-1718 \mathrm{~K} \text {, up to } 20 \text { bar and various } \\
\text { equivalence ratios }\end{array}$ \\
\hline & & & & Bugler et al., 2017 [287] & NA & $\begin{array}{l}\text { Slight modifications on multi-oxygenated spe- } \\
\text { cies. Validated against species profiles (JSR) at } \\
500-1100 \mathrm{~K} \text { up to } 10 \text { bar and various equiva- } \\
\text { lence ratios }\end{array}$ \\
\hline & & & & Cai and Pitsch, 2014 [288] & $\begin{array}{l}107 \text { species and } \\
1135 \text { reactions }\end{array}$ & $\begin{array}{l}\text { Optimized model. Validated against ignition } \\
\text { delay times at } 600-1491 \mathrm{~K} \text { and } 1.9 \text { bar (stoi- } \\
\text { chiometric mixture) }\end{array}$ \\
\hline 2-methylbutane & C5H12 & 72.15 & 301 & Bugler et al., 2016 [247,248] & NA & $\begin{array}{l}\text { Validated against ignition delay times from } \\
643-1718 \mathrm{~K} \text {, up to } 20 \text { bar and various } \\
\text { equivalence }\end{array}$ \\
\hline 2,2-dimethylpropane & C5H12 & 72.15 & 283 & Bugler et al., 2016 [247,248] & NA & $\begin{array}{l}\text { Validated against ignition delay times from } \\
643-1718 \mathrm{~K} \text {, up to } 20 \text { bar and various } \\
\text { equivalence }\end{array}$ \\
\hline n-hexane & C6H14 & 86.18 & 341 & Zhang et al., 2015 [249] & NA & $\begin{array}{l}\text { Validated against ignition delay times from } \\
627-1365 \mathrm{~K}(\mathrm{ST}) \text { up to } 32 \text { bar and various } \\
\text { equivalence ratios }\end{array}$ \\
\hline \multirow[t]{9}{*}{ n-heptane } & \multirow[t]{9}{*}{ C7H16 } & \multirow[t]{9}{*}{100.21} & \multirow[t]{9}{*}{372} & Zhang et al., 2016 [250] & $\begin{array}{l}1268 \text { species and } \\
5336 \text { reactions }\end{array}$ & $\begin{array}{l}\text { Validated against ignition delay times at } \\
726-1412 \mathrm{~K} \text { up to } 38 \text { bar of stoichiometric } \\
\text { mixtures }\end{array}$ \\
\hline & & & & Hu et al., 2017 [289] & $\begin{array}{l}702 \text { species and } \\
3123 \text { reactions }\end{array}$ & $\begin{array}{l}\text { Validated against ignition delay times at } \\
1100-1600 \mathrm{~K} \text { up to } 10 \text { bar and various equiva- } \\
\text { lence ratios }\end{array}$ \\
\hline & & & & Karwat et al., 2013 [290] & NA & $\begin{array}{l}\text { Validated against ignition delay times and spe- } \\
\text { cies profiles at } 660-710 \mathrm{~K} \text { and } 9 \text { bar }\end{array}$ \\
\hline & & & & Hakka et al., 2015 [291] & $\begin{array}{l}244 \text { species and } \\
2310 \text { reactions }\end{array}$ & $\begin{array}{l}\text { Validated against species profiles (JSR) at } \\
550-1100 \mathrm{~K} \text { and } 1.06 \text { bar and phi }=3\end{array}$ \\
\hline & & & & Seidel et al., 2015 [292] & $\begin{array}{l}349 \text { species and } \\
3686 \text { reactions }\end{array}$ & $\begin{array}{l}\text { Validated against auto-ignition timing, flame } \\
\text { speeds and species compositions at } \\
500-2000 \mathrm{~K} \text { up to } 40 \mathrm{bar} \text { and phi }=1.69 \text {. }\end{array}$ \\
\hline & & & & Zhang et al, 2013 [293] & $\begin{array}{l}734 \text { species and } \\
3142 \text { reactions }\end{array}$ & $\begin{array}{l}\text { Validated against ignition delay time at } \\
1200-1500 \mathrm{~K} \text { up to } 10 \text { bar and at phi }=0.5 \\
\text { and } 1 .\end{array}$ \\
\hline & & & & Herbinet et al., 2012 [294] & NA & $\begin{array}{l}\text { Validated against species compositions at } \\
500-1100 \mathrm{~K} \text { and } 1,06 \text { bar and phi }=1\end{array}$ \\
\hline & & & & Dagaut and Togbe, 2010 [295] & $\begin{array}{l}564 \text { species and } \\
2589 \text { reactions }\end{array}$ & $\begin{array}{l}\text { Validated against species mole fractions at } \\
530-1070 \mathrm{~K} \text { and } 10 \text { bar and phi }=0.5 \text { and } 1 .\end{array}$ \\
\hline & & & & Cai et al., 2016 [251] & $\begin{array}{l}624 \text { species and } \\
2727 \text { reactions }\end{array}$ & $\begin{array}{l}\text { Validated against ignition delay times across a } \\
\text { range of temperatures and pressures up to } \\
42 \text { bar. }\end{array}$ \\
\hline \multirow[t]{2}{*}{ 2-methylhexane } & \multirow[t]{2}{*}{ C7H16 } & \multirow[t]{2}{*}{100.21} & \multirow[t]{3}{*}{363} & Mohamed et al., 2016 [296] & $\begin{array}{l}1187 \text { species and } \\
4567 \text { reactions }\end{array}$ & $\begin{array}{l}\text { Validated against ignition delay times at } \\
740-1258 \mathrm{~K} \text { at } 20 \text { and } 40 \text { bar and various } \\
\text { equivalence ratios. }\end{array}$ \\
\hline & & & & Wang et al., 2017 [245] & NA & $\begin{array}{l}\text { Validated against ignition delay times and spe- } \\
\text { cies profiles at low temperatures up to } 40 \text { bar } \\
\text { and various equivalence ratios. }\end{array}$ \\
\hline heptane isomers & C7H16 & 100.21 & & Westbrook et al, 2001 [262] & NA & $\begin{array}{l}\text { Validated against ignition delay times at } \\
600-1400 \mathrm{~K} \text { up to } 50 \text { bar at phi }=1 \text {. }\end{array}$ \\
\hline \multirow[t]{3}{*}{ n-octane } & \multirow[t]{3}{*}{ C8H18 } & \multirow[t]{3}{*}{114.23} & \multirow[t]{3}{*}{398} & Sarathy et al., 2011 [234] & NA & $\begin{array}{l}\text { Validated against species profiles (JSR, at } \\
550-1150 \mathrm{~K} \text { up to } 10 \text { bar) and ignition delay } \\
\text { times at } 574-1500 \mathrm{~K} \text { up to } 40 \text { bar and various } \\
\text { equivalence ratios. }\end{array}$ \\
\hline & & & & Westbrook et al., 2009 [235] & NA & $\begin{array}{l}\text { Validated against thermolysis (measuring fuel } \\
\text { conversion) at } 623-893 \mathrm{~K} \text { and } 1 \text { bar. }\end{array}$ \\
\hline & & & & Cai et al., 2016 [251] & $\begin{array}{l}624 \text { species and } \\
2727 \text { reactions }\end{array}$ & $\begin{array}{l}\text { Validated against ignition delay times across a } \\
\text { range of temperatures and pressures up to } \\
42 \text { bar. }\end{array}$ \\
\hline $\begin{array}{l}\text { 2,2,4-trimethylpentane } \\
\text { (iso-octane) }\end{array}$ & C8H18 & 114.23 & 372 & Atef et al., 2017 [297] & $\begin{array}{r}2768 \text { species and } \\
9920 \text { reactions }\end{array}$ & $\begin{array}{l}\text { Validated against ignition delay times at } \\
630-1800 \mathrm{~K} \text { up to } 50 \text { bar and different equiva- } \\
\text { lence ratios. }\end{array}$ \\
\hline
\end{tabular}


Table 4 (Continued)

\begin{tabular}{|c|c|c|c|c|c|c|}
\hline Molecule & $\begin{array}{l}\text { Molecular } \\
\text { Formula }\end{array}$ & $\begin{array}{l}\text { MW } \\
(\mathrm{g} / \mathrm{mol})\end{array}$ & $\begin{array}{l}\text { Boiling } \\
\text { Point }(\mathrm{K})\end{array}$ & Reference, Year & $\begin{array}{l}\text { \# of Species and \# } \\
\text { of Reactions }\end{array}$ & Comments \\
\hline & & & & Li et al., 2016 [298] & NA & $\begin{array}{l}\text { Validated against laminar flame speeds at } \\
363-393 \mathrm{~K} \text { and at } 0,1 \mathrm{MPa} \text { and various equiva- } \\
\text { lence ratios }\end{array}$ \\
\hline & & & & Chaos et al., 2007 [225] & $\begin{array}{l}107 \text { species and } \\
723 \text { reactions }\end{array}$ & $\begin{array}{l}\text { Iso-octane/n-heptane. Validated against ignition } \\
\text { delay times (ST), premixed laminar-burning } \\
\text { velocities, variable pressure flow reactor and } \\
\text { species profiles (JSR) at } 950-1450 \mathrm{~K} \text { up to } \\
15 \text { bar and various equivalence ratios. }\end{array}$ \\
\hline & & & & Curran et al., 2002 [299] & NA & $\begin{array}{l}\text { Validated against ignition delay times((ST), spe- } \\
\text { cies concentrations (JSR and FR) at } \\
550-1700 \mathrm{~K} \text { up to } 45 \text { bar and various equiva- } \\
\text { lence ratios. }\end{array}$ \\
\hline & & & & Malewicki et al., 2013 [300] & NA & $\begin{array}{l}\text { Validated against ignition delay times and spe- } \\
\text { cies profiles at } 835-1757 \mathrm{~K} \text { up to } 65 \text { bar and } \\
\text { various equivalence ratios. }\end{array}$ \\
\hline $\begin{array}{l}\text { octane isomers } \\
\text { (2-methyl heptane, } \\
\text { 3-methylheptane, } \\
\text { 2,5-dimethylhexane }\end{array}$ & C8H18 & 114.23 & 392 & Sarathy et al., 2015 [234,254-256] & NA & $\begin{array}{l}\text { Validated against species profiles (JSR, at } \\
550-1150 \mathrm{~K} \text { up to } 10 \text { bar) and ignition delay } \\
\text { times at } 574-1500 \mathrm{~K} \text { up to } 40 \text { bar and various } \\
\text { equivalence ratios. }\end{array}$ \\
\hline \multirow[t]{2}{*}{ n-nonane } & $\mathrm{C} 9 \mathrm{H} 20$ & 128.21 & 424 & Westbrook et al., 2009 [235] & NA & $\begin{array}{l}\text { Validated against thermolysis (measuring fuel } \\
\text { conversion) at } 623-893 \mathrm{~K} \text { and } 1 \text { bar. }\end{array}$ \\
\hline & & & & Cai et al., 2016 [251] & $\begin{array}{l}624 \text { species and } \\
2727 \text { reactions }\end{array}$ & $\begin{array}{l}\text { Validated against ignition delay times across a } \\
\text { range of temperatures and pressures up to } \\
42 \text { bar. }\end{array}$ \\
\hline \multirow[t]{2}{*}{ benzene } & $\mathrm{C} 6 \mathrm{H} 6$ & 78.11 & 353 & Yang et al., 2015 [301] & $\begin{array}{l}263 \text { species and } \\
1374 \text { reactions }\end{array}$ & $\begin{array}{l}\text { Validated against species concentration profiles } \\
\text { at } 300 \mathrm{~K}, 30 \text { Torr and various equivalence } \\
\text { ratios. }\end{array}$ \\
\hline & & & & Saggese et al., 2013 [302] & NA & $\begin{array}{l}\text { Validated against ignition delay times and spe- } \\
\text { cies profiles at } 1100-1366 \mathrm{~K} \text { up to } 9.51 \mathrm{bar} \\
\text { and various equivalence ratios. }\end{array}$ \\
\hline \multirow[t]{7}{*}{ toluene } & $\mathrm{C} 7 \mathrm{H} 8$ & 92.14 & 384 & Pitz et al., 2001 [303] & NA & $\begin{array}{l}\text { Validated against ignition delay times at } \\
1300-1900 \mathrm{~K} \text { up to } 9.4 \text { bar and various equiv- } \\
\text { alence ratios. }\end{array}$ \\
\hline & & & & Metcalfe et al., 2011 [304] & 329 species and 1888 & $\begin{array}{l}\text { Validated over a wide range of experimental } \\
\text { conditions in flow reactor, shock tube, jet- } \\
\text { stirred reactor, and flames. }\end{array}$ \\
\hline & & & & Zhang et al., 2017 [266] & NA & $\begin{array}{l}\text { Validated against shock tube and rapid compres- } \\
\text { sion machine ignition delay at temperatures } \\
624-1459 \mathrm{~K} \text {, pressures } 20-40 \text { bar, equiva- } \\
\text { lence ratio } 0.5-2.0 \text {, and with mixtures of } \\
\text { dimethylether. }\end{array}$ \\
\hline & & & & Yuan et al., 2015 [305] & NA & $\begin{array}{l}\text { Validated against species profiles, flame speeds } \\
\text { and ignition delay times at } 920-1100 \mathrm{~K} \text { up to } \\
45 \text { bar and various equivalence ratios. }\end{array}$ \\
\hline & & & & Andrae, 2013 [306] & $\begin{array}{l}635 \text { reactions and } \\
137 \text { species }\end{array}$ & $\begin{array}{l}\text { Validated against species profiles and ignition } \\
\text { delay times at } 1210-1480 \mathrm{~K} \text { up to } 50 \text { bar and } \\
\text { various equivalence ratios. }\end{array}$ \\
\hline & & & & Tian et al., 2011 [307] & $\begin{array}{l}273 \text { species and } \\
1740 \text { reactions }\end{array}$ & Validated against flame data. \\
\hline & & & & Detilleux and Vandooren, 2011 [308] & NA & $\begin{array}{l}\text { Validated against mole fraction profiles of } 18 \\
\text { species at pressures up to } 36 \text { Torr. }\end{array}$ \\
\hline m-xylene & $\mathrm{C} 8 \mathrm{H} 10$ & 106.16 & 412 & Gail and Dagaut, 2007 [309] & $\begin{array}{l}189 \text { species and } \\
1359 \text { reactions }\end{array}$ & $\begin{array}{l}\text { Validated against species profiles in JSR at } \\
900-1400 \mathrm{~K}, 1 \text { bar and various equivalence } \\
\text { ratios. }\end{array}$ \\
\hline o-xylene & $\mathrm{C} 8 \mathrm{H} 10$ & 106.16 & 417 & Zhao et al., 2015 [310] & $\begin{array}{l}236 \text { species and } \\
1331 \text { reactions }\end{array}$ & $\begin{array}{l}\text { Validated against mole fraction profiles of flame } \\
\text { species at } 40 \mathrm{kPa} \text { and various equivalence } \\
\text { ratios. }\end{array}$ \\
\hline p-xylene & $\mathrm{C} 8 \mathrm{H} 10$ & 106.16 & 411 & Gail et al., 2005 [311] & $\begin{array}{l}160 \text { species and } \\
1175 \text { reactions }\end{array}$ & $\begin{array}{l}\text { Validated against ignition delay times at } \\
900-1300 \mathrm{~K} \text { up to } 1.4 \mathrm{tm} \text { and various equiva- } \\
\text { lence ratios. }\end{array}$ \\
\hline \multirow[t]{3}{*}{ ethylbenzene } & $\mathrm{C} 8 \mathrm{H} 10$ & 106.16 & 409 & Yuan et al., 2016 [312] & $\begin{array}{l}229 \text { species and } \\
1563 \text { reactions }\end{array}$ & $\begin{array}{l}\text { Validated against ignition delay times, laminar } \\
\text { flame speeds and species concentration pro- } \\
\text { files at } 850-1500 \mathrm{~K} \text { up to } 10 \text { bar and various } \\
\text { equivalence ratios. }\end{array}$ \\
\hline & & & & Husson et al., 2013 [313] & $\begin{array}{l}285 \text { species and } \\
1411 \text { reactions }\end{array}$ & $\begin{array}{l}\text { Validated against mole fraction profiles in JSR at } \\
750-1100 \mathrm{~K}, 800 \text { Torr and various equivalence } \\
\text { ratios. }\end{array}$ \\
\hline & & & & Li et al., 2011 [314] & $\begin{array}{l}176 \text { species and } \\
804 \text { reactions }\end{array}$ & $\begin{array}{l}\text { Validated against of mole fraction profiles of } \\
\text { flame species at } 4 \mathrm{kPa}, 300 \mathrm{~K} \text { and various } \\
\text { equivalence ratios. }\end{array}$ \\
\hline
\end{tabular}


Table 4 (Continued)

\begin{tabular}{|c|c|c|c|c|c|c|}
\hline Molecule & $\begin{array}{l}\text { Molecular } \\
\text { Formula }\end{array}$ & $\begin{array}{l}\text { MW } \\
(\mathrm{g} / \mathrm{mol})\end{array}$ & $\begin{array}{l}\text { Boiling } \\
\text { Point (K) }\end{array}$ & Reference, Year & $\begin{array}{l}\text { \# of Species and \# } \\
\text { of Reactions }\end{array}$ & Comments \\
\hline 1,2,3-trimethylbenzene & С9H12 & 120.19 & 449 & Gudiyella and Brezinsky, 2012 [315] & NA & $\begin{array}{l}\text { Validated against species formation in shock } \\
\text { tube oxidation at } 20 \text { and } 50 \text { bar, lean to rich } \\
\text { equivalence ratios, and a temperature range of } \\
1017-1645 \mathrm{~K} \text {. }\end{array}$ \\
\hline 1,2,4-trimethylbenzene & C9H12 & 120.19 & 442 & Weng et al., 2017 [316] & $\begin{array}{l}544 \text { species and } \\
3248 \text { reactions }\end{array}$ & $\begin{array}{l}\text { Validated against species profiles at } 700-1100 \mathrm{~K} \text {, } \\
1 \text { bar and phi }=2 \text {. }\end{array}$ \\
\hline cyclopentane & C5H10 & 70.13 & 322 & Rashidi et al., 2017 [317] & NA & $\begin{array}{l}\text { Validated against concentration profiles at } \\
740-1250 \mathrm{~K}, 10 \text { bar and various equivalence } \\
\text { ratios. }\end{array}$ \\
\hline \multirow[t]{3}{*}{ cyclohexane } & \multirow[t]{3}{*}{ C6H12 } & \multirow[t]{3}{*}{84.16} & \multirow[t]{3}{*}{354} & Buda et al., 2006 [318] & $\begin{array}{l}513 \text { species and } \\
2446 \text { reactions }\end{array}$ & $\begin{array}{l}\text { Validated against mole fraction profiles } \\
(750-1050 \mathrm{~K}) \text { and ignition delay times } \\
(650-900 \mathrm{~K}) \text { up to } 10 \text { bar and various equiva- } \\
\text { lence ratios. }\end{array}$ \\
\hline & & & & Serinyel et al., 2013 [319] & NA & $\begin{array}{l}\text { Validated against mole fraction profiles at } \\
500-1100 \mathrm{~K} \text { and } 1.07 \text { bar and various equiva- } \\
\text { lence ratios. }\end{array}$ \\
\hline & & & & Silke et al., 2007 [276] & NA & $\begin{array}{l}\text { Validated against ignition delay times and spe- } \\
\text { cies profiles at } 650-1150 \mathrm{~K} \text { up to } 12.5 \text { bar and } \\
\text { various equivalence ratios. }\end{array}$ \\
\hline \multirow[t]{4}{*}{ methylcyclohexane } & \multirow[t]{4}{*}{ C7H14 } & \multirow[t]{4}{*}{98.19} & \multirow[t]{4}{*}{374} & Pitz et al., 2007 [320] & NA & $\begin{array}{l}\text { Validated against ignition delay times(RCM) and } \\
\text { species profiles (flow reactor) at } 680-900 \mathrm{~K} \text { up } \\
\text { to } 20 \text { bar. }\end{array}$ \\
\hline & & & & Orme et al., 2006 [321] & NA & $\begin{array}{l}\text { Validated against ignition delay times at } \\
1200-2100 \mathrm{~K} \text { up to } 4 \text { bar and various equiva- } \\
\text { lence ratios. }\end{array}$ \\
\hline & & & & Weber et al., 2014 [322] & $\begin{array}{l}1540 \text { species and } \\
6498 \text { reactions }\end{array}$ & $\begin{array}{l}\text { Validated against ignition delay times at } \\
600-900 \mathrm{~K} \text { up to } 50 \text { bar and various equiva- } \\
\text { lence ratios. }\end{array}$ \\
\hline & & & & Wang et al., 2014 [323] & $\begin{array}{l}249 \text { species and } \\
1570 \text { reactions }\end{array}$ & $\begin{array}{l}\text { Validated against ignition delay times at pres- } \\
\text { sure range of } 30-7600 \text { Torr. }\end{array}$ \\
\hline ethylcyclohexane & C8H16 & 112.22 & 405 & Wang et al., 2015 [324] & $\begin{array}{l}540 \text { species and } \\
2825 \text { reactions }\end{array}$ & $\begin{array}{l}\text { Validated against species concentrations(JSR), } \\
\text { ignition delay times (ST) and laminar flame } \\
\text { speeds at } 900-1348 \mathrm{~K} \text { up to } 760 \text { Torr and vari- } \\
\text { ous equivalence ratios. }\end{array}$ \\
\hline dimethylcyclohexane & C8H16 & 112.22 & 401 & Eldeeb et al., 2016 [325] & NA & $\begin{array}{l}\text { Validated against ignition delay times at } \\
1049-1544 \mathrm{~K} \text { up to } 12 \text { bar and various equiva- } \\
\text { lence ratios. }\end{array}$ \\
\hline 1-pentene & C5H10 & 70.13 & 303 & Cheng et al., 2016 [326] & $\begin{array}{l}316 \text { species and } \\
1805 \text { reactions }\end{array}$ & $\begin{array}{l}\text { Validated against laminar flame speeds, ignition } \\
\text { delay times above } 100 \mathrm{~K} \text { and up to } 10 \mathrm{bar} \text {, and } \\
\text { various equivalence ratios. }\end{array}$ \\
\hline \multirow[t]{3}{*}{ 1-hexene } & \multirow[t]{3}{*}{ C6H12 } & \multirow[t]{3}{*}{84.16} & \multirow[t]{3}{*}{337} & Fan et al., 2016 [327] & $\begin{array}{l}122 \text { species and } \\
919 \text { reactions }\end{array}$ & $\begin{array}{l}\text { Validated against ignition delay times and lami- } \\
\text { nar flame speeds at } 800-1350 \mathrm{~K} \text { up to } 10 \mathrm{bar} \\
\text { at various equivalence ratios. }\end{array}$ \\
\hline & & & & Yahyaoui et al., 2006 [328,329] & $\begin{array}{l}177 \text { species and } \\
1171 \text { reactions }\end{array}$ & $\begin{array}{l}\text { Validated against ignition delay times at } \\
1270-1700 \mathrm{~K} \text { at } 0.2 \mathrm{MPa} \text { and various equiva- } \\
\text { lence ratios, and species profiles (JSR) at } \\
1270-1700 \mathrm{~K} \text { up to } 1 \mathrm{MPa} \text { and various equiva- } \\
\text { lence ratios. }\end{array}$ \\
\hline & & & & Touchard et al., 2005 [330] & NA & $\begin{array}{l}\text { Validated against cool flame and autoignition } \\
\text { delay times at } 615-850 \mathrm{~K} \text { up to } 10.9 \text { bar and } \\
\text { phi }=1 \text {. }\end{array}$ \\
\hline hexene isomers & C6H12 & 84.16 & & Mehl et al., 2008 [331] & $\begin{array}{l}100 \text { species and } \\
900 \text { reactions } \\
\text { (sub-mechanism) }\end{array}$ & $\begin{array}{l}\text { Validated against ignition delay times at } \\
750-1050 \mathrm{~K} \text { up to } 1,1 \mathrm{MPa} \text { and various equiva- } \\
\text { lence ratios. }\end{array}$ \\
\hline di-isobutylene (DIB) & C8H16 & 56.11 & 2662 & Metcalfe et al, 2007 [283] & NA & $\begin{array}{l}\text { Validated against ignition delay times at } \\
1200-1550 \mathrm{~K} \text { up to } 4 \text { bar and various equiva- } \\
\text { lence ratios. }\end{array}$ \\
\hline
\end{tabular}

concentrations of the various radical species and their formation rates are remarkably similar despite the size of the parent n-alkane fuel [237]. These findings support the thesis of Dooley et al. [218], which states that only distinct chemical functionalities govern the reactivity of fuels; and in the case of large n-alkanes, the size of the carbon chain is not a distinct chemical functionality with respect to high temperature reactivity. An important implication of this finding is that in replicating the high temperature combustion characteristics of a target gasoline fuel, any n-alkane (n-pentane or larger) could be a suitable surrogate to represent all the n-alkanes in the gasoline.
The activation energy for alkyl radical decomposition reactions is around $30 \mathrm{kcal} / \mathrm{mol}$ [238], so at lower temperatures (i.e., below $900-950 \mathrm{~K})$ these reactions are unimportant. Therefore, the nalkane oxidation mechanism is dominated by a series of low temperature auto-oxidation reactions. This scheme has been previously described in detail in articles by Zador et al. [239] and Battin-Leclerc [233]. It includes the early schemes postulated by Cartlidge and Tipper [240], refined by Knox [241] and Cox and Cole [242], and extended by Wang et al. [243-245]. 

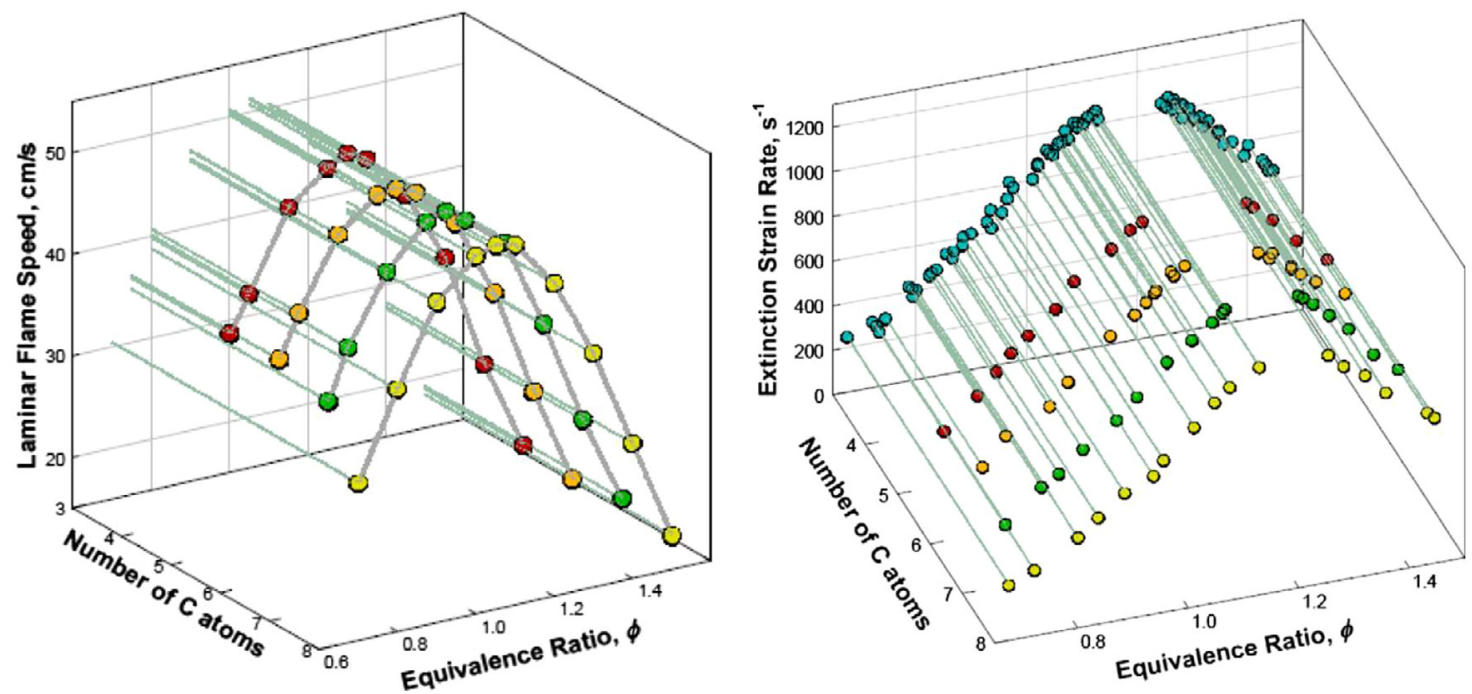

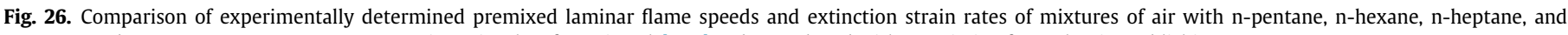
n-octane. Unburnt gas temperature was $353 \mathrm{~K}$. Figure is taken from Ji et al. [236] and reproduced with permission from Elsevier Publishing.

The classic low temperature oxidation mechanism is widely used to explain the process leading to ignition of n-alkanes at low temperatures, as well as the monotonic decrease in ignition delay time with temperatures below $\sim 800 \mathrm{~K}$. At intermediate temperatures of $\sim 800-900 \mathrm{~K}$, several reactions overcome their activation energy to become competitive with the reactions leading to chain branching. First, the ROO radical can undergo a concerted elimination reaction, leading to the formation of an alkene and $\mathrm{HO}_{2}$ radical, widely accepted as a chain terminating route because $\mathrm{HO}_{2}$ radical is not as reactive as $\mathrm{OH}$ radical. Second, the $\mathrm{QOOH}$ radical can undergo cyclization to form a cyclic ether and an $\mathrm{OH}$ radical, which is a chainpropagating pathway. These two competing pathways are responsible for the negative temperature coefficient behavior observed in nalkane ignition at temperatures of $\sim 800-950 \mathrm{~K}$, in which ignition delay time increases with increased temperature.

Table 4 presents comprehensive chemical kinetic models for various n-alkanes found in gasoline fuels. It is clear that well validated kinetic models exist for all the important n-alkanes, i.e., n-butane, npentane, n-hexane, n-heptane, and n-octane. Arguably the most upto-date and widely validated n-alkane mechanisms include those developed at NUI Galway by Henry Curran's group for n-butane [246], n-pentane [247,248], n-hexane [249], and n-heptane [250]. These models are capable of predicting ignition phenomenon at a range of temperatures, speciation profiles in flames and flow reactors, and high temperature flame phenomenon (e.g., laminar flame speed, extinction, etc.). All these models are built on the same base chemistry (i.e., AramcoMech), therefore making them easy to merge for gasoline surrogate fuel kinetic modeling. They have also been useful for developing comprehensive models for $C_{8}$ and larger nalkanes, as recently demonstrated by Cai et al. [251] by optimizing and extrapolating rate rules. It is important to note that none of these models contain the aforementioned $3 \mathrm{rd} \mathrm{O}_{2}$ addition reaction mechanism.

A comparison of the simulated homogeneous gas-phase ignition delay times of various n-alkanes is presented in Fig. 27 for initial conditions of 25 bar and stoichiometric fuel/air mixtures. It is clear that high temperature (above $\sim 950 \mathrm{~K}$ ) ignition delay times of n-alkanes are similar. Similar ignition delay times are also observed at low temperatures (below $\sim 725 \mathrm{~K}$ ) for $\mathrm{C}_{5}-\mathrm{C}_{7} \mathrm{n}$-alkanes. However, in the intermediate temperature regime $(750-950 \mathrm{~K})$, there is a clear difference in the reactivity of various $n$-alkanes. The ignition delay time decreases with increasing carbon chain length, which is directly relevant to observed octane number decrease with increasing chain length. This indicates that there is a strong relationship between homogeneous gas-phase ignition delay times and octane numbers. The differences in ignition delay times for various n-alkanes is attributed to the number of consecutive secondary $\mathrm{CH}_{2}$ (i.e., methylene) in the carbon chain. Secondary $\mathrm{C}-\mathrm{H}$ bonds enable low temperature chain branching pathways because their low bond dissociation energy facilitates hydrogen abstraction and intramolecular $\mathrm{H}$-atom migration reactions. In the context of low temperature reactivity, Won et al. [252] and Lapuerta et al. [253] have shown that the ratio of methylene to methyl $\left(\mathrm{CH}_{2} / \mathrm{CH}_{3}\right)$ groups is a distinct chemical functionality that controls ignition. Larger n-alkanes have higher $\mathrm{CH}_{2}$ / $\mathrm{CH}_{3}$ ratios and therefore shorter ignition delay times in the intermediate temperature regime.

These findings are important for gasoline surrogate fuel formulation and kinetic modeling because they imply that predictions of $n$ alkane ignition characteristics-and thereby antiknock quality-are sensitive to n-alkane carbon number. Therefore, surrogate fuel studies focusing on ignition and/or combustion phasing at intermediate

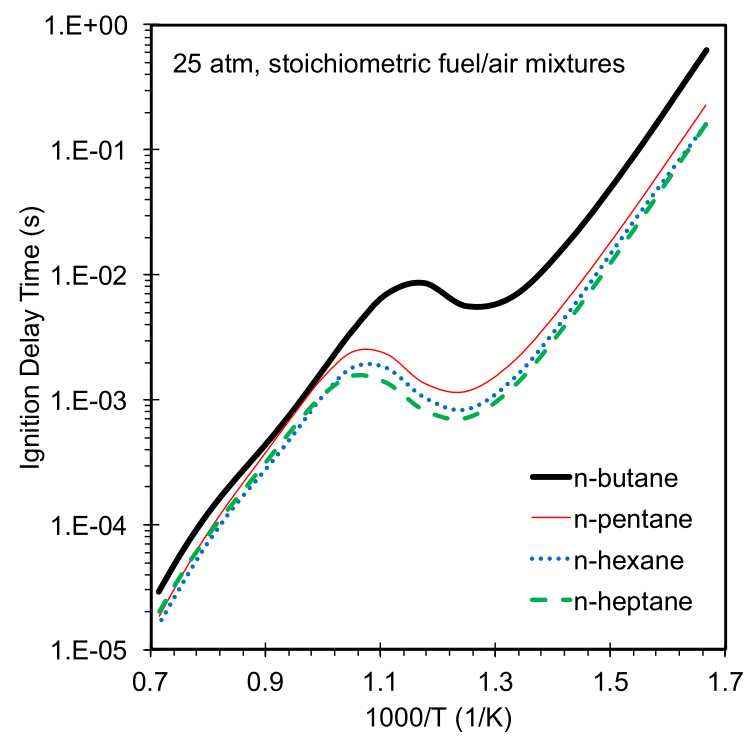

Fig. 27. Simulated homogeneous gas-phase ignition delay times for various n-alkanes at 25 bar, stoichiometric fuel/air mixtures. 
temperatures need to select n-alkane surrogate components that are representative of those present in the real fuel. This can be achieved by selecting $n$-alkanes at the low and high end of the carbon number spectrum, so that when they are blended together in appropriate proportions, they match the reactivity of the n-alkane mixture in the real fuel.

\subsection{2. isoParaffins/isoAlkanes}

isoAlkanes, or isoparaffins, are alkanes hydrocarbons with one or more alkyl substitution. This class of molecules constitutes an important fraction of gasoline fuels, in which methyl and ethyl substitutions are arranged on a carbon backbone. Despite their predominance in gasoline fuels, there is a dearth of fundamental combustion kinetic studies of such species, especially true for ignition at low and intermediate temperatures. The most widely studied isoalkane is 2,2,4-trimethylpentane (isooctane), because it is a primary reference fuel surrogate. Most gasoline fuels comprise various isomers of heptane (nine possible isomers) and octane (18 possible isomers); isomers of other alkanes also exist. As shown in Fig. 28, C7 isoalkanes have higher octane numbers than their n-alkane counterpart (i.e., n-heptane). Octane number increases with the number of alkyl substitutions, and the latter is also dependent on the position of the alkyl substitutions. Kinetic modeling of various octane and decane isomers by Sarathy et al. [234,254-258] has provided chemical kinetic explanations for the variations in ignition delay time, and hence octane number, observed with varying number and location of alkyl substitutions. These kinetic aspects are discussed in more detail below.

The high and low temperature oxidation of isoalkanes is conceptually similar to that of $\mathrm{n}$-alkanes. The same types of reactions occur; however, the primary effect of introducing alkyl substitutions is to alter the rates of various reactions, thereby changing branching ratios to the pool of reactive intermediate species. Alkyl substitutions introduce tertiary and quaternary carbon sites to the alkane structure, of which the former have lower $\mathrm{C}-\mathrm{H}$ bond dissociation energies than primary $\mathrm{C}-\mathrm{H}$ and secondary $\mathrm{C}-\mathrm{H}$ bonds. This reduces the energy barrier for $\mathrm{H}$-atom abstraction and $\mathrm{H}$-atom migration reactions from tertiary $\mathrm{C}-\mathrm{H}$ when compared to primary and secondary $\mathrm{C}-\mathrm{H}$ bonds. Several studies exist on the higher temperature combustion kinetics of various isoalkanes. Exemplary studies depicting the role of methyl substitution on high temperature reactivity are those by Ji et al. [259] on laminar flame propagation of octane isomers and Liu et al. [260] on counterflow flame non-premixed flame ignition of octane and decane isomers. In the former work [259], the authors presented measured and simulated laminar flame speeds for various octane isomers, as shown in. Their results showed that branched isomers exhibit lower laminar flame speeds,

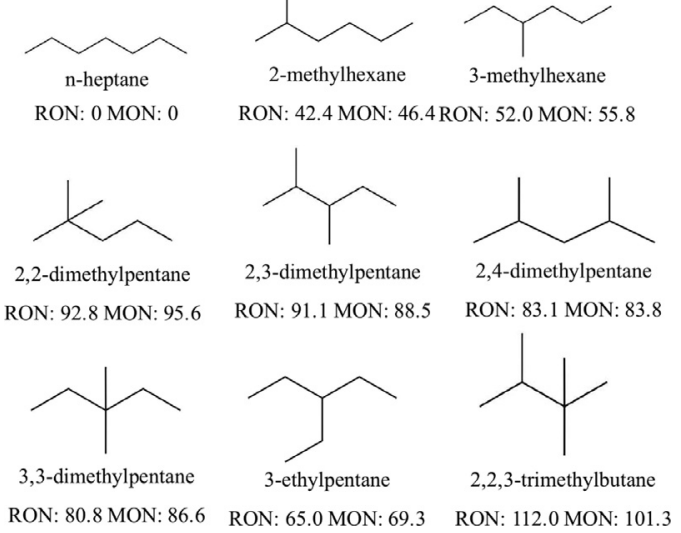

Fig. 28. The nine isomers of heptane and their measured RON/MON values. which is attributed to the increased production of H-atom scavenging resonantly stabilized intermediate radical species, such as allyl and isobutenyl radicals. The initial high temperature oxidation of the fuel molecules is similar between n-alkane and isoalkanes, but increasing the number of methyl branches alters the pool of $C_{1}-C_{4}$ intermediate species, which in turn alters the overall flame structure and reactivity.

As mentioned previously, altering the rates of internal $\mathrm{H}$-atom migration also has important implications on low temperature radical chain branching, propagation, and termination reactions, which in turn affect ignition delay times. Introducing alkyl substitutions also increases the total number of primary $\mathrm{C}-\mathrm{H}$ bonds, which are comparably less reactive than secondary and tertiary $\mathrm{C}-\mathrm{H}$ bonds. For this reason, the critical parameter governing the low and intermediate temperature reactivity of isoalkanes is typically the relative amounts of $\mathrm{CH}, \mathrm{CH} 2$, and $\mathrm{CH} 3$ functional groups [252,253]. This has been demonstrated and explained in chemical kinetic modeling studies of $\mathrm{C}_{8} \mathrm{n}$ - and isoalkanes [256].

Table 4 presents comprehensive chemical kinetic models for various isoalkanes found in gasoline fuels. Indeed, there is a lack of available kinetic models for isoalkanes larger than $C_{5}$. This makes it challenging to develop surrogate fuels, as the majority of isoalkanes found in real gasolines are in the $\mathrm{C}_{6}-\mathrm{C}_{8}$ range. As mentioned previously, 2,2,4-trimethylpentane has received the most attention from the kinetic modeling community. The heptane isomers have been modeled by Westbrook et al. [261,262], but the data available for model validation was limited at the time. A series of studies by Sarathy et al. [234,254-257,263] modeled three different octane isomers, but this was limited to mono- and di-methylated alkanes. Although only a limited number of isoalkane kinetic models are available for gasoline surrogate fuel kinetic studies, recent works by Won et al. [252,264] and Lapuerta et al. [253] have shown that the ignition characteristics of branched hydrocarbons can be accurately captured by a mixture of n-alkanes and highly branched isoalkanes that are to blended match the functional group distribution (i.e., $\mathrm{CH}$, $\mathrm{CH}_{2}, \mathrm{CH}_{3}$ ) in the targeted isoalkane (or real fuel). This greatly facilitates the kinetic modeling effort, as it permits complex gasoline mixtures with many isoalkanes variants to be modeled as simpler mixtures of an n-alkane and a highly branched alkane.

\subsubsection{Aromatics}

Because they are known to have high octane numbers and high sensitivity, aromatics are widely used to improve octane in gasoline fuels. The maximum blending fraction of aromatics is typically below $30 \mathrm{vol} \%$ is US and European gasolines. Typical aromatics in the gasoline boiling point range include benzene, toluene, xylene isomers, ethylbenzene, and trimethylbenzene isomers. Benzene concentrations in gasoline fuels are extremely low due to its high toxicity and carcinogenicity.

The combustion kinetics of aromatics is different than that of nand isoparaffins particularly, and in low and intermediate temperatures. Initiating the oxidation of aromatics is difficult because hydrogen atoms bonded to the aromatic ring have high bond dissociation energies. $\mathrm{H}$-atom abstraction from alkyl aromatics, such as toluene, are easier to initiate because the formed benzyl radical is stabilized by the presence of the aromatic ring. The oxidation pathways of aromatics at high temperatures have been detailed by Brezinsky [265], but fewer studies are available at lower temperatures of relevance to ignition in gasoline engines. Recently, Zhang et al. [266] studied the low temperature oxidation chemistry of toluene by blending it with dimethyl ether, a highly reactive fuel which generates $\mathrm{OH}$ radicals that can initiate toluene oxidation.

Toluene oxidation is primarily initiated by hydrogen abstraction from the methyl group of toluene, thereby forming the benzyl radical. Minor pathways include $\mathrm{H}$-atom abstraction from the ring or $\mathrm{O}$ radical addition to the ring. Both these radicals lead to the formation 
of cresol or cyclopentadienone. In the presence of large amounts of $\mathrm{OH}$ and $\mathrm{HO}_{2}$ radicals, the benzyl radical leads to the formation of an alkoxy intermediate that decomposes to form either benzyladehyde and $\mathrm{H}$ radical or formaldehyde and benzene. These reactions of resonantly stabilized benzyl radicals with other radicals is a key contributor to the lack of low temperature reactivity of aromatics. There are no low energy isomerization reactions that can lead to radical chain branching intermediates.

The oxidation of other alkylaromatics, such as xylene isomers and trimethylbenzene isomers, follows pathways similar to toluene. $\mathrm{H}$ atom abstraction from the methyl group alpha to the ring leads to the formation of a benzylic radical. Subsequent reactions of the benzylic radicals are similar to those in toluene. In the case of multiple substituted alkylaromatics where the methyl groups are adjacent (e. g., ortho-xylene and 1,2,3-trimethylbenzene), there is the possibility of $\mathrm{O}_{2}$ addition to benzyl radical and subsequent internal $\mathrm{H}$-atom migration from the adjacent methyl group. This pathway requires the formation of a seven-membered transition rate that is highly strained. Nevertheless, it is still a possible route to low temperature chain propagation, or chain branching intermediates.

Detailed chemical kinetic models for aromatic fuels are presented in Table 4. The major focus to date has been on benzene and toluene models, which are readily adopted into gasoline surrogate kinetic models. Only a few models exist for the various isomers of xylene and trimethylbenzene. Indeed, there is a need to develop more robust kinetic models for larger alkylaromatics in the gasoline boiling point range. A suitable approach for gasoline surrogate kinetic modeling would be to focus efforts on toluene and 1,2,4-trimethylbenzene, because a mixture of these two aromatics can represent the general functional groups and relative positions of side chains found in various alkylaromatics hydrocarbons.

\subsubsection{Naphthenes/Cycloalkanes}

The naphthenic/cycloalkane content of gasoline is typically below 20 vol\%, but may be higher in fuels derived from oil sands and shale. Their octane quality is typically increased by dehydrogenation during refining to produce aromatics. Nevertheless, a significant quantity exists in gasoline fuels, and their presence effects engine ignition quality and $\mathrm{PAH} /$ soot formation.

Cycloalkanes have the same molecular formula as mono-alkenes with the same carbon number, but their combustion chemistry is remarkably different. Early studies by Walker et al. [267,268] showed that oxidation chemistry of cycloalkanes is similar to that of n-alkanes, although the branching ratios to various low temperature reactive intermediates are considerably different. At high temperature pyrolytic conditions, cycloalkanes can undergo sequential dehydrogenation to form aromatic species, which explains their high sooting tendency. Under high temperature oxidation conditions, cycloalkyl radicals are formed and ring-opening leads to eventual formation of dienes.

The low temperature oxidation of cycloalkanes proceeds in a similar manner as discussed earlier for $\mathrm{n}$ - and isoalkanes. Cycloalkyl radicals react with molecular $\mathrm{O}_{2}$ to form alkylperoxy radicals. These can undergo concerted elimination reactions to form cycloalkenes and $\mathrm{HO}_{2}$ radicals, or isomerize to QOOH radicals via internal $\mathrm{H}$ atom migration reactions. $\mathrm{QOOH}$ radicals can react again with molecular $\mathrm{O}_{2}$ and lead to eventual chain branching intermediates (e.g., ketohydroperoxides). The cycloalkane ring structure takes various confirmation and introduces steric hindrances. Internal $\mathrm{H}$-atom migration of alkylperoxy radicals is hindered due to the bicyclic and highly strained nature of the transition state. Therefore, concerted elimination reactions leading to radical chain termination are favored over internal $\mathrm{H}$-atom migration reactions leading to radical chain branching.

As shown previously for $\mathrm{n}$ - and isoalkanes, homogeneous batch reactor ignition delay time simulations can be correlated with fuel octane numbers. Fig. 29 presents experimental and simulated ignition delay times for $\mathrm{C}_{5}$ and $\mathrm{C}_{6} \mathrm{n}$-alkanes and cycloalkanes. There is a clear difference in reactivity between n-alkanes and their cycloalkane counterparts below $900 \mathrm{~K}$. Yang et al. $[269,270]$ explained that conformational inhibition of the 1,5 H-atom migration (six-member ring transition state) chain branching pathway in cyclohexylperoxy radicals is responsible for their lower reactivity compared to n-hexane. Al Rashidi et al. [271,272] provided a similar explanation for the lower reactivity of cylopentane compared to n-pentane; they attribute cyclopentane's lower reactivity to higher energy barriers in forming the strained bicyclic transition state, which increase the flux to concerted elimination reactions forming unreactive cyclopentene and $\mathrm{HO}_{2}$ radicals. Methyl substitutions on cycloalkanes (e.g., methylcyclopentane and methylcyclohexane) lower the activation energy of 1,5 H-atom migration (six-member ring transition state) of cycloalkylperoxy radicals $\left(\mathrm{RO}_{2}=\mathrm{QOOH}\right)[269,270]$. Therefore, methylcyclopentane and methylcyclohexane are more reactive than their non-substituted counterparts.

Comprehensive chemical kinetic models for cycloalkanes are presented in Table 4. To date, most of the kinetic modeling focus has been on cyclohexane and methylcyclohexane. The recent methylcyclohexane kinetic model by Weber et al. [273] has been validated across a broad range of pressures, temperatures, and mixture fraction conditions; it is recommended for use in gasoline surrogate kinetic models. Kinetic models for cyclohexane are not as well developed as those for methylcyclohexane, primarily due to the challenges in acquiring experimental data. A recent study by Vranckx et al. [274] measured ignition delay times at 15 bar and
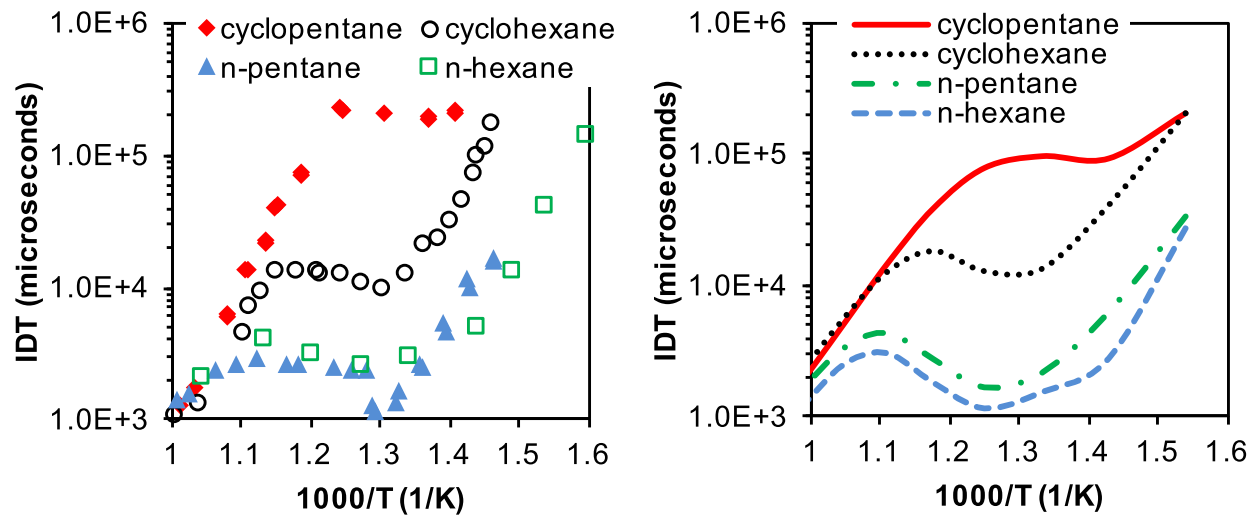

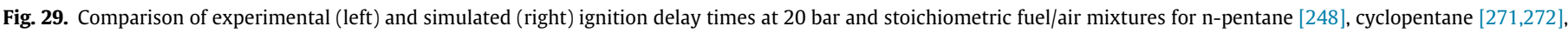
n-hexane [249], and cyclohexane [276]. Figure adapted from Al Rashidi et al. [272] with permission from Elsevier Publishing. 
showed NTC behavior in the $\sim 700-900 \mathrm{~K}$ temperature regime, which indicates complex low temperature oxidation chemistry. The authors found that current cyclohexane chemical kinetic models could not accurately capture experimental ignition delay data, and suggested future work be focused on improving the kinetics of low temperature oxidation pathways. Only one [271,272,275] comprehensive chemical kinetic model with detailed high and low temperature chemistry exists with cyclopentane. The model was developed based on theoretical calculations of the cyclopentyl radical decomposition and oxidation potential energy surfaces and pressuredependent kinetics. Additional work is needed to develop a similar model for methylcyclopentane. Comprehensive and accurate chemical kinetic models for cyclopentane, methylcyclopentane, cyclohexane, and methylcyclohexane would be sufficient for formulating gasoline surrogate fuels with various cycloalkane hydrocarbons.

\subsubsection{Olefins/alkenes}

Olefins/alkenes represent a small fraction of gasoline fuel, but they have a notable effect on oxidative stability and autoignition characteristics. Olefins in gasoline are typically limited to $C_{5}-C_{8}$ linear and branched hydrocarbons; however, they are also common intermediates in the oxidation of paraffins, which highlights their importance in gasoline combustion chemistry. These molecules are distinguished by the presence of double bonds in the hydrocarbon structure, which introduces allylic and vinylic hydrogens and resonantly stabilized intermediate radicals. The double bond adds to the complexity of their oxidation, especially at low temperatures where radical additions to the double bond are possible. The presence of olefins in gasoline can change its knocking tendency and soot emissions. Their octane numbers are higher than those of corresponding paraffins, and the double bond position has a notable effect on antiknock quality.

The high temperature oxidation (above $1000 \mathrm{~K}$ ) of olefins is initiated by the abstraction of allylic hydrogen atoms ( $\beta$ to the double bond), which have lower bond dissociation energies than vinylic and normal alkylic hydrogen atoms. The resulting allylic radicals exhibit electron delocalization and are extremely stable due to their resonance structure. These stable allylic radicals can undergo recombination reactions with other allylic radicals to produce larger chain hydrocarbons, which can lead to the formation of PAH species. This explains why alkenes display higher sooting tendencies than alkanes. As the carbon chain increases in 1-alkenes, the relative importance of the double bond on chemical kinetic reactivity decreases. For example, the reactivity of 1-octene is not significantly different than n-octane because hydrogen abstraction can proceed from one of the secondary carbon sites in the alkyl chain. As the double bond position moves towards the center of a molecule (e.g., 1-alkene to 2-alkene to 3-alkene), it tends to have a greater effect of the overall reactivity of the molecule. This is attributed to the fact that more secondary carbon sites are converted to allylic and vinylic sites as the double bond shifts.

The low temperature oxidation (below $1000 \mathrm{~K}$ ) of alkenes influences its octane rating in engines [277]. Hydrogen abstraction from allylic sites becomes more common at lower temperatures due to the low activation energies. However, $\mathrm{H}$-atom abstraction form normal secondary carbon sites is also possible, and the resulting allylic radicals react like those derived from n-alkanes. The subsequent addition of $\mathrm{O}_{2}$ to the allylic radical is possible, but the resulting $\mathrm{RO}_{2}$ radical is thermodynamically unstable [278]. As a result, subsequent isomerization and $\mathrm{O}_{2}$ addition reactions leading to chain branching are hindered. This is the primary reason why alkenes display lower reactivity [279] and higher octane numbers under low temperature ignition conditions.

In addition to $\mathrm{H}$-atom abstraction, $\mathrm{OH}, \mathrm{H}$, and $\mathrm{HO}_{2}$ radical addition to the double bond is possible at very low temperatures (below $700 \mathrm{~K}$ ). $\mathrm{OH}$ radical addition is the most important under typical

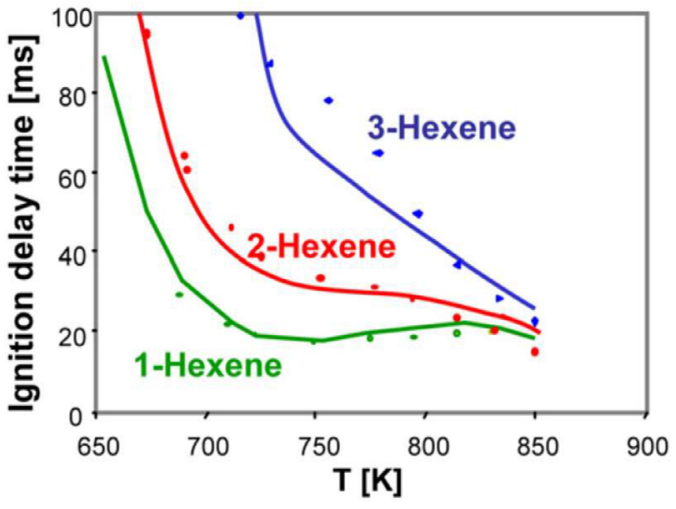

Fig. 30. Ignition delay times of hexene isomers (0.86-1.09 MPa, stoichiometric fuel/ air mixtures). Symbols are experiments and lines are simulations. Figure reproduced from Mehl et al. [277] with permission from Elsevier Publishing.

engine conditions because $\mathrm{OH}$ is the predominant radical at lower temperatures. Waddington [280-282] was the first to show that $\mathrm{OH}$ addition to the double bond of alkenes leads to the formation of $\beta$-hydroxyalkyl radicals. These radicals add $\mathrm{O}_{2}$ to form hydroxyalkylperoxy radicals, which subsequently isomerize and decompose to form aldehydes and $\mathrm{OH}$ radicals.

Fig. 30 from Mehl et al. [277] presents the role of double bond position on the autoignition of various hexene isomers in the low temperature oxidation regime. It is clear that alkenes display less NTC behavior than n-alkanes because the double bonds hinder low temperature oxidation pathways. NTC behavior becomes less pronounced as the double bond moves towards the interior of the molecule, because the double bond begins influencing a larger number of possible oxidation pathways. The ignition delay times of 3-hexene is significantly lower than 1-hexene because the former has two vinyllic carbon sites, two allylic carbon sites, and two primary carbon sites, while the latter has one vinyllic carbon site, one allylic carbon site, three secondary carbon sites, and one primary carbon site. Increasing the number of vinyllic and allylic carbon sites, while reducing the number of secondary carbon sites, effectively decreases reactivity, and hence increases octane number.

Comprehensive chemical kinetic models for alkenes are presented in Table 4. Gasoline typically contains $C_{5}-C_{8}$ alkenes, and very few comprehensive kinetic models exist in the literature. While many models are available for high temperature oxidation/pyrolysis conditions, due to the lack of comprehensive kinetic models for alkenes, we were unable to find many detailed models covering the typical temperature and pressure ranges encountered under real engine condition. Table 4 presents several alkene kinetic models that have been developed and validated at high temperatures. At present, it is recommended that 1-hexene be used as a surrogate in gasoline fuels because it has the most widely validated chemical kinetic model [277]. Models for other pentenes and hexenes are valid at high temperatures and should be used only under relevant combustion conditions. An interesting additive for improving the octane quality of gasoline is di-isobutylene (DIB), for which a kinetic model developed by Metcalfe et al. [283] can be used to study DIB blending effects on ignition quality $[164,284]$.

\subsection{Detailed chemical kinetic models for gasoline surrogate mixtures}

Chemical kinetic models for gasoline surrogate mixtures are simply combinations of various pure component models. However, it is important for the individual fuel components to share a common core mechanism, so that they can be easily merged. Cross-reactions between fuel components are typically considered in the development of these models; however, an extensive analysis and 
discussion by Battin-Leclerc [233] indicates that such cross-reaction terms are largely negligible in alkane mixtures, and mildly important in mixtures containing alkenes and/or aromatics. Indeed, fuel mixtures behave notably different than pure components, but the cross effects are realized in species and reactions within the intermediate radical pool (and rarely with the parent fuel molecules), which highlights the importance of a robust core mechanism.

The mixture of components included in a surrogate fuel kinetic model is defined based on the selected gasoline target properties, as described in Section 3. Traditionally, gasoline fuels were modeled as simple PRF mixtures with n-heptane and isooctane blended to match either the RON or the MON. However, it was quickly realized that an additional component-mainly an aromatic-is needed to match both the RON and MON, and thus TPRF mixtures became widely used. More recently, multicomponent mixtures that match additional gasoline properties (e.g., $\mathrm{H} / \mathrm{C}$ ratio, average molecular weight, PIONA, distillation curve, etc.) were utilized to predict more complex combustion phenomenon. The following sub-sections describe the formulation of detailed gasoline surrogate chemical kinetic models. A subset of the models is employed to demonstrate the effects of surrogate fuel composition on important combustion properties, such as ignition delay times.

\subsubsection{PRF and TPRF mixtures}

The introduction of PRF detailed chemical kinetic models dates back to the late 20th century, when models for the low-temperature oxidation of $\mathrm{n}$-heptane and isooctane were first developed [299,332-337]. These models were based on fundamental understanding of alkane oxidation chemistry proposed by Cox and Cole [242]. The primary focus of these PRF models was to understand autoignition characteristics and engine knock, as the octane rating methodologies are based on these surrogate mixtures. Morley et al.
[338] and Westbrook et al. [336] were amongst the first to develop PRF kinetic models and use them to understand the octane ratings of fuels. The latter team from LLNL typically validated their surrogate mixture kinetic models against a range of experimental data (ignition delay, flow and stirred reactors, and premixed laminar flame speeds), which made them widely applicable to predict combustion phenomenon other than knock-relevant autoignition. More recently, interest shifted from only modeling PRF surrogates towards developing models for TPRF mixtures. As mentioned previously, TPRF mixtures are needed if a surrogate is to match both the RON and the MON of the target gasoline fuel [70,114].

Table 5 lists several detailed chemical kinetic models for PRF and TPRF mixtures. These detailed models are useful for predicting a wide range of combustion phenomenon, including homogeneous gas-phase ignition delay, premixed laminar flame propagation, speciation profiles in reactors, and PAH and soot formation in flames. These models can also be reduced in complexity (as discussed in the next section) and used in CFD engine simulations.

An example of the predictive capabilities of detailed chemical kinetic models for PRFs is given here in the context of $\mathrm{HCCI}$ engine simulations. Operation of these engines may be controlled by the rate of heat release rate (ROHR) of the PRF/air mixture in-cylinder. Under $\mathrm{HCCl}$ conditions, ROHR is a function of the PRF mixture composition, equivalence ratio, intake air temperature, and intake air pressure. A recent experimental HCCI engine study by Vuilleumier et al. [339] investigated the effect of PRF mixture composition on ROHR at fixed intake pressure, equivalence ratio, and engine combustion phasing. In this study, numerical HCCI engine simulations were also performed using a detailed chemical kinetic model for PRF mixtures from LLNL[149]. Both experimental (left panel) and numerical (right panel) results are shown in Fig. 31. The experimental results show that PRF 100 (pure isooctane) and the mixture with

Table 5

Detailed chemical kinetic models for gasoline surrogate mixtures.

\begin{tabular}{|c|c|c|c|}
\hline Fuel components & & \# of Species and \# of Reactions & Comments \\
\hline n-heptane/isooctane (PRF) & Curran et al., $2002[299,333,346]$ & NA & $\begin{array}{l}\text { LLNL. Validated against ignition delay times, } \\
\text { speciation measurements in perfectly } \\
\text { stirred and flow reactors, and HCCI engine } \\
\text { combustion. }\end{array}$ \\
\hline n-heptane/isooctane (PRF) & Westbrook et al., 2011 [347] & NA & $\begin{array}{l}\text { LLNL. Validated against ignition delay times } \\
\text { and speciation measurements in perfectly } \\
\text { stirred flow reactors. }\end{array}$ \\
\hline n-heptane/isooctane/toluene (TPRF) & Pires da Cruz et al, $2007[348,349]$ & NA & $\begin{array}{l}\text { CNRS-NANCY EXGAS. Detailed mechanism } \\
\text { validated against ignition delay times, jet } \\
\text { stirred reactor speciation profiles, and } \\
\text { HCCI engine combustion. }\end{array}$ \\
\hline n-heptane/isooctane/toluene (TPRF) & Park et al., 2017 [350] & 2021 species and 8688 reactions & $\begin{array}{l}\text { KAUST. Detailed mechanism validated } \\
\text { against ignition delay times, laminar flame } \\
\text { speeds, and PAH and soot measurements } \\
\text { in counterflow diffusion flames. }\end{array}$ \\
\hline $\begin{array}{l}\text { n-heptane/isooctane/toluene/di-isobutyl- } \\
\text { ene/ethanol }\end{array}$ & Andrae, $2008[351,352]$ & 1121 species and 4961 reactions & $\begin{array}{l}\text { Validated against ignition delay times and } \\
\text { HCCI engine combustion. }\end{array}$ \\
\hline $\begin{array}{l}\text { n-heptane/isooctane/toluene/1-hexene/2- } \\
\text { pentene }\end{array}$ & Mehl et al., 2011 [149] & 1338 species and 5933 reaction & $\begin{array}{l}\text { LLNL. Detailed mechanism validated against } \\
\text { ignition delay times, laminar flame speeds, } \\
\text { and perfectly stirred reactor speciation. } \\
3-50 \text { bar, } 650-1200 \mathrm{~K} \text {. }\end{array}$ \\
\hline $\begin{array}{l}\text { n-butane/n-pentane/n-hexane/n-heptane/n- } \\
\text { octane/isopentane/isohexane/isooctane/1- } \\
\text { pentene/2-pentene/1-hexene/2-hexene/3- } \\
\text { hexene/methylcyclohexane/toluene/o- } \\
\text { xylene/m-xylene/p-xylene/ethanol. }\end{array}$ & Pudupakkam, Naik et al., 2011 [341-343] & 1833 species and 8764 reaction & $\begin{array}{l}\text { Reaction Design. Detailed mechanism vali- } \\
\text { dated against ignition delay times, laminar } \\
\text { flame speeds, and perfectly stirred and } \\
\text { flow reactor speciation. } 1-50 \text { bar, } \\
650-1800 \mathrm{~K} \text {. }\end{array}$ \\
\hline $\begin{array}{l}\text { n-heptane/isooctane/toluene/2-methylbu- } \\
\text { tane/2-methylhexane/n-butane/1-hexene/ } \\
\text { 1,2,4-trimethylbenzene/cyclopentane }\end{array}$ & Sarathy et al. 2016 [58,150,182,184] & 2315 species and 10,079 reaction & $\begin{array}{l}\text { KAUST, LLNL, NUIG. Detailed mechanism val- } \\
\text { idated against ignition delay times for } \\
\text { FACE gasolines. 3-50 bar, } 650-1200 \mathrm{~K} \text {. }\end{array}$ \\
\hline
\end{tabular}

n-heptane/isooctane/toluene/di-isobutylene/methylcyclochexane/ethanol/ETBE 

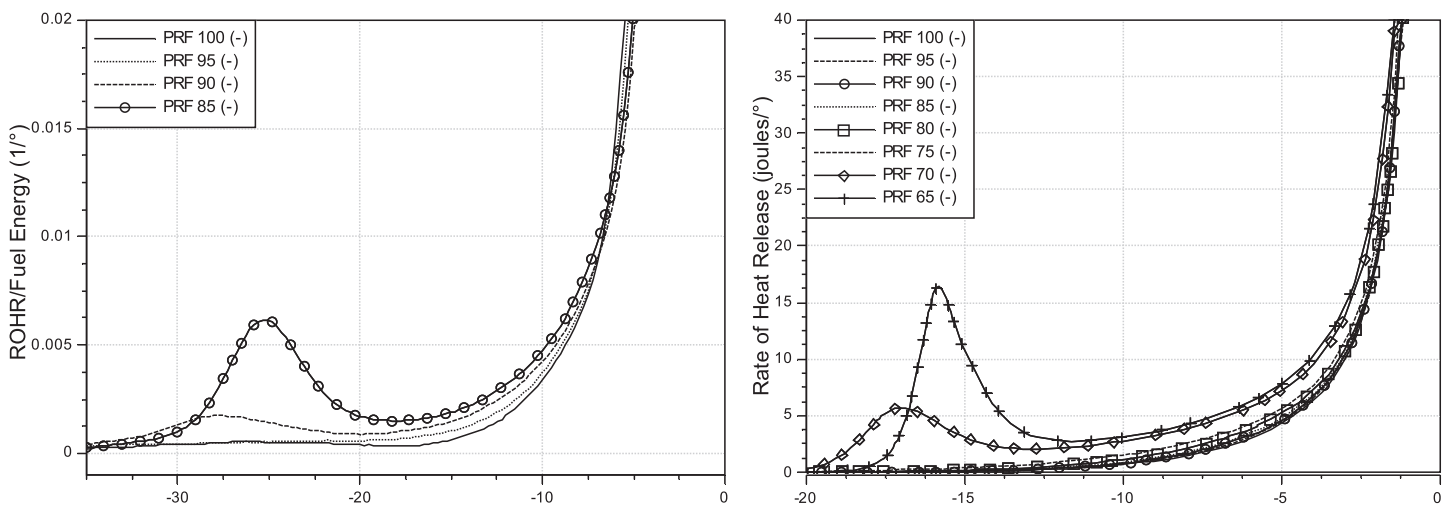

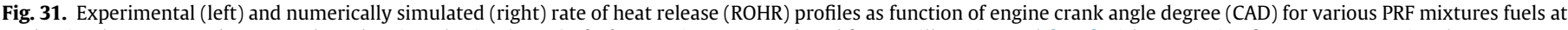
1.4 bar intake pressure, $\phi=0.4$, and combustion phasing (CA50) of $6^{\circ}$ aTDC. Figures reproduced from Vuilleumier et al. [339] with permission from SAE International.

5 vol\% n-heptane (PRF 95) do not show prominent low temperature heat release (LTHR), which is characterized by the local rise in ROHR from -30 to -20 CAD after CA50. The existence of LTHR is due to low temperature oxidation reactions that lead to radical chain branching, and the detailed chemical kinetic modeling of PRF100 and PRF95 confirm that such reactions are not important. The lack of LTHR is attributed to the presence of a large fraction isooctane, which lacks low temperature reactivity.

Experimental results indicate that PRF85 with 15 vol\% of n-heptane shows significant LTHR. Numerical simulations of PRF85 using the kinetic model from [149] cannot reproduce the experimentally observed LTHR behavior. Instead, PRF70 is the highest PRF mixture that displays LTHR in the numerical simulations. n-Heptane displays prominent low temperature reactivity due to the large fraction of $\mathrm{CH}_{2}$ groups, and the magnitude of LTHR is directly proportional to its amount. A study by Hwang et al. [340] showed similar results, in which the volume fraction of n-heptane in the PRF simulations had to be changed to reproduce experimentally observed heat release characteristics. These results indicate that further work is needed in PRF kinetic models to improve the prediction of LTHR in HCCI engine simulations.

Detailed chemical kinetic models for TPRF mixtures can predict ignition delay times. Javed et al. [158] measured ignition delay times of various TPRF mixtures across a range of RON and S (RON 70, S 4; RON 80, S 5.7; RON 91, S 7.6; and RON 97.5, S $10.9)$ in both shock tubes and rapid compression machines. The authors conducted numerical simulations using the detailed chemical kinetic model from LLNL[149]. The exact mixture compositions are present in the original study; briefly, the n-heptane and isooctane concentrations decrease with increasing RON and $S$, while toluene content increases. The experimental and numerical results presented in Fig. 32 show a clear reduction in ignition delay time at intermediate temperatures of $\sim 725-900 \mathrm{~K}$ as the TPRF number increases. Numerical simulations show that TPRF70 with the largest fraction of n-heptane has the shortest ignition delay time due to the low temperature reactivity of nheptane, which produces $\mathrm{OH}$ radicals required for ignition. As the toluene fraction increases, the ignition delay time increases too. As mentioned previously, toluene lacks low temperature reactivity because it forms stable benzylic radicals, and further acts as a sink for $\mathrm{OH}$ radicals produced by n-heptane in the mixture. The net effect is an overall reduction in the reactivity of the TPRF mixture. Another interesting observation in experimental and numerical results is the difference in NTC behavior of the various mixtures. There is a clear change in slope of the ignition delay time versus temperature curve in the NTC region, as the
TPRF RON and S varies. Further discussion on this behavior is presented in the following section, within the context of multicomponent gasoline surrogate mixtures.

\subsubsection{Multicomponent mixtures}

Gasoline surrogates with more than the typical three components (i.e., n-heptane, isooctane, and toluene) are termed multicomponent mixtures. Such mixtures typically include the usual three components and additional components needed to replicate various target fuel properties. Important properties that require the addition of more components in the surrogate mixture include distillation curve, functional group or hydrocarbon class distribution, average molecular weight, and octane sensitivity. Real gasoline fuels have a broad distillation profile, which PRF and TPRF mixtures cannot replicate. Therefore, surrogates should include components that cover the entire boiling point range of typical gasoline fuels. Real gasolines also often contain naphthenes, olefins, and oxygenates, none of which are found in PRF and TPRF mixtures. If a surrogate is to match the hydrocarbon class distribution and functional groups of the real fuel, then molecules representing all hydrocarbon classes should be included in the surrogate.

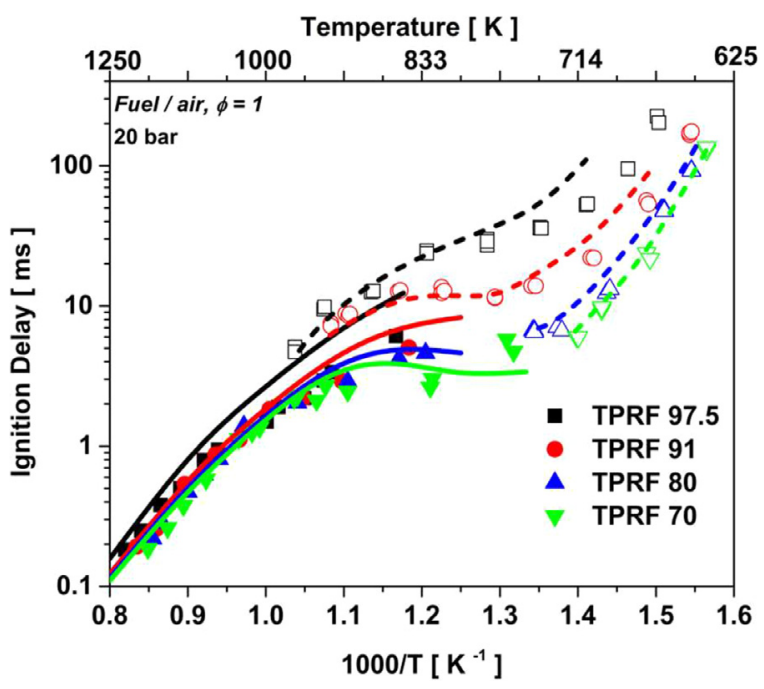

Fig. 32. Measured (symbols) and simulated (lines) ignition delay times for various TPRF mixtures near 20 bar and stoichiometric fuel/air mixtures. Each mixture is identified by its RON $(97.5,91,80,70)$. Figure taken from Javed et al. [158] and reproduced with permission from Elsevier Publishing. 
A summary of multicomponent gasoline surrogate detailed chemical kinetic models is presented in Table 5. The largest detailed chemical kinetic model for gasoline surrogates is currently available from Reaction Design and contains up to 20 components [341-343]. These include various hydrocarbons in the gasoline boiling point range as well as ethanol. The chemical kinetic model is utilized in Reaction Design's Surrogate Blend Optimizer [343], which formulates surrogates to match desired target properties of a real fuel. Puduppakam et al. [341] and Naik et al. [343] have shown that the species palette can be successfully utilized to create surrogate mixtures of various complexity, which replicate real gasoline fuel properties. The chemical kinetic model is large in size, so mechanism reduction is applied, and then CFD multi-zone engine simulations are conducted to predict important engine performance parameters.

The team at LLNL $[112,149]$ has worked for many years on multicomponent kinetic surrogate models for gasoline fuels. These include mixtures of n-heptane, isooctane, and toluene with various alkenes (1-hexene and/or 2-pentene). The models are developed on the C0-C4 base chemistry from NUIG [219-222], which facilitates the addition of new components as kinetic models become available. Recently, LLNL, NUIG, and KAUST collaborated $[58,150]$ to develop a gasoline surrogate kinetic model comprising 10 components with representatives from each of the major hydrocarbon classes. The kinetic model was used to simulate the ignition characteristics of FACE (fuels for advanced combustion engines) gasolines by the formulation of multicomponent surrogates that match various target properties (distillation curve, $\mathrm{H} / \mathrm{C}$ ratio, octane number, PIONA, carbon types, and average molecular weight) [125]. The authors showed that ignition simulations with simpler PRF and TPRF surrogate for FACE gasolines can reproduce experimentally measured ignition delay times of the real gasoline at high temperatures. However, at low and intermediate temperatures, the authors found that simulations using multicomponent surrogates better replicate the ignition characteristics of the real fuels $[58,150]$. The 10-component model has also been used to simulate surrogate mixtures of high octane oxygenated gasolines containing ethanol [154] and low octane gasolines produced from light and heavy naphtha [152,153a].

To further understand the role of surrogate fuel composition on ignition characteristics, Singh et al. [344] measure the RON and MON of various multicomponent mixtures comprising n-heptane, isooctane, toluene, 1-hexene, and 1,2,4-trimethylbenzene. They showed that increasing the aromatic and olefin content in the mixture resulted in higher octane sensitivity. Furthermore, the authors utilized chemical kinetic simulations with the KAUST-LLNL-NUIG gasoline surrogate kinetic model $[58,150]$ under homogeneous conditions to correlate ignition delay times with RON and MON. Fig. 33 presents a portion of the results from Singh et al. [344] for surrogate fuel mixtures listed in Table 6. All fuels covered have the same RON with varying levels of sensitivity and differing mixture composition. The goal of presenting this subset of fuels is to clarify the effects of mixture composition on octane sensitivity.

As shown in Fig. 33, all mixtures have similar ignition delay times at high temperatures (above $900 \mathrm{~K}$ ), indicating that fuel composition does not significantly affect reactivity at these conditions. At low and intermediate temperatures there are notable differences in ignition delay times for the different mixtures; however, the effect of

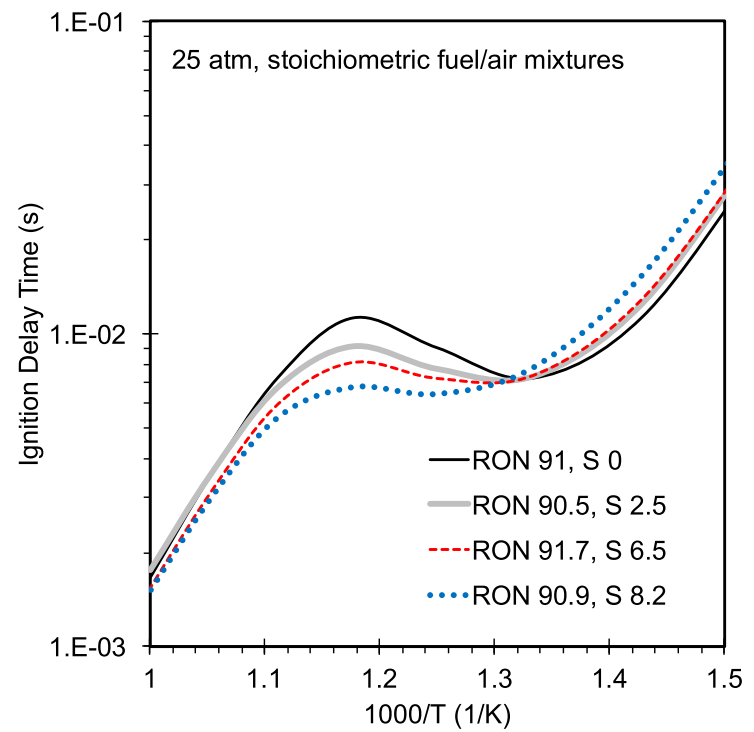

Fig. 33. Simulated ignition delay times for various gasoline surrogate mixtures at 25 bar and stoichiometric fuel/air mixtures. Legend denotes the mixtures RON and sensitivity (S). Figure adapted from Singh et al. [344] with permission from The American Chemical Society.

fuel composition on ignition delay time varies depending on the specific temperature regime. An interesting observation is that near $\sim 750 \mathrm{~K}$, all the mixtures have the same ignition delay time, suggesting a strong correlation between RON and ignition delay time and this temperature (recall that all fuels are RON 91).

The qualitative variation of ignition delay time with temperature is indicative of the octane sensitivity of the mixture. The simplest surrogate presented is PRF 91 with a RON of 91 and zero sensitivity. The simulated ignition delay times of this fuel display significant NTC characteristics. Below $\sim 750 \mathrm{~K}$, PRF91 has the shortest ignition delay time, but above $\sim 750 \mathrm{~K}$ it has the longest ignition delay time. This prominent NTC behavior is indicative of non-sensitive fuel [345]. Surrogate mixtures with increasing sensitivity show longer ignition delay times below $\sim 750 \mathrm{~K}$ and shorter ignition delay times above $\sim 750 \mathrm{~K}$. Essentially, the NTC characteristic of the mixture is diminished as the octane sensitivity increases.

These phenomena can be directly linked to fuel composition. PRF91 is a purely paraffinic fuel that shows prominent low temperature radical chain branching chemistry below $\sim 750 \mathrm{~K}$, but as the temperature increases, competing chain propagating and chain terminating reactions inhibit reactivity, leading to the observed NTC behavior. Higher sensitivity mixtures contain larger fractions of aromatics and olefins, both of which contain carbon-carbon double bonds. These mixtures still include a significant amount of $\mathrm{n}$-heptane, which undergoes radical chain branching reactions at low temperatures below $\sim 750 \mathrm{~K}$. However, the formed radicals reaction with the aromatics and/or olefins form resonantly stabilized intermediates, which do not lead to low temperature radical chain branching. As the temperature increases above $\sim 750 \mathrm{~K}$, n-heptane reacts to form $\mathrm{HO}_{2}$ radicals (as opposed to $\mathrm{OH}$ radical), due to

Table 6

Composition, RON, and S of selected gasoline surrogate mixtures studied by Singh et al. [344].

\begin{tabular}{llllllll}
\hline Fuel mixture & isooctane (vol\%) & n-heptane (vol\%) & toluene (vol\%) & 1-hexene (vol\%) & RON & MON & S \\
\hline RON 91, S 0 (PRF 91) & 91 & 9 & 0 & 0 & 91 & 91 & 0 \\
RON 90.5, S 2.5 & 72.5 & 12.5 & 15 & 0 & 90.5 & 88 & 2.5 \\
RON 91.7, S 6.5 & 58 & 7 & 15 & 20 & 91.7 & 85.2 & 6.5 \\
RON 90.9, S 8.2 & 39 & 11 & 30 & 20 & 90.9 & 82.7 & 8.2 \\
\hline
\end{tabular}


concerted elimination reactions; however, these $\mathrm{HO}_{2}$ radicals can readily react with benzyl radicals to form $\mathrm{OH}$ and benzoxyl radicals [161]. The production of $\mathrm{OH}$ radicals by these pathways results in a higher sensitivity fuel (i.e., higher aromatic content), having shorter ignition delay times in the intermediate temperature regime.

In summary, kinetic modeling simulations with multicomponent surrogate mixtures give deeper insight into the effects of molecular composition on important gasoline combustion properties, such as ignition delay. Novel gasoline engine technologies that rely on stratified or partially premixed charges may also be increasingly sensitive to physical properties of the gasoline fuel, such as density, viscosity, and distillation profile. Complex surrogate mixtures are typically needed to match the entire boiling point range of real gasoline fuels. Additional research will determine the required complexity of gasoline surrogates needed to replicate coupled chemical kinetic phenomenon (i.e., gas-phase reactivity) and physically driven phenomenon (i.e., mixture formation, spray characteristics, etc.).

\section{Summary and outlook}

Growing global demand for transportation is increasing the need for gasoline fuels. It is expected that gasoline fuels will be widely used in both SI and CI engines, with various fundamental research topics requiring attention. This review demonstrates the need for a fundamental understanding of gasoline combustion characteristics to overcome the challenges limiting the development of advanced gasoline engine technologies. These included, but were not limited to, mitigation of knock and superknock in SI engines, robust ignition and combustion control of gasoline in $\mathrm{CI}$ engines, and mitigation of harmful pollutant emissions. These practical engine phenomena were shown to be linked to several fundamental combustion properties, such as ignition delay time, laminar flame speed, heat release rates, and species formation. The development of surrogate mixtures, together with corresponding experimental and theoretical studies on gasoline fuels and their surrogates, were comprehensively discussed in this work.

Despite recent advances in our understanding of gasoline surrogate fuel formulation, experimental measurements and chemical kinetic modeling, this review identifies areas where significant research advances are required to overcome challenges facing the development of high efficiency and low emission gasoline engines. This review identifies an overarching fuel-engine design methodology that has evolved in recent decades. The general design process presented in Fig. 1 shows how fuels and engines can be optimized to maximize efficiency and decrease negative environmental impacts. Current challenges in the design process are highlighted in the following discussion, while future research directions are provided in Box 1 .

The first step is to gain detailed knowledge of gasoline fuel production and engine technologies. The combustion characteristics of gasoline strongly depend on the type of crude oil, the refining process, and the blending of petroleum derived fuels with bio-derived components. The fuels must be well characterized, using not only standard ASTM or EN test methodologies, but also more advanced molecular characterization techniques. Technologies already exist to perform fuel production and characterization measurements needed for the proposed design process; but, improved simulation tools are needed to predict fuel properties based on production processes.

With a sound understanding of the physical-chemical characteristics of a gasoline fuel, the second step is to generate surrogate mixtures comprising a limited number of components. As shown in this review, this can be readily achieved using computational tools to match a range of gasoline fuel target properties. The primary challenge remains, wherein determining the important target properties requires detailed knowledge of the engine combustion process. Therefore, a systematic study is needed to determine the relationship between various physical-chemical target properties and their impact on combustion processes in a specific engine hardware.

Once a surrogate is defined, it should be tested in fundamental combustion devices alongside the real gasoline fuel. As shown in this review, experiments in high pressure ignition devices, flow reactors, and laminar flames provide detailed insights into gasoline combustion chemistry. Despite the large amount of data available, there is a dearth of experimental measurements on complex mixtures comprising more than two or three surrogate molecules. Such information is needed for the development of kinetic models and understanding mixture effects. This leads to the fourth step in the design process: developing a surrogate chemical kinetic model. This review has shown that chemical kinetic models are available for many gasoline relevant moelcules, but better models are still needed for cycloalkanes (naphthenes) and alkenes (olefins). Furthermore, the development of kinetic models for gasoline mixtures with many components is required.

The present review provides a detailed overview of steps one through four; and it has been shown that understanding complex gasoline fuel properties on combustion processes can help predict important phenomenon, such as heat release rates in advanced combustion engines and octane rating. However, significantly more research is needed to extend this approach to realistic engine environments. The sixth step in the design process requires translating the fundamental knowledge of gasoline combustion into complex engine hardware environments. Under such conditions, spray processes and mixing act together with gas-phase chemistry to control the combustion process. While many studies from engine literature have interpreted fuel/engine interactions, this review identifies a scarcity in the use of multi-component surrogates in engine research. The use of these complex surrogates in engine experiments and numerical simulations can help develop a more detailed understanding of gasoline fuel/engine interactions.

Finally, an important aspect of the design process is a fundamental understanding of fuel/engine combustion processes, emissions, and environmental impact. A large amount of experimental literature (e.g., [354,355]) already exists to study the link between fuels, combustion emissions (i.e., soot, $\mathrm{NOx}$, etc.) and environmental impact. However, an implementation of this knowledge into the design process requires large-scale computational simulations, which predict the effects of combustion emissions on regional and global air quality [356-358]. This realization of this framework can lead to new opportunities of designing optimal fuel/engine technologies with maximum efficiency and minimal environmental impact.

BOX 1 - Future directions for gasoline surrogate formulation research

- Insights into the relationship between gasoline composition and engine performance are achieved by studying surrogate mixtures in fundamental experiments. However, these experiments must be designed to investigate engine-relevant phenomenon. The fuel effects of on pre-ignition and super-knock can be better understood with fundamental experiments in ST and RCM. Recent work [132,359-361] has shown that ignition in these devices is not always homogeneous, and phenomenon such as early flame development and transition to detonation can be studied in ST and RCM.

- Spray combustion devices such as constant volume combustion chambers (CVCC) and ignition quality testers (IQT) have been extensively used to study diesel spray combustion 
[207,362 - 365], but only a few studies exist on gasoline fuels [366,367]. Research should be directed towards acquiring liquid spray and combustion data for various gasoline fuels, surrogate mixtures, and injector geometries. This would also facilitate the development of high-fidelity spray combustion simulations.

- This review identified a lack of kinetic modeling validation data for practical gasoline fuels and multicomponent surrogate mixtures. Laminar flame speed measurements are needed at higher pressures (up to 30 bar) and unburnt gas temperatures $(400-600 \mathrm{~K})$. Total and first stage ignition delay time measurements at higher pressures (up to 100 bar) and lower temperatures (550-950 K) are required to validate kinetic models in the low temperature and NTC regimes. Speciation measurements in flames and flow reactors have been largely restricted to higher temperatures and lower pressures. Therefore, efforts are needed to better capture combustion intermediates at elevated pressures ( $>$ 1 bar) and low- to intermediate- temperatures (550-950 K). In particular, measurements are needed to understand mixture effects on oxidation intermediates in the low temperature regime and particulate matter formation at higher pressures.

- Engines experiments with multi-component surrogate mixtures are needed. These experiments should use the same surrogate mixtures as those used in fundamental devices (e. g., ST, RCM, flames), so a link can be established between fundamental and applied combustion systems. In addition, engine experiments with surrogate fuels will improve the accuracy of CFD engine simulations by removing uncertainties in the modeling of fully blended gasoline fuels.

- Chemical kinetic models for various gasoline surrogate components have advanced significantly in the last decade. However, consistency in thermochemical and kinetic rate parameters is currently limited to n-alkane models, and significant work is needed to improve kinetic models for other hydrocarbons. Improved models for $\mathrm{C}_{6}-\mathrm{C}_{8}$ isoalkanes, $\mathrm{C}_{6}-\mathrm{C}_{8}$ cycloalkanes, and $\mathrm{C}_{7}-\mathrm{C}_{9}$ aromatics are needed. Furthermore, kinetic models capable of simulations multicomponent mixtures (e.g., up to ten components) will be useful for determining if and when complex surrogate mixtures are needed.

- Engine combustion is governed by complex physical (e.g., droplet breakup, spray evaporation, air/fuel mixing) and chemical (e.g., gas-phase chemical reactions) processes, but it is often difficult to decouple fuel property effects, especially in new combustion concept engines [368,369]. Surrogate fuel mixtures offer an opportunity to study these processes separately. For example, mixtures with similar physical properties but widely varying chemical kinetic properties (e.g., various isomers of octane) could be investigated.

- Reduced mechanisms are regularly published to simulation gasoline surrogate mixture combustion in engines [370,371]. However, the release of reduced models often cannot keep up with the pace of advances in detailed chemical kinetic models. Therefore, new open-source model reduction tools should be developed to enable use of the latest detailed chemical kinetic models in CFD simulations.

- Research has been conducted on non-oxygenated gasoline fuels and their surrogates, but few fundamental studies exist on the effects of various additives to gasoline fuels. Common antiknock additives, such as ethanol and MTBE, have been studied in engines, but the underlying chemical kinetic mechanisms contributing to their improved antiknock quality could be better investigated in fundamental devices. Indeed, it is widely known that blending octane numbers of additives (e.g., ethanol [118,372-374]) vary depending on base fuel octane number and composition. However, theoretical explanations and models capable of prediction blending octane can only be achieved by detailed studies with surrogate mixtures. These studies could improve the design of higher efficiency octane on demand technologies.

- Finally, a cradle-to-grave approach for gasoline fuel development research is needed. The environmental impact of new gasoline fuel production technologies as well as improvements in end-use engine technologies need to be analyzed and optimized together. Surrogate fuel mixtures are necessary for developing complex models to simulate fuel production, combustion, and environmental fate. Systems wide studies [375-378] on net $\mathrm{CO}_{2}$ emissions and other environmental indicators offers the potential for optimal fuel/engine design.

\section{Acknowledgments}

Fig. 1 was produced by Heno Hwang, scientific illustrator at King Abdullah University of Science and Technology (KAUST). The research reported in this publication was supported by Saudi Aramco and KAUST under the FUELCOM program. Authors from KAUST were also supported by competitive research funding given to the Clean Combustion Research Center's Future Fuels program.

\section{Supplementary materials}

Supplementary material associated with this article can be found, in the online version, at doi:10.1016/j.pecs.2017.09.004.

\section{References}

[1] U.S. Energy Information Administration. International energy outlook 2016. Washington; 2016.

[2] OPEC Secretariat. World oil outlook. Vienna; 2013.

[3] International Energy Agency. Oil market report. 2016.

[4] Kalghatgi GT. The outlook for fuels for internal combustion engines. Int J Engine Res 2014;15(4):383-98.

[5] Kalghatgi GT, Gosling C, Wier M. The outlook for transport fuels: part 1. Petrol Technol Q 2016: 23-31.

[6] Kalghatgi GT. Petroleum-based fuels for transport. J Autom Saf Energy 2015;5 (2):1-16.

[7] Kalghatgi GT. Developments in internal combustion engines and implications for combustion science and future transport fuels. Proc Combust Inst 2015;35 (1):101-15.

[8] Kalghatgi GT. Fuel/engine interactions. Warrendale: Pennsylvania: SAE International; 2014.

[9] Richards P. Automotive fuels reference book. 3rd ed Warrendale: Pennsylvania: SAE International; 2014

[10] Pitz WJ, Cernansky NP, Dryer FL, Egolfopoulos FN, Farrell JT, Friend DG et al. Development of an experimental database and chemical kinetic models for surrogate gasoline fuels. SAE Technical Paper 2007-01-0175 2007.

[11] Farrell JT, Cernansky NP, Dryer FL, Friend DG, Hergart CA, Law CK. et al. Development of an experimental database and kinetic models for surrogate diesel fuels. SAE Technical Paper 2007-01-0201 2007.

[12] Pitz WJ, Mueller CJ. Recent progress in the development of diesel surrogate fuels. Prog Energy Combust Sci 2011;37:330-50.

[13] ASTM D4814. Specification for automotive spark-ignition engine fuel. West Conshohocken: PA: ASTM International; 2017

[14] Rand SJ, Verstuyft AW. Fuels specifications: what they are, why we have them, and how they are used. West Conshohocken: PA: ASTM International; 2016

[15] ASTM D2699. Standard test method for research octane number of spark-ignition engine fuel. West Conshohocken: PA: ASTM International; 2012.

[16] ASTM D2700. Standard test method for motor octane number of spark-ignition engine fuel. West Conshohocken: PA: ASTM International; 2012.

[17] ASTM D4953. Standard test method for vapor pressure of gasoline and gasoline-oxygenate blends (dry method). West Conshohocken: PA: ASTM International; 2016.

[18] ASTM D5191. Standard test method for vapor pressure of petroleum products (mini method). West Conshohocken: PA: ASTM International; 2016. 
[19] ASTM D86. Standard test method for distillation of petroleum products and liquid fuels at atmospheric pressure. West Conshohocken: PA: ASTM International; 2017.

[20] ASTM D4052. Standard test method for density, relative density, and API gravity of liquids by digital density meter. West Conshohocken: PA: ASTM International; 2017.

[21] ASTM D240. Standard test method for heat of combustion of liquid hydrocarbon fuels by bomb calorimeter. West Conshohocken: PA: ASTM International; 2017.

[22] ASTM D6730. Standard test method for determination of individual components in spark ignition engine fuels by 100 -metre capillary (with precolumn) high- resolution gas chromatography. West Conshohocken: PA: ASTM International; 2016.

[23] ASTM D1319. Test method for hydrocarbon types in liquid petroleum products by fluorescent indicator adsorption. West Conshohocken: PA: ASTM International; 2016.

[24] ASTM D5291. Standard test methods for instrumental determination of carbon, hydrogen, and nitrogen in petroleum products and lubricants. West Conshohocken: PA: ASTM International; 2016.

[25] ASTM D4815. Standard test method for determination of MTBE, ETBE, TAME, DIPE, tertiary-amyl alcohol and C1 to C4 alcohols in gasoline by gas chromatography. West Conshohocken: PA: ASTM International; 2016.

[26] ASTM D5599. Standard test method for determination of oxygenates in gasoline by gas chromatography and oxygen selective flame ionization detection. West Conshohocken: PA: ASTM International; 2017

[27] ASTM D5580. Test method for determination of benzene, toluene, ethylbenzene, p/m-xylene, o-xylene, C9 and heavier aromatics, and total aromatics in finished gasoline by gas chromatography. West Conshohocken: PA: ASTM International; 2016

[28] ASTM D6550. Standard test method for determination of olefin content of gasolines by supercritical-fluid chromatography. West Conshohocken: PA: ASTM International; 2016

[29] Bruno TJ, Ott LS, Smith BL, Lovestead TM. Complex fluid analysis with the advanced distillation curve approach. Anal Chem 2010;82:777-83.

[30] Bruno TJ. Improvements in the measurement of distillation curves. 1. A composition-explicit approach. Ind Eng Chem Res 2006;45:4371-80.

[31] Bruno TJ, Smith BL. Improvements in the measurement of distillation curves. 2. Application to aerospace/aviation fuels RP-1 and S-8. Ind Eng Chem Res 2006;45:4381-8

[32] Burger JL, Schneider N, Bruno TJ. Application of the advanced distillation curve method to fuels for advanced combustion engines gasolines. Energy Fuels 2015;29:4227-35.

[33] Bruno TJ, Huber ML. Evaluation of the physicochemical authenticity of aviation kerosene surrogate mixtures. Part 2: analysis and prediction of thermophysical properties. Energy Fuels 2010;24:4277-84

[34] Ferris AM, Rothamer DA. Methodology for the experimental measurement of vapor-liquid equilibrium distillation curves using a modified ASTM D86 setup. Fuel 2016;182:467-79.

[35] Huber ML, Smith BL, Ott LS, Bruno TJ. Surrogate mixture model for the thermophysical properties of synthetic aviation fuel S-8: explicit application of the advanced distillation curve. Energy Fuels 2008;22:1104-14.

[36] Chevron. Motor gasolines technical review. Chevron 2009:1-124.

[37] CONCAWE. Gasoline volatility and vehicle performance. 2012.

[38] Skippon SM, Norton D. The effects of gasoline volatility on mass and composition of the inlet port wall film in port injected SI engines. SAE Technical Paper 9825171998.

[39] Takei Y, Kinugasa Y, Okada M, Tanaka T, Fujimoto Y. Fuel property requiremen for advanced technology engines. SAE Technical Paper 2000-01-2019 2000

[40] Ryan TW, Matheaus AC. Fuel requirements for HCCI engine operation. SAE Technical Paper 2003-01-1813 2003.

[41] Chang J, Kalghatgi G, Amer A, Viollet Y. Enabling high efficiency direct injection engine with naphtha fuel through partially premixed charge compression ignition combustion. SAE Technical Paper 2012-01-0677 2012.

[42] Chang J, Viollet Y, Amer A, Kalghatgi G. Fuel economy potential of partially premixed compression ignition (PPCI) combustion with naphtha fuel. SAE Technical Paper 2013-01-2701 2013.

[43] Chang J, Kalghatgi G, Amer A, Adomeit P, Rohs H, Heuser B. Vehicle demonstration of naphtha fuel achieving both high efficiency and drivability with EURO6 engine-out NOx emission. SAE Int J Engines 2013;6:101-19.

[44] Sellnau MC, Sinnamon J, Hoyer K, Husted H. Full-time gasoline direct-injection compression ignition (GDCI) for high efficiency and low NOx and PM. SAE Int J Engines 2012;5:300-14

[45] Kodavasal J, Kolodziej C, Ciatti S, Som S. CFD simulation of gasoline compression ignition. J Energy Resour Technol 2015;137:1-13.

[46] Adhikary Das B, Ra Y, Reitz RD, Ciatti S. Numerical optimization of a light-duty compression ignition engine fueled with low-octane gasoline. SAE Technical Paper 2012-01-1336 2012.

[47] Kalghatgi GT, Hildingsson L, Harrison AJ, Johansson B. Autoignition quality of gasoline fuels in partially premixed combustion in diesel engines. Proc Combust Inst 2011:33:3015-21.

[48] VanDerWege BA, Hochgreb S. Effects of fuel volatility and operating conditions on fuel sprays in DISI engines:(1) Imaging investigation 2000. SAE Technical Paper 2000-01-0535 2000.

[49] Li T, Xu M, Hung D, Wu S, Cheng S. Understanding the effects of fuel type and injection conditions on spray evaporation using optical diagnostics. SAE Technical Paper 2015-01-0926 2015.
[50] Davy MH, Williams PA, Anderson RW. Effects of fuel composition on mixture formation in a firing direct-injection spark-ignition (DISI) engine: an experimental study using Mie-scattering and planar laser-induced fluorescence (PLIF) techniques. SAE Technical Paper 2000-01-1904 2000.

[51] Zigan L, Schmitz I, Flügel A, Knorsch T, Wensing M, Leipertz A. Effect of fuel properties on spray breakup and evaporation studied for a multihole direct injection spark ignition injector. Energy Fuels 2010;24:4341-50.

[52] Anderson JE, Wallington TJ, Stein RA, Studzinski WM. Issues with T50 and T90 as match criteria for ethanol-gasoline blends. SAE Int J Fuels Lubr 2014:7:1027-40

[53] Mayer M, Hofmann P, Geringer B, Williams J, Moss J. Influence of different fuel properties and gasoline - ethanol blends on low-speed pre-ignition in turbocharged direct injection spark ignition engines. SAE Int J Engines 2016;9:8418.

[54] Narayanaswamy K, Pitsch H, Pepiot P. A component library framework for deriving kinetic mechanisms for multi-component fuel surrogates: application for jet fuel surrogates. Combust Flame 2016;165:288-309.

[55] Jones DSJ, Pujadó PR. Handbook of petroleum processing. Springer; 2006.

[56] Smolenskii EA, Vlasova GV, Lapidus AL. A study of the structure-octane number relationship for hydrocarbons. Dokl Phys Chem 2004;397:145-9.

[57] Lapidus AL, Smolenskii EA, Bavykin VM, Myshenkova TN, Kondrat'ev LT. Models for the calculation and prediction of the octane and cetane numbers of individual hydrocarbons. Pet Chem 2008;48:277-86.

[58] Sarathy SM, Kukkadapu G, Mehl M, Javed T, Ahmed A, Naser N, et al. Compositional effects on the ignition of FACE gasolines. Combust Flame 2016;169:17193.

[59] Sarathy SM, Vranckx S, Yasunaga K, Mehl M, Oßwald P, Metcalfe WK, et al. A comprehensive chemical kinetic combustion model for the four butanol isomers. Combust Flame 2012;159:2028-55.

[60] Sarathy SM, Oßwald P, Hansen N, Kohse-Höinghaus K. Alcohol combustion chemistry. Prog Energy Combust Sci 2014;44:40-102.

[61] Yang Y, Dec JE, Dronniou N, Simmons B. Characteristics of isopentanol as a fuel for HCCI engines. SAE Int J Fuels Lubr 2010;3:725-41.

[62] Tsujimura T, Pitz WJ, Gillespie F, Curran HJ, Weber BW, Zhang Y, et al. Development of isopentanol reaction mechanism reproducing autoignition character at high and low temperatures. Energy Fuels 2012;26:4871-86.

[63] Sarathy SM, Park S, Weber BW, Wang W, Veloo PS, Davis AC, et al. A comprehensive experimental and modeling study of iso-pentanol combustion. Combust Flame 2013;160:2712-28.

[64] Park S, Mannaa O, Khaled F, Bougacha R, Mansour MS, Farooq A, et al. A comprehensive experimental and modeling study of 2-methylbutanol combustion. Combust Flame 2015;162:2166-76

[65] Brassat A, Thewes M, Müther M, Pischinger S, Lee C, Fernandes RX, et al. Analysis of the effects of certain alcohol and furan-based biofuels on controlled auto ignition. SAE Technical Paper 2012-01-1135 2012

[66] Thewes M, Müther M, Pischinger S, Budde M, Brunn A, Sehr A, et al. Analysis of the impact of 2-methylfuran on mixture formation and combustion in a directinjection spark-ignition engine. Energy Fuels 2011;25:5549-61.

[67] Kerschgens B, Cai L, Pitsch H, Janssen A, Jakob M, Pischinger S. Surrogate fuels for the simulation of diesel engine combustion of novel biofuels. Int J Engine Res 2015;16:531-46.

[68] Christensen E, Yanowitz J, Ratcliff MA, McCormick RL. Renewable oxygenate blending effects on gasoline properties. Energy Fuels 2011;25:4723-33.

[69] McCormick RL, Ratcliff MA, Christensen E, Fouts L, Luecke J, Chupka GM, et al. Properties of oxygenates found in upgraded biomass pyrolysis oil as components of spark and compression ignition engine fuels. Energy Fuels 2015;29:2453-61

[70] Kalghatgi G, Babiker H, Badra J. A simple method to predict knock using toluene, n-heptane and iso-octane blends (TPRF) as gasoline surrogates. SAE Int J Engines 2015;8:505-19.

[71] Kalghatgi G, Morganti K, Algunaibet I, Sarathy M, Dibble R. Knock prediction using a simple model for ignition delay. SAE Technical Paper 2016-01-0702 2016.

[72] Bratsky D, Stacho D. Impact of motor gasoline chemical composition and additive treatment on inlet valve and combustion chamber deposits. SAE Technical Paper 2000-01-2022 2000.

[73] Aradi AA, Imoehl B, Avery NL, Wells PP, Grosser RW. The effect of fuel composition and engine operating parameters on injector deposits in a high-pressure direct injection gasoline (DIG) research engine. SAE Technical Paper 1999-0136901999.

[74] Carlisle HW, Frew RW, Mills JR, Aradi AA, Avery NL. The effect of fuel composition and additive content on injector deposits and performance of an airassisted direct injection spark ignition (DISI) research engine. SAE Technical Paper 2001-01-2030 2001.

[75] Di Iorio S, Catapano F, Sementa P, Vaglieco BM, Florio S, Rebesco E, et al. Effect of octane number obtained with different oxygenated components on the engine performance and emissions of a small GDI engine. SAE Technical Paper 2014-32-0038 2014

[76] Pepiot-Desjardins P, Pitsch H, Malhotra R, Kirby SR, Boehman AL. Structural group analysis for soot reduction tendency of oxygenated fuels. Combust Flame 2008;154:191-205.

[77] McEnally CS, Pfefferle LD. Sooting tendencies of oxygenated hydrocarbons in laboratory-scale flames. Environ Sci Technol 2011:45:2498-503.

[78] Butler AD, Sobotowski RA, Hoffman GJ, Machiele P. Influence of fuel PM Index and ethanol content on particulate emissions from light-duty gasoline vehicles. SAE Technical Paper 2015-01-1072 2015. 
[79] Machado GB, Barros J, Braga SL, Braga C. The impact of fuel composition on SI engine calibration and performance. SAE Technical Paper 2014-36-0161 2014

[80] Chang J, Viollet Y, Alzubail A, Abdul-Manan AFN, Arfaj Al A. Octane-on-demand as an enabler for highly efficient spark ignition engines and greenhouse gas emissions improvement. SAE Technical Paper 2015-01-1264 2015.

[81] Viollet Y, Abdullah M, Alhajhouje A, Chang J. Characterization of high efficiency octane-on-demand fuels requirement in a modern spark ignition engine with dual injection system. SAE, vol. 1, 400 Commonwealth drive, Warrendale, PA, United States: SAE International; 2015, pp. 2015-01-1265-14.

[82] Morganti K, Abdullah M, Alzubail A, Viollet Y, Head R, Chang J, et al. Improving the efficiency of conventional spark-ignition engines using octaneon-demand combustion. Part I: engine studies. SAE Technical Paper 2016-01-0679 2016.

[83] Hochhauser AM, Benson JD, Burns V, Gorse RA, Koehl WJ, Painter LJ, et al. The effect of aromatics, MTBE, olefins and T90 on mass exhaust emissions from current and older vehicles - the auto/oil air quality improvement research program. SAE Technical Paper 9123221991.

[84] Sarathy SM. Fuel class higher alcohols editor. In: Boot MD, editor. Biofuels from lignocellulosic biomass. Weinheim, Germany: Wiley-VCH Verlag GmbH \& Co; 2016. p. 29-57.

[85] Boot M, Frijters P, Luijten C, Somers B, Baert R, Donkerbroek A, et al. Cyclic oxygenates: a new class of second-generation biofuels for diesel engines? Energy Fuels 2009;23:1808-17.

[86] Zhou L, Boot MD, Johansson BH. Comparison of emissions and performance between saturated cyclic oxygenates and aromatics in a heavy-duty diesel engine. Fuel 2013;113:239-47.

[87] Zhou L, Boot MD, Johansson BH, Reijnders JJE. Performance of lignin derived aromatic oxygenates in a heavy-duty diesel engine. Fuel 2014;115:469-78.

[88] Jain AK, Pathak S, Singh Y, Singh S, Saxena M, Subramanian M, et al. Effect of gasoline composition (olefins, aromatics and benzene) on exhaust mass emissions from two-wheelers-an experimental study. SAE Technical Paper 200726-014 2007.

[89] Mittal V, Heywood JB. The shift in relevance of fuel RON and MON to knock onset in modern SI engines over the last 70 years. SAE Int J Engines 2010;2:110.

[90] Davies T, Cracknell R, Lovett G, Cruff L, Fowler J. Fuel effects in a boosted DISI engine. SAE Technical Paper 2011-01-1985 2011.

[91] Machado GB, Barros JEM, Braga SL, Braga CVM, de Oliveira EJ, da Silva AHM da FT, et al. Investigations on surrogate fuels for high-octane oxygenated gasolines. Fuel 2011;90:640-6.

[92] Ahmed A, Waqas M, Naser N, Singh E, Roberts W, Chung S, et al. Compositional effects of gasoline fuels on combustion, performance and emissions in engine. SAE Int J Fuels Lubr 2016;9(3):460-8

[93] Shibata G, Urushihara T. Auto-ignition characteristics of hydrocarbons and development of HCCI fuel index. SAE Technical Paper 2007-01-0220 2007.

[94] Lacey J, Kameshwaran K, Sathasivam S, Filipi Z, Cannella W, Fuentes-Afflick PA. Effects of refinery stream gasoline property variation on the auto-ignition quality of a fuel and homogeneous charge compression ignition combustion. Int J Engine Res 2017;18:1-14.

[95] Truedsson I, Tuner M, Johansson B, Cannella W. Pressure sensitivity of HCCI auto-ignition temperature for gasoline surrogate fuels. SAE Technical Paper 2013-01-1669 2013.

[96] Truedsson I, Tunér M, Johansson B. Pressure sensitivity of HCCI auto-ignition temperature for primary reference fuels. SAE Int J Engines 2012;5:1089-108.

[97] Truedsson I, Tuner M, Johansson B, Cannella W. Emission formation study of HCCI combustion with gasoline surrogate fuels. SAE Technical Paper 2013-0126262013.

[98] Aronsson HS, Truedsson I, Tunér M, Johansson B, Cannella W. Comparison of fuel effects on low temperature reactions in PPC and $\mathrm{HCCI}$ combustion. SAE Technical Paper 2014-01-2679 2014.

[99] Amann M, Mehta D, Alger T. Engine operating condition and gasoline fuel composition effects on low-speed pre-ignition in high-performance spark ignited gasoline engines. SAE Int J Engines 2011;4:274-85

[100] Mueller CJ, Cannella WJ, Bays JT, Bruno TJ, DeFabio K, Dettman HD, et al. Diesel surrogate fuels for engine testing and chemical-kinetic modeling: Compositions and properties. Energy Fuels 2016:30:1445-61.

[101] Mueller CJ, Cannella WJ, Bruno TJ, Bunting B, Dettman HD, Franz JA, et al. Methodology for formulating diesel surrogate fuels with accurate compositional, ignition-quality, and volatility characteristics. Energy Fuels 2012;26:3284-303.

[102] Dooley S, Won SH, Chaos M, Heyne J, Ju Y, Dryer FL, et al. A jet fuel surrogate formulated by real fuel properties. Combust Flame 2010;157:2333-9.

[103] Dooley S, Won SH, Jahangirian S, Ju Y, Dryer FL, Wang H, et al. The combustion kinetics of a synthetic paraffinic jet aviation fuel and a fundamentally formulated, experimentally validated surrogate fuel. Combust Flame 2012;159:3014-20,

[104] Honnet S, Seshadri K, Niemann U, Peters N. A surrogate fuel for kerosene. Proc Combust Inst 2009;32:485-92

[105] Kim D, Martz J, Violi A. A surrogate for emulating the physical and chemical properties of conventional jet fuel. Combust Flame 2014;161:1489-98.

[106] Kang D, Kalaskar V, Kim D, Martz J, Violi A, Boehman A. Experimental study of autoignition characteristics of jet-A surrogates and their validation in a motored engine and a constant-volume combustion chamber. Fuel 2016:184:565-80.

[107] Kim D, Martz J, Violi A. Effects of fuel physical properties on direct injection spray and ignition behavior. Fuel 2016;180:481-96.
[108] Kalghatgi GT, Hildingsson L, Harrison AJ, Johansson B. Surrogate fuels for premixed combustion in compression ignition engines. Int J Engine Res 2011:12:452-65.

[109] Bunting BG, Eaton S, Naik CV, Puduppakkam KV, Chou CP, Meeks E. A Comparison of $\mathrm{HCCl}$ ignition characteristics of gasoline fuels using a single-zone kinetic model with a five component surrogate fuel. SAE Technical Paper 2008-0123992008.

[110] Puduppakkam K, Liang L, Naik CV, Meeks E, Bunting BG. Combustion and emissions modeling of a gasoline $\mathrm{HCCl}$ engine using model fuels. SAE Technical Paper 2009-01-0669 2009.

[111] Su X, Ra Y, Reitz RD. A surrogate fuel formulation approach for real transportation fuels with application to multi-dimensional engine simulations. SAE Int J Fuels Lubr 2014;7:236-49.

[112] Mehl M, Chen JY, Pitz WJ, Sarathy SM, Westbrook CK. An approach for formulating surrogates for gasoline with application toward a reduced surrogate mechanism for CFD engine modeling. Energy Fuels 2011;25:5215-23.

[113] Badra JA, Bokhumseen N, Mulla N, Sarathy SM, Farooq A, Kalghatgi G, et al. A methodology to relate octane numbers of binary and ternary n-heptane, isooctane and toluene mixtures with simulated ignition delay times. Fuel 2015;160:458-69.

[114] Pera C, Knop V. Methodology to define gasoline surrogates dedicated to autoignition in engines. Fuel 2012;96:59-69.

[115] Knop V, Loos M, Pera C, Jeuland N. A linear-by-mole blending rule for octane numbers of n-heptane/iso-octane/toluene mixtures. Fuel 2014:115:666-73.

[116] Morgan N, Smallbone A, Bhave A, Kraft M, Cracknell R, Kalghatgi G. Mapping surrogate gasoline compositions into RON/MON space. Combust Flame 2010;157:1122-31.

[117] Anderson JE, Leone TG, Shelby MH, Wallington TJ, Bizub JJ, Foster M, et al Octane numbers of ethanol-gasoline blends: measurements and novel estimation method from molar composition. SAE Technical Paper 2012-01-1274 2012.

[118] AlRamadan AS, Sarathy SM, Khurshid M, Badra J. A blending rule for octane numbers of PRFs and TPRFs with ethanol. Fuel 2016;180:175-86.

[119] Slavinskaya NA, Zizin A, Aigner M. On model design of a surrogate fuel formulation. J Eng Gas Turbines Power 2010;132:111501-11.

[120] Elwardany AE, Sazhin SS. A quasi-discrete model for droplet heating and evaporation: application to diesel and gasoline fuels. Fuel 2012;97:685-94.

[121] Elwardany AE, Sazhin SS, Im HG. A new formulation of physical surrogates of FACE A gasoline fuel based on heating and evaporation characteristics. Fue 2016;176:56-62.

[122] Su M, Chen CP. Heating and evaporation of a new gasoline surrogate fuel: a discrete multicomponent modeling study. Fuel 2015;161:215-21.

[123] Abianeh OS, Chen CP, Cerro RL. Batch Distillation: the forward and inverse problems. Ind Eng Chem Res 2012;51:12435-48.

[124] Al Qubeissi M, Sazhin SS, Turner J, Begg S, Crua C, Heikal MR. Modelling of gasoline fuel droplets heating and evaporation. Fuel 2015;159:373-84.

[125] Ahmed A, Goteng G, Shankar VSB, Al-Qurashi K, Roberts WL, Sarathy SM. A computational methodology for formulating gasoline surrogate fuels with accurate physical and chemical kinetic properties. Fuel 2015;143:290-300.

[126] Abianeh OS, Oehlschlaeger MA, Sung C-J. A surrogate mixture and kinetic mechanism for emulating the evaporation and autoignition characteristics of gasoline fuel. Combust Flame 2015;162:3773-84.

[127] Dec JE, Sjöberg M. Isolating the effects of fuel chemistry on combustion phasing in an HCCI engine and the potential of fuel stratification for ignition control. SAE Technical Paper 2004-01-0557 2004.

[128] Zhi W, Hui L, Reitz RD. Knocking combustion in spark-ignition engines. Prog Energy Combust Sci 2017;61:78-112.

[129] Trass O, Mackay D. Contact surface tailoring in a chemical shock tube. AIAA J $1963 ; 1: 2161-3$

[130] Uygun Y, Ishihara S, Olivier H. A high pressure ignition delay time study of 2-methylfuran and tetrahydrofuran in shock tubes. Combust Flame 2014:161:2519-30.

[131] Javed T. Combustion kinetic studies of gasolines and surrogates (doctoral dissertation). King Abdullah University of Science and Technology; 2016.

[132] Javed T, Badra J, Jaasim M, Es-Sebbar E, Labastida MF, Chung SH, et al. Shock tube ignition delay data affected by localized ignition phenomena. Combust Sci Technol 2017; 189:1138-61.

[133] Sung C-J, Curran HJ. Using rapid compression machines for chemical kinetics studies. Prog Energy Combust Sci 2014;44:1-18.

[134] Nasir EF, Farooq A. Time-resolved temperature measurements in a rapid compression machine using quantum cascade laser absorption in the intrapulse mode. Proc Combust Inst 2016;36:4453-60.

[135] Goldsborough SS, Mittal G, Banyon C. Methodology to account for multi-stage ignition phenomena during simulations of RCM experiments. Proc Combust Inst 2013;34:685-93.

[136] Egolfopoulos FN, Hansen N, Ju Y, Kohse-Höinghaus K, Law CK, Qi F. Advances and challenges in laminar flame experiments and implications for combustion chemistry. Prog Energy Combust Sci 2014;43:36-67.

[137] Sileghem L, Alekseev VA, Vancoillie J, Van Geem KM NEJK, Verhelst S, et al. Laminar burning velocity of gasoline and the gasoline surrogate components isooctane, n-heptane and toluene. Fuel 2013;112:355-65.

[138] Heitor MV, Moreira ALN. Thermocouples and sample probes for combustion studies. Prog Energy Combust Sci 1993;19:259-78.

[139] Hartlieb AT, Atakan B, Kohse-Höinghaus K. Effects of a sampling quartz nozzle on the flame structure of a fuel-rich low-pressure propene flame. Combust Flame 2000;121:610-24. 
[140] Li S, Farooq A, Hanson RK. $\mathrm{H}_{2} \mathrm{O}$ temperature sensor for low-pressure flames using tunable diode laser absorption near $2.9 \mu \mathrm{m}$. Meas Sci Techno 2011;22:1-11.

[141] Smith OI, Chandler DW. An experimental-study of probe distortions to the structure of one-dimensional flames. Combust Flame 1986;63:19-29.

[142] Stepowski D, Puechberty D, Cottereau MJ. Use of laser-induced fluorescence of $\mathrm{OH}$ to study the perturbation of a flame by a probe. Symp (Int) Combust 1981; $18: 1567-73$.

[143] Gauthier BM, Davidson DF, Hanson RK. Shock tube determination of ignition delay times in full-blend and surrogate fuel mixtures. Combust Flame 2004;139:300-11.

[144] Kukkadapu G, Kumar K, Sung C-J, Mehl M, Pitz WJ. Experimental and surrogate modeling study of gasoline ignition in a rapid compression machine. Combust Flame 2012;159:3066-78.

[145] Chung J, Lee S, An H, Song S, Chun KM. Rapid-compression machine studies on two-stage ignition characteristics of hydrocarbon autoignition and an investigation of new gasoline surrogates. Energy 2015:93:1505-14.

[146] Agbro E, Tomlin AS, Lawes M, Park S, Sarathy SM. The influence of n-butanol blending on the ignition delay times of gasoline and its surrogate at high pressures. Fuel 2017:187:211-9.

[147] Kukkadapu G, Kumar K, Sung C-J, Mehl M, Pitz WJ. Autoignition of gasoline and its surrogates in a rapid compression machine. Proc Combust Inst 2013;34:345-52.

[148] Kukkadapu G, Kumar K, Sung C-J, Mehl M, Pitz WJ. Autoignition of gasoline surrogates at low temperature combustion conditions. Combust Flame 2015;162:2272-85

[149] Mehl M, Pitz WJ, Westbrook CK, Curran HJ. Kinetic modeling of gasoline surrogate components and mixtures under engine conditions. Proc Combust Inst 2011;33:193-200.

[150] Sarathy SM, Kukkadapu G, Mehl M, Wang W, Javed T, Park S, et al. Ignition of alkane-rich FACE gasoline fuels and their surrogate mixtures. Proc Combust Inst 2015;35:249-57

[151] Javed T, Ahmed A, Lovisotto L, Issayev G, Badra J, Sarathy SM, et al. Ignition studies of two low-octane FACE gasolines. Combust Flame 2017;185:152-9.

[152] Javed T, Nasir EF, Ahmed A, Badra J, Djebbi K, Beshir M, et al. Ignition delay measurements of light naphtha: a fully blended low octane fuel. Proc Combust Inst 2017;36:315-22

[153a]AlAbbad M, Issayev G, Badra J, Voice AK, Giri BR, Djebbi K, Ahmed A, Sarathy SM, Farooq A. Autoignition of Straight-Run Naphtha: A Promising Fuel for Advanced Compression Ignition Engines. Combust Flame 2017.

[153b]AlAbbad M, Javed T, Khaled F, Badra J, Farooq A. Ignition delay time measurements of primary reference fuel blends. Combustion and Flame 2017;178:205-16

[154] Lee C, Ahmed A, Nasir EF, Badra J, Kalghatgi G, Sarathy SM, Curran HJ, Farooq A Autoignition characteristics of oxygenated gasolines. Combust Flame 2017; 186:114-28.

[155] Fieweger K, Blumenthal R, Adomeit G. Self-ignition of S.I. engine model fuels: a shock tube investigation at high pressure. Combust Flame 1997:109:599-619.

[156] Callahan CV, Held TJ, Dryer FL. Experimental data and kinetic modeling of primary reference fuel mixtures. Symp (Int) Combust 1996;26:739-46.

[157] Tanaka S, Ayala F, Keck JC, Heywood JB. Two-stage ignition in HCCI combustion and HCCI control by fuels and additives. Combust Flame 2003;132:219-39.

[158] Javed T, Lee C, AlAbbad M, Djebbi K, Beshir M, Badra J, et al. Ignition studies of n-heptane/iso-octane/toluene blends. Combust Flame 2016;171:223-33.

[159] Sakai Y., Ozawa H., Ogura T., Miyoshi A., Koshi M., Pitz W.J.. Effects of toluene addition to primary reference fuels at high temperatures. SAE Technical Paper 2007-01-41042014.

[160] Li H, Yu L, Lu X, Ouyang L, Sun S, Huang Z. Autoignition of ternary blends for gasoline surrogate at wide temperature ranges and at elevated pressure: shock tube measurements and detailed kinetic modeling. Fuel 2016;181:916-25.

[161] Vanhove G, Petit G, Minetti R. Experimental study of the kinetic interactions in the low-temperature autoignition of hydrocarbon binary mixtures and a surrogate fuel. Combust Flame 2006;145:521-32.

[162] Herzler J, Fikri M, Hitzbleck K, Starke R, Schulz C, Roth P, et al. Shock-tube study of the autoignition of n-heptane/toluene/air mixtures at intermediate temperatures and high pressures. Combust Flame 2007:149:25-31.

[163] Cancino LR, Fikri M, Oliveira AAM, Schulz C. Ignition delay times of ethanolcontaining multi-component gasoline surrogates: shock-tube experiments and detailed modeling. Fuel 2011;90:1238-44

[164] Fikri M, Herzler J, Starke R, Schulz C, Roth P, Kalghatgi GT. Autoignition of gasoline surrogate mixtures at intermediate temperatures and high pressures. Combust Flame 2008; 152:276-81.

[165] Cancino LR, Fikri M, Oliveira AAM, Schulz C. Autoignition of gasoline surrogate mixtures at intermediate temperatures and high pressures: experimental and numerical approaches. Proc Combust Inst 2009;32:501-8.

[166] Yahyaoui M, Djebaili-Chaumeix N, Dagaut P, Paillard CE, Gail S. Experimenta and modelling study of gasoline surrogate mixtures oxidation in jet stirred reactor and shock tube. Proc Combust Inst 2007;31:385-91.

[167] Yahyaoui M, Djebailli-Chaumeix N, Dagaut P, Paillard CE, Heyberger B, Pengloan G. Ignition and oxidation of 1-hexene/toluene mixtures in a shock tube and a jet-stirred reactor: experimental and kinetic modeling study. Int J Chem Kinet 2007;39:518-38.

[168] AlRamadan AS, Badra J, Javed T, Al-Abbad M, Bokhumseen N, Gaillard P, et al. Mixed butanols addition to gasoline surrogates: shock tube ignition delay time measurements and chemical kinetic modeling. Combust Flame 2015;162:3971-9.
[169] Zhao Z, Conley JP, Kazakov A, Dryer FL. Burning velocities of real gasoline fuel at $353 \mathrm{~K}$ and $500 \mathrm{~K}$. SAE Technical Paper 2003-01-3265 2003.

[170] Jerzembeck S, Peters N, Pepiot-Desjardins P, Pitsch H. Laminar burning velocities at high pressure for primary reference fuels and gasoline: experimental and numerical investigation. Combust Flame 2009;156:292-301.

[171] Tian G, Daniel R, Li H, Xu H, Shuai S, Richards P. Laminar burning velocities of 2,5-dimethylfuran compared with ethanol and gasoline. Energy Fuels 2010;24:3898-905.

[172] Dirrenberger P, Glaude PA, Bounaceur R, Le Gall H, da Cruz AP, Konnov AA, et al. Laminar burning velocity of gasolines with addition of ethanol. Fuel 2014;115:162-9

[173] Mannaa OA, Mansour MS, Roberts WL, Chung SH. Laminar burning velocities at elevated pressures for gasoline and gasoline surrogates associated with RON Combust Flame 2015;162:2311-21.

[174] Mannaa OA, Mansour MS, Roberts WL, Chung SH. Laminar burning velocities of fuels for advanced combustion engines (FACE) gasoline and gasoline surrogates with and without ethanol blending associated with octane rating. Combust Sci Technol 2016;188:692-706.

[175] Huang Y, Sung CJ, Eng JA. Laminar flame speeds of primary reference fuels and reformer gas mixtures. Combust Flame 2004;139:239-51.

[176] Bradley D, Hicks RA, Lawes M, Sheppard CGW, Woolley R. The measurement of laminar burning velocities and Markstein numbers for iso-octane-air and isooctane-n-heptane-air mixtures at elevated temperatures and pressures in an explosion bomb. Combust Flame 1998:115:126-44.

[177] van Lipzig JPJ, Nilsson EJK, de Goey LPH, Konnov AA. Laminar burning velocities of n-heptane, iso-octane, ethanol and their binary and tertiary mixtures. Fuel 2011;90:2773-81.

[178] Liao YH, Roberts WL. Laminar flame speeds of gasoline surrogates measured with the flat flame method. Energy Fuels 2016;30:1317-24

[179] Gulder OL. Burning velocities of ethanol-isooctane blends. Combust Flame 1984;56:261-8.

[180] Broustail G, Seers P, Halter F, Moréac G, Mounaim-Rousselle C. Experimental determination of laminar burning velocity for butanol and ethanol iso-octane blends. Fuel 2011:90:1-6.

[181] Broustail G, Halter F, Seers P, Moréac G, Mounaim-Rousselle C. Experimental determination of laminar burning velocity for butanol/iso-octane and ethanol/ iso-octane blends for different initial pressures. Fuel 2013;106:310-7.

[182] Chen B, Togbé C, Wang Z, Dagaut P, Sarathy SM. Jet-stirred reactor oxidation of alkane-rich FACE gasoline fuels. Proc Combust Inst 2017;36:517-24

[183] Chen B, Togbe C, Selim HM, Dagaut P, Sarathy SM. Quantities of interest in jet stirred reactor oxidation of a high-octane gasoline. Energy Fuels 2017:31:5543-53.

[184] Selim H, Mohamed SY, Dawood AE, Sarathy SM. Understanding premixed flame chemistry of gasoline fuels by comparing quantities of interest. Proc Combust Inst 2017:36:1203-11.

[185] Selim H, Mohamed SY, Hansen N, Sarathy SM. Premixed flame chemistry of a gasoline primary reference fuel surrogate. Combust Flame 2017;179:300-11.

[186] Javed T, Nasir EF, Es-sebbar E-T, Faroog A. A comparative study of the oxidation characteristics of two gasoline fuels and an n-heptane/iso-octane surrogate mixture. Fuel 2015;140:201-8

[187] Dagaut P, Reuillon M, Cathonnet M. High pressure oxidation of liquid fuels from low to high temperature. 2. Mixtures of n-heptane and iso-octane. Combust Sci Technol 1994;103:315-36.

[188] Dubreuil A, Foucher F, Mounaim-Rousselle C, Dayma G, Dagaut P. HCCI combustion: effect of NO in EGR. Proc Combust Inst 2007:31:2879-86.

[189] Hori M, Nakamura H, Tezuka T, Hasegawa S, Maruta K. Characteristics of n-heptane and toluene weak flames in a micro flow reactor with a controlled temperature profile. Proc Combust Inst 2013;34:3419-26.

[190] Dagaut P, Togbé C. Oxidation kinetics of butanol-gasoline surrogate mixtures in a jet-stirred reactor: experimental and modeling study. Fuel 2008;87:331321.

[191] Dagaut P, Togbé C. Experimental and modeling study of the kinetics of oxidation of ethanol-gasoline surrogate mixtures (E85 surrogate) in a jet-stirred reactor. Energy Fuels 2008;22:3499-505.

[192] Dagaut P, Togbé C. Experimental and modeling study of the kinetics of oxidation of ethanol-n-heptane mixtures in a jet-stirred reactor. Fuel 2010;89:280-

[193] Togbé C, Ahmed AM, Dagaut P. Experimental and modeling study of the kinetics of oxidation of methanol-gasoline surrogate mixtures (M85 surrogate) in a jetstirred reactor. Energy Fuels 2009;23:1936-41.

[194] Wilk RD, Koert DN, Cernansky NP. Low-temperature carbon monoxide formation as a means of assessing the autoignition tendency of hydrocarbons and hydrocarbon blends. Energy Fuels 1989;3:292-8.

[195] Lenhert DB, Miller DL, Cernansky NP, Owens KG. The oxidation of a gasoline surrogate in the negative temperature coefficient region. Combust Flame 2009;156:549-64

[196] Stojkovic BD, Fansler TD, Drake MC, Sick V. High-speed imaging of $\mathrm{OH}^{*}$ and soot temperature and concentration in a stratified-charge direct-injection gasoline engine. Proc Combust Inst 2005;30:2657-65.

[197] Sick V. High speed imaging in fundamental and applied combustion research. Proc Combust Inst 2013;34:3509-30.

[198] Maricq MM. Soot formation in ethanol/gasoline fuel blend diffusion flames. Combust Flame 2012:159:170-80.

[199] Khosousi A, Liu F, Dworkin SB, Eaves NA, Thomson MJ, He X, et al. Experimental and numerical study of soot formation in laminar coflow diffusion flames of gasoline/ethanol blends. Combust Flame 2015;162:3925-33. 
[200] Lemaire R, Therssen E, Desgroux P. Effect of ethanol addition in gasoline and gasoline-surrogate on soot formation in turbulent spray flames. Fuel 2010;89:3952-9.

[201] Bieleveld T, Frassoldati A, Cuoci A, Faravelli T, Ranzi E, Niemann U, et al. Experimental and kinetic modeling study of combustion of gasoline, its surrogates and components in laminar non-premixed flows. Proc Combust Inst 2009;32:493-500

[202] Choi BC, Choi SK, Chung SH. Soot formation characteristics of gasoline surrogate fuels in counterflow diffusion flames. Proc Combust Inst 2011;33:609-16.

[203] Kashif M, Bonnety J, Matynia A, da Costa P, Legros G. Sooting propensities of some gasoline surrogate fuels: combined effects of fuel blending and air vitiation. Combust Flame 2015;162:1840-7.

[204] Liu YC, Avedisian CT. A comparison of the spherical flame characteristics of submillimeter droplets of binary mixtures of n-heptane/iso-octane and n-heptane/ toluene with a commercial unleaded gasoline. Combust Flame 2012;159:77083.

[205] Farouk TI, Xu Y, Avedisian CT, Dryer FL. Combustion characteristics of primary reference fuel (PRF) droplets: single stage high temperature combustion to multistage "cool flame" behavior. Proc Combust Inst 2017;36:2585-94.

[206] Baumgardner ME, Sarathy SM, Marchese AJ. Autoignition characterization of primary reference fuels and n-heptane/n-butanol mixtures in a constant volume combustion device and homogeneous charge compression ignition engine. Energy Fuels 2013;27:7778-89.

[207] Naser N, Yang SY, Kalghatgi G, Chung SH. Relating the octane numbers of fuels to ignition delay times measured in an ignition quality tester (IQT). Fuel 2017;187:117-27

[208] Hartmann M, Gushterova I, Fikri M, Schulz C, Schießl R, Maas U. Auto-ignition of toluene-doped n-heptane and iso-octane/air mixtures: high-pressure shocktube experiments and kinetics modeling. Combust Flame 2011;158:172-8.

[209] Susnow RG, Dean AM, Green WH, Peczak P, Broadbelt LJ. Rate-based construction of kinetic models for complex systems. J Phys Chem A 1997:101:3731-40.

[210] Touchard S, Fournet R, Glaude PA, Warth V, Battin-Leclerc F, Vanhove G, et al. Modeling of the oxidation of large alkenes at low temperature. Proc Combust Inst 2005;30:1073-81.

[211] Bounaceur R., Herbinet O., Fournet R., Glaude P.A., Battin-Leclerc F., da Cruz A.P., et al. Modeling the laminar flame speed of natural gas and gasoline surrogates. SAE Technical Paper 2010-01-0546 2010.

[212] Green WH, Allen JW, Buesser BA, Ashcraft RW, Beran GJ, Class CA, et al. RMGreaction mechanism generator v4.0.1. http://rmg.sourceforge.net/; 2013.

[213] Gao CW, Allen JW, Green WH, West RH. Reaction mechanism generator: automatic construction of chemical kinetic mechanisms. Comput Phys Commun 2016;203:212-25

[214] Sumathi R, Carstensen H-H, Green WH. Reaction rate prediction via group additivity part 1: h-abstraction from alkanes by $\mathrm{H}$ and $\mathrm{CH}_{3}$. J Phys Chem $\mathrm{A}$ 2001;105:6910-25.

[215] Sumathi R, Carstensen HH, Green WH. Reaction rate prediction via group additivity, part 2: h-abstraction from alkenes, alkynes, alcohols, aldehydes, and acids by $\mathrm{H}$ atoms. J Phys Chem A 2001;105:8969-84.

[216] Green WH, Barton PI, Bhattacharjee B, Matheu DM, Schwer DA, Song J, et al. Computer construction of detailed chemical kinetic models for gas-phase reactors. Ind Eng Chem Res 2001;40:5362-70.

[217] Vandewiele NM, Van Geem KM RM-F, Marin GB. Genesys: kinetic model construction using chemo-informatics. Chem Eng J 2012;207-208:526-38.

[218] Dooley S, Won SH, Heyne J, Farouk TI, Ju Y, Dryer FL, et al. The experimental evaluation of a methodology for surrogate fuel formulation to emulate gas phase combustion kinetic phenomena. Combust Flame 2012;159:1444-66.

[219] Metcalfe WK, Burke SM, Ahmed SS, Curran HJ. A hierarchical and comparative kinetic modeling study of $C_{1}-C_{2}$ hydrocarbon and oxygenated fuels. Int J Chem Kinet 2013:45:638-75.

[220] Burke SM, Metcalfe W, Herbinet O, Battin-Leclerc F, Haas FM, Santner J, et al. An experimental and modeling study of propene oxidation. Part 1: speciation measurements in jet-stirred and flow reactors. Combust Flame 2014;161: 2765-84.

[221] Burke SM, Burke U, Mc Donagh R, Mathieu O, Osorio I, Keesee C, et al. An experimental and modeling study of propene oxidation. Part 2: ignition delay time and flame speed measurements. Combust Flame 2015;162:296-314.

[222] Zhou C-W, Li Y, O'Connor E, Somers KP, Thion SB, Keesee C, et al. A comprehensive experimental and modeling study of isobutene oxidation. Combust Flame 2016;167:353-79.

[223] Li J, Zhao Z, Kazakov A, Chaos M, Dryer FL, Scire JJ. A comprehensive kinetic mechanism for $\mathrm{CO}, \mathrm{CH}_{2} \mathrm{O}$, and $\mathrm{CH}_{3} \mathrm{OH}$ combustion. Int $\mathrm{J}$ Chem Kinet 2007;39:109-36.

[224] Li J, Kazakov A, Dryer FL. Ethanol pyrolysis experiments in a variable pressure flow reactor. Int J Chem Kinet 2001;33:859-67.

[225] Chaos M, Kazakov A, Zhao Z, Dryer FL. A high-temperature chemical kinetic model for primary reference fuels. Int J Chem Kinet 2007;39:399-414

[226] Burke MP, Chaos M, Ju Y, Dryer FL, Klippenstein SJ. Comprehensive $\mathrm{H}_{2} / \mathrm{O}_{2}$ kinetic model for high-pressure combustion. Int J Chem Kinet 2012;44:444-74.

[227] Chemical-kinetic mechanisms for combustion applications, San Diego Mechanism http://web.eng.ucsd.edu/mae/groups/combustion/mechanism.html; 2016.

[228] Prince JC, Williams FA. A short reaction mechanism for the combustion of dimethyl-ether. Combust Flame 2015;162:3589-95.

[229] Prince JC, Williams FA, Ovando GE. A short mechanism for the low-temperature ignition of n-heptane at high pressures. Fuel 2015;149:138-42.
[230] Frassoldati A, Cuoci A, Faravelli T, Ranzi E. Kinetic modeling of the oxidation of ethanol and gasoline surrogate mixtures. Combust Sci Technol 2010;182:65367.

[231] Smith GP, Tao Y, Wang H. Foundational fuel chemistry model version 1.0 (FFCM-1). http://nanoenergy.stanford.edu/ffcm $1 ; 2016$.

[232] Simmie JM. Detailed chemical kinetic models for the combustion of hydrocarbon fuels. Prog Energy Combust Sci 2003;29:599-634.

[233] Battin-Leclerc F. Detailed chemical kinetic models for the low-temperature combustion of hydrocarbons with application to gasoline and diesel fuel surrogates. Prog Energy Combust Sci 2008;34:440-98.

[234] Sarathy SM, Westbrook CK, Mehl M, Pitz WJ, Togbé C, Dagaut P, et al. Comprehensive chemical kinetic modeling of the oxidation of 2-methylalkanes from C7 to C20. Combust Flame 2011;158:2338-57.

[235] Westbrook CK, Pitz WJ, Herbinet O, Curran HJ, Silke EJ. A comprehensive detailed chemical kinetic reaction mechanism for combustion of n-alkane hydrocarbons from n-octane to n-hexadecane. Combust Flame 2009;156:18199.

[236] Ji C, Dames E, Wang YL, Wang H, Egolfopoulos FN. Propagation and extinction of premixed $C_{5}-C_{12}$ n-alkane flames. Combust Flame 2010;157:277-87.

237] Ranzi E, Frassoldati A, Grana R, Cuoci A, Faravelli T, Kelley AP, et al. Hierarchica and comparative kinetic modeling of laminar flame speeds of hydrocarbon and oxygenated fuels. Prog Energy Combust Sci 2012;38:468-501.

[238] Ranzi E, Dente M, Goldaniga A, Bozzano G, Faravelli T. Lumping procedures in detailed kinetic modeling of gasification, pyrolysis, partial oxidation and combustion of hydrocarbon mixtures. Prog Energy Combust Sci 2001;27:99-139.

[239] Zádor J, Taatjes CA, Fernandes RX. Kinetics of elementary reactions in low-temperature autoignition chemistry. Prog Energy Combust Sci 2011;37:371-421.

[240] Cartlidge J, Tipper CF. The peroxides formed during hydrocarbon slow combustion and their role in mechanism. Proc R Soc Lond Ser A: Math, Phys Eng Sci 1961;261:388-401

[241] Knox JH. A new mechanism for the low temperature oxidation of hydrocarbons in the gas phase. Combust Flame 1965;9:297-310.

[242] Cox RA, Cole JA. Chemical aspects of the autoignition of hydrocarbon-air mixtures. Combust Flame 1985;60:109-23.

[243] Wang Z, Zhang L, Moshammer K, Popolan-Vaida DM, Shankar VSB, Lucassen A et al. Additional chain-branching pathways in the low-temperature oxidation of branched alkanes. Combust Flame 2016;164:386-96.

[244] Wang Z, Sarathy SM. Third $\mathrm{O}_{2}$ addition reactions promote the low-temperature auto-ignition of n-alkanes. Combust Flame 2016;165:364-72.

[245] Wang Z, Mohamed SY, Zhang L, Moshammer K, Popolan-Vaida DM, Shankar VSB, et al. New insights into the low-temperature oxidation of 2-methylhexane. Proc Combust Inst 2017;36:373-82.

[246] Healy D, Donato NS, Aul CJ, Petersen EL, Zinner CM, Bourque G, et al. n-Butane: Ignition delay measurements at high pressure and detailed chemical kinetic simulations. Combust Flame 2010;157:1526-39.

[247] Bugler J, Somers KP, Silke EJ, Curran HJ. Revisiting the kinetics and thermodynamics of the low-temperature oxidation pathways of alkanes: a case study o the three pentane isomers. J Phys Chem A 2015;119:7510-27.

[248] Bugler J, Marks B, Mathieu O, Archuleta R, Camou A, Grégoire C, et al. An ignition delay time and chemical kinetic modeling study of the pentane isomers. Combust Flame 2016;163:138-56.

[249] Zhang K, Banyon C, Togb C, Dagaut P, Bugler J, Curran HJ. An experimenta and kinetic modeling study of n-hexane oxidation. Combust Flame 2015;162: 4194-207.

[250] Zhang K, Banyon C, Bugler J, Curran HJ, Rodriguez A, Herbinet O, et al An updated experimental and kinetic modeling study of n-heptane oxidation. Combust Flame 2016;172:116-35

[251] Cai L, Pitsch H, Mohamed SY, Raman V, Bugler J, Curran H, et al. Optimized reaction mechanism rate rules for ignition of normal alkanes. Combust Flame 2016;173:468-82

[252] Won SH, Dooley S, Veloo PS, Wang H, Oehlschlaeger MA, Dryer FL, et al. The combustion properties of 2,6,10-trimethyl dodecane and a chemical functional group analysis. Combust Flame 2014;161:826-34.

[253] Lapuerta M, Hernandez JJ, Sarathy SM. Effects of methyl substitution on the auto-ignition of C16 alkanes. Combust Flame 2016;164:259-69.

[254] Wang W, Li Z, Oehlschlaeger MA, Healy D, Curran HJ, Sarathy SM, et al. An experimental and modeling study of the autoignition of 3-methylheptane. Proc Combust Inst 2013;34:335-43.

[255] Karsenty F, Sarathy SM, Togbé C, Westbrook CK, Dayma G, Dagaut P, et al. Experimental and kinetic modeling study of 3-methylheptane in a jet-stirred reactor. Energy Fuels 2012;26:4680-9.

[256] Sarathy SM, Javed T, Karsenty F, Heufer A, Wang W, Park S, et al. A comprehensive combustion chemistry study of 2,5-dimethylhexane. Combust Flame 2014;161:1444-59

[257] Sarathy SM, Niemann U, Yeung C, Gehmlich R, Westbrook CK, Plomer M, et al. A counterflow diffusion flame study of branched octane isomers. Proc Combust Inst 2013;34:1015-23.

[258] Li S, Sarathy SM, Davidson DF, Hanson RK, Westbrook CK. Shock tube and modeling study of 2,7-dimethyloctane pyrolysis and oxidation. Combust Flame $2015 \cdot 162: 2296-306$

[259] Ji C, Sarathy SM, Veloo PS, Westbrook CK, Egolfopoulos FN. Effects of fue branching on the propagation of octane isomers flames. Combust Flame 2012;159:1426-36.

[260] Liu N, Sarathy SM, Westbrook CK, Egolfopoulos FN. Ignition of non-premixed counterflow flames of octane and decane isomers. Proc Combust Inst 2013;34:904-10. 
[261] Westbrook C, Pitz WJ, Boercker JE, Curran HJ, Griffiths JF, Mohamed C, et al. Detailed chemical kinetic reaction mechanisms for autoignition of isomers of heptane under rapid compression. Proc Combust Inst 2002;29:1311-8.

[262] Westbrook CK, Pitz WJ, Curran HJ, Boercker J, Kunrath E. Chemical kinetic modeling study of shock tube ignition of heptane isomers. Int J Chem Kinet 2001;33:868-77.

[263] Selim H, Mohamed SY, Lucassen A, Hansen N, Sarathy SM. Effect of the methy substitution on the combustion of two methylheptane isomers: flame chemistry using vacuum-ultraviolet (VUV) photoionization mass spectrometry. Energy Fuels 2015;29:2696-708.

[264] Won SH, Haas FM, Tekawade A, Kosiba G, Oehlschlaeger MA, Dooley S, et al Combustion characteristics of C4 iso-alkane oligomers: Experimental characterization of iso-dodecane as a jet fuel surrogate component. Combust Flame 2016;165:137-43.

[265] Brezinsky K. The high-temperature oxidation of aromatic-Hydrocarbons. Prog Energy Combust Sci 1986;12:1-24

[266] Zhang Y, Somers KP, Mehl M, Pitz WJ, Cracknell RF, Curran HJ. Probing the antagonistic effect of toluene as a component in surrogate fuel models at low temperatures and high pressures. A case study of toluene/dimethyl ether mixtures. Proc Combust Inst 2017:36:413-21.

[267] Gulati SK, Walker RW. Addition of cyclohexane to slowly reacting $\mathrm{H}_{2}-\mathrm{O}_{2}$ mix tures at $480^{\circ} \mathrm{C}$. J Chem Soc, Faraday Trans 2 1989;85:1799-812.

[268] Handford-Styring SM, Walker RW. Addition of cyclopentane to slowly reacting mixtures of $\mathrm{H} 2+\mathrm{O}_{2}$ between 673 and $783 \mathrm{~K}$ : Reactions of $\mathrm{H}$ and $\mathrm{OH}$ with cyclopentane and of cyclopentyl radicals. J Chem Soc, Faraday Trans 1995;91:14318

[269] Yang Y, Boehman AL, Simmie JM. Effects of molecular structure on oxidation reactivity of cyclic hydrocarbons: experimental observations and conformational analysis. Combust Flame 2010;157:2369-79.

[270] Yang Y, Boehman AL, Simmie JM. Uniqueness in the low temperature oxidation of cycloalkanes. Combust Flame 2010;157:2357-68

[271] Al Rashidi MJ, Mehl M, Pitz WJ, Mohamed S, Sarathy SM. Cyclopentane combustion chemistry. Part I: mechanism development and computational kinetics. Combust Flame 2017;183:358-71.

[272] Al Rashidi MJ, Mármol JC, Banyon C, Sajid MB, Mehl M, Pitz WJ, et al. Cyclopentane combustion. Part II. Ignition delay measurements and mechanism validation. Combust Flame 2017;183:372-85.

[273] Weber BW, Pitz WJ, Mehl M, Silke EJ, Davis AC, Sung C-J. Experiments and modeling of the autoignition of methylcyclohexane at high pressure. Combust Flame 2014;161:1972-83.

[274] Vranckx S, Lee C, Chakravarty HK, Fernandes RX. A rapid compression machine study of the low temperature combustion of cyclohexane at elevated pressures. Proc Combust Inst 2013;34:377-84

[275] Al Rashidi MJ, Thion S, Togbe C, Dayma G, Mehl M, Dagaut P, et al. Elucidating reactivity regimes in cyclopentane oxidation: jet stirred reactor experiments, computational chemistry, and kinetic modeling. Proc Combust Inst 2017;36: 469-77.

[276] Silke EJ, Pitz WJ, Westbrook CK, Ribaucour M. Detailed chemical kinetic modeling of cyclohexane oxidation. J Phys Chem A 2007;111:3761-75.

[277] Mehl M, Vanhove G, Pitz WJ, Ranzi E. Oxidation and combustion of the nhexene isomers: a wide range kinetic modeling study. Combust Flame 2008; 155:756-72.

[278] Zhang F, Dibble TS. Effects of olefin group and its position on the kinetics for intramolecular h-shift and $\mathrm{HO}_{2}$ elimination of alkenyl peroxy radicals. J Phys Chem A 2011;115:655-63.

[279] Westbrook CK, Pitz WJ, Sarathy SM, Mehl M. Detailed chemical kinetic modeling of the effects of CC double bonds on the ignition of biodiesel fuels. Proc Combust Inst 2013;34:3049-56.

[280] Ray DJM, Waddington DJ. Gas phase oxidation of alkenes-Part II. The oxidation of 2-methylbutene-2 and 2,3-dimethylbutene-2. Combust Flame 1973;20:32734.

[281] Ray DJM, Waddington DJ. Co-oxidation of acetaldehyde and alkenes in the gas phase. Symp (Int) Combust 1971;13:261-70.

[282] Ray DJM, Ruiz Diaz R, Waddington DJ. Gas-phase oxidation of butene-2: the role of acetaldehyde in the reaction. Symp (Int) Combust 1973;14:259-66.

[283] Metcalfe WK, Pitz WJ, Curran HJ, Simmie JM, Westbrook CK. The development of a detailed chemical kinetic mechanism for diisobutylene and comparison to shock tube ignition times. Proc Combust Inst 2007;31:377-84.

[284] Zhong B-J, Zheng D. A chemical mechanism for ignition and oxidation of multicomponent gasoline surrogate fuels. Fuel 2014;128:458-66.

[285] Cord M, Sirjean B, Fournet R, Tomlin A, Ruiz-Lopez M, Battin-Leclerc F. Improvement of the modeling of the low-temperature oxidation of n-butane: study of the primary reactions. J Phys Chem A 2012;116:6142-58.

[286] Healy D, Donato NS, Aul CJ, Petersen EL, Zinner CM, Bourque G, et al. Isobutane ignition delay time measurements at high pressure and detailed chemical kinetic simulations. Combust Flame 2010;157:1540-51

[287] Bugler J, Rodriguez A, Herbinet O, Battin-Leclerc F, Togbe C, Dayma G, et al. An experimental and modelling study of n-pentane oxidation in two jet-stirred reactors: the importance of pressure-dependent kinetics and new reaction pathways. Proc Combust Inst 2017;36:441-8.

[288] Cai L, Pitsch H. Mechanism optimization based on reaction rate rules. Combus Flame 2014;161:405-15.

[289] Hu E, Gao Z, Liu Y, Yin G, Huang Z. Experimental and modeling study on ignition delay times of dimethoxy methane/n-heptane blends. Fuel 2017;189:350-7.
[290] Karwat DMA, Wagnon SW, Wooldridge MS, Westbrook CK. Low-temperature speciation and chemical kinetic studies of n-heptane. Combust Flame 2013:160:2693-706

[291] Hakka HM, Cracknell RF, Pekalski A, Glaude PA, Battin-Leclerc F. Experimental and modeling study of ultra-rich oxidation of n-heptane. Fuel 2015;144:35868.

[292] Seidel L, Moshammer K, Wang X, Zeuch T, Kohse-Höinghaus K, Mauss F. Comprehensive kinetic modeling and experimental study of a fuel-rich, premixed n-heptane flame. Combust Flame 2015;162:2045-58.

[293] Zhang J, Niu S, Zhang Y, Tang C, Jiang X, Hu E, et al. Experimental and modeling study of the auto-ignition of n-heptane/n-butanol mixtures. Combust Flame 2013;160:31-9.

[294] Herbinet O, Husson B, Serinyel Z, Cord M, Warth V, Fournet R, et al. Experimental and modeling investigation of the low-temperature oxidation of n-heptane. Combust Flame 2012;159:3455-71

[295] Dagaut P, Togbe C. Experimental and modeling study of the kinetics of oxidation of ethanol-n-heptane mixtures in a jet-stirred reactor. Fuel 2010;89:280-

[296] Mohamed SY, Cai L, Khaled F, Banyon C, Wang Z, Al Rashidi MJ, et al. Modeling ignition of a heptane isomer: improved thermodynamics, reaction pathways, kinetics, and rate rule optimizations for 2-methylhexane. J Phys Chem A 2016;120:2201-17.

[297] Atef N, Kukkadapu G, Mohamed SY, Al Rashidi M, Banyon C, Mehl M, et al. A comprehensive iso-octane combustion model with improved thermochemistry and chemical kinetics. Combust Flame 2017;178:111-34.

[298] Li Q, Zhang W, Jin W, Xie Y, Huang Z. Laminar flame characteristics and kinetic modeling study of methanol-isooctane blends at elevated temperatures. Fuel 2016;184:836-45

[299] Curran HJ, Gaffuri P, Pitz WJ, Westbrook CK. A comprehensive modeling study of iso-octane oxidation. Combust Flame 2002;129:253-80.

[300] Malewicki T, Comandini A, Brezinsky K. Experimental and modeling study on the pyrolysis and oxidation of iso-octane 2012;34:353-360. Proc Combust Inst 2013;34:353-60.

[301] Yang J, Zhao L, Yuan W, Qi F, Li Y. Experimental and kinetic modeling investigation on laminar premixed benzene flames with various equivalence ratios. Proc Combust Inst 2015;35:855-62.

[302] Saggese C, Frassoldati A, Cuoci A, Faravelli T, Ranzi E. A wide range kinetic modeling study of pyrolysis and oxidation of benzene. Combust Flame 2013; 160:1168-90.

[303] Pitz WJ, Seiser R, Bozzelli JW, Da-Costa I, Fournet R, Battin-Leclerc F, et al. Chemical kinetic characterization of combustion of toluene. 2nd Joint Meeting of the U. S. Section of the Combustion Institute; 2001.

[304] Metcalfe WK, Dooley S, Dryer FL. Comprehensive detailed chemical kinetic modeling study of toluene oxidation. Energy Fuels 2011;25:4915-36.

[305] Yuan W, Li Y, Dagaut P, Yang J, Qi F. Investigation on the pyrolysis and oxidation of toluene over a wide range conditions. II. A comprehensive kinetic modeling study.. Combust Flame 2015;162:22-40.

[306] Andrae JCG. Comprehensive chemical kinetic modeling of toluene reference fuels oxidation. Fuel 2013:107:740-8.

[307] Tian Z, Pitz WJ, Fournet R, Glaude P-A, Battin-Leclerc F. A detailed kinetic modeling study of toluene oxidation in a premixed laminar flame. Proc Combust Inst 2011:33:233-41.

[308] Detilleux VR, Vandooren J. Experimental and kinetic modeling investigation of toluene combustion in premixed, one-dimensional and laminar toluene-oxygen-argon flames. Proc Combust Inst 2011;33:217-24.

[309] Gail S, Dagaut P. Oxidation Of m-xylene in a JSR: Experimental study and detailed chemical kinetic modeling. Combust Sci Technol 2007;179:813-44.

[310] Zhao L, Cheng Z, Ye L, Zhang F, Zhang L, Qi F, et al. Experimental and kinetic modeling study of premixed o-xylene flames. Proc Combust Inst 2015;35: 1745-52.

[311] Gail S, Dagaut P. Experimental kinetic study of the oxidation of -xylene in a JSR and comprehensive detailed chemical kinetic modeling. Combust Flame 2005;141:281-97.

[312] Yuan W, Li Y, Pengloan GL, Togb C, Dagaut P, Qi F. A comprehensive experimental and kinetic modeling study of ethylbenzene combustion. Combust Flame 2016:166:255-65

[313] Husson B, Ferrari M, Herbinet O, Ahmed SS, Glaude P-A, Battin-Leclerc F. New experimental evidence and modeling study of the ethylbenzene oxidation. Proc Combust Inst 2013;34:325-33.

[314] Li Y, Cai J, Zhang L, Yang J, Wang Z, Qi F. Experimental and modeling investigation on premixed ethylbenzene flames at low pressure. Proc Combust Inst 2011;33:617-24.

[315] Gudiyella S, Brezinsky K. High pressure study of 1,3,5-trimethylbenzene oxidation. Combust Flame 2012;159:3264-85.

[316] Weng J, Liu Y, Wang B, Xing L, Zhang L, Tian Z. Experimental and kinetic investigation of 1,2,4-trimethylbenzene oxidation at low temperature. Proc Combust Inst 2017:36:909-17.

[317] Al Rashidi MJ, Thion S, Togbe C, Dayma G, Mehl M, Dagaut P, et al. Elucidating reactivity regimes in cyclopentane oxidation: jet stirred reactor experiments, computational chemistry, and kinetic modeling. Proc Combust Inst 2017;36:469-77.

[318] Buda F, Heyberger B, Fournet R, Glaude P-A, Warth V, Battin-Leclerc F. Modeling of the gas-phase oxidation of cyclohexane. Energy Fuel 2006;20:1450-9.

[319] Serinyel Z, Herbinet O, Frottier O, Dirrenberger P, Warth V, Glaude P-A, et al. An experimental and modeling study of the low- and high-temperature oxidation of cyclohexane. Combust Flame 2013;160:2319-32. 
[320] Pitz WJ, Naik CV, Mhaoldúin TN, Westbrook CK, Curran HJ, Orme JP, et al. Modeling and experimental investigation of methylcyclohexane ignition in a rapid compression machine. Proc Combust Inst 2007:31:267-75.

[321] Orme JP, Curran HJ, Simmie JM. Experimental and modeling study of methyl cyclohexane pyrolysis and oxidation. J Phys Chem A 2006;110:114-31.

[322] Weber BW, Pitz WJ, Mehl M, Silke EJ, Davis AC, Sung C-J. Experiments and modeling of the autoignition of methylcyclohexane at high pressure. Combust Flame 2014;161:1972-83.

[323] Wang Z, Ye L, Yuan W, Zhang L, Wang Y, Cheng Z, et al. Experimental and kinetic modeling study on methylcyclohexane pyrolysis and combustion. Combust Flame 2014;161:84-100.

[324] Wang Z, Bian H, Wang Y, Zhang L, Li Y, Zhang F, et al. Investigation on primary decomposition of ethylcyclohexane at atmospheric pressure. Proc Combust Inst 2015;35:365-75.

[325] Eldeeb MA, Jouzdani S, Wang Z, Sarathy SM, Akih-Kumgeh B. Experimental and chemical kinetic modeling study of dimethylcyclohexane oxidation and pyrolysis. Energy Fuels 2016;30:8648-57.

[326] Cheng Y, Hu E, Deng F, Yang F, Zhang Y, Tang C, et al. Experimental and kinetic comparative study on ignition characteristics of 1-pentene and n-pentane. Fuel 2016:172:263-72.

[327] Fan X, Wang G, Li Y, Wang Z, Yuan W, Zhao L. Experimental and kinetic modeling study of 1-hexene combustion at various pressures. Combust Flame 2016;173:151-60

[328] Yahyaoui M, Djebaïli-Chaumeix N, Paillard CE, Touchard S, Fournet R, Glaude $\mathrm{PA}$, et al. Experimental and modeling study of 1-hexene oxidation behind reflected shock waves. Proc Combust Inst 2005;30:1137-45.

[329] Yahyaoui M, Djebaili-Chaumeix N, Dagaut P, Paillard CE, Gail S. Kinetics of 1hexene oxidation in a JSR and a shock tube: experimental and modeling study. Combust Flame 2006;147:67-78.

[330] Touchard S, Fournet R, Glaude PA, Warth V, Battin-Leclerc F, Vanhove G, et al. Modeling of the oxidation of large alkenes at low temperature. Proc Combust Inst 2005;30:1073-81

[331] Mehl M, Vanhove G, Pitz W, Ranzi E. Oxidation and combustion of the n-hexene isomers: a wide range kinetic modeling study. Combust Flame 2008;155:75672

[332] Minetti R, Carlier M, Ribaucour M, Therssen E, Sochet LR. A rapid compression machine investigation of oxidation and auto-ignition of n-Heptane: measurements and modeling. Combust Flame 1995:102:298-309.

[333] Curran HJ, Gaffuri P, Pitz WJ, Westbrook CK. A comprehensive modeling study of n-heptane oxidation. Combust Flame 1998;114:149-77.

[334] Curran HJ, Gaffuri P, Pitz WJ, Westbrook CK, Leppard WR. Autoignition chemistry in a motored engine: an experimental and kinetic modeling study. Symp (Int) Combust 1996;26:2669-77.

[335] Ranzi E, Gaffuri P, Faravelli T, Dagaut P. A wide-range modeling study of n-heptane oxidation. Combust Flame 1995:103:91-106.

[336] Westbrook CK, Warnatz J, Pitz WJ. A detailed chemical kinetic reaction mechanism for the oxidation of iso-octane and n-heptane over an extended temperature range and its application to analysis of engine knock. Symp (Int) Combust 1989;22:893-901.

[337] Chevalier C, Pitz WJ, Warnatz J, Westbrook CK. Hydrocarbon ignition: automatic generation of reaction mechanisms and applications to modeling of engine knock. Symp (Int) Combust 1992;24:93-101.

[338] Morley C. A fundamentally based correlation between alkane structure and octane number. Combust Sci Technol 1987;55(4-6):115-23.

[339] Vuilleumier D., Selim H., Dibble R., Sarathy M.. Exploration of heat release in a homogeneous charge compression ignition engine with primary reference fuels. SAE Technical Paper 2013-01-2622 2013.

[340] Hwang W, Dec J, Sjöberg M. Spectroscopic and chemical-kinetic analysis of the phases of HCCI autoignition and combustion for single- and two-stage ignition fuels. Combust Flame 2008;154:387-409.

[341] Puduppakkam KV, Liang L, Naik CV, Meeks E, Kokjohn SL, Reitz RD. Use of detailed kinetics and advanced chemistry-solution techniques in CFD to investigate dual-fuel engine concepts. SAE Int J Engines 2011;4:1127-49.

[342] Puduppakkam K.V., Naik C.V., Wang C., Meeks E.. Validation studies of a detailed kinetics mechanism for diesel and gasoline surrogate fuels. SAE Technical Paper 2010-01-0545 2010.

[343] Naik CV, Puduppakkam K, Wang C, Kottalam J, Liang L, Hodgson D, et al. Applying detailed kinetics to realistic engine simulation: the surrogate blend optimizer and mechanism reduction strategies. SAE Int. J. Engines 2010;3:241-59.

[344] Singh E, Badra J, Mehl M, Sarathy SM. Chemical kinetic insights into the octane number and octane sensitivity of gasoline surrogate mixtures. Energy Fuels 2017;31:1945-60.

[345] Leppard W.R. The chemical origin of fuel octane sensitivity. SAE Technical Paper 9021371990.

[346] Curran HJ, Pitz WJ, Westbrook CK, Callahan GV, Dryer FL. Oxidation of automotive primary reference fuels at elevated pressures. Symp (Int) Combust 1998;27:379-87.

[347] Westbrook CK, Pitz WJ, Mehl M, Curran HJ. Detailed chemical kinetic reaction mechanisms for primary reference fuels for diesel cetane number and sparkignition octane number. Proc Combust Inst 2011;33:185-92.

[348] Pires da Cruz A, Pera C, Anderlohr J, Bounaceur R, Battin-Leclerc F. A complex chemical kinetic mechanism for the oxidation of gasoline surrogate fuels: n heptane, iso octane and toluene - mechanism development and validation. In: Proceedings of the European combustion meeting; 2007.

[349] Buda F, Bounaceur R, Warth V, Glaude PA, Fournet R, Battin-Leclerc F. Progress toward a unified detailed kinetic model for the autoignition of alkanes from C4 to C10 between 600 and 1200 K. Combust Flame 2005;142:170-86.

[350] Park S, Wang Y, Chung SH, Sarathy SM. Compositional effects on PAH and soot formation in counterflow diffusion flames of gasoline surrogate fuels. Combust Flame 2017;178:46-60

[351] Andrae JCG. Development of a detailed kinetic model for gasoline surrogate fuels. Fuel 2008:87:2013-22.

[352] Andrae JCG, Björnbom P, Cracknell RF, Kalghatgi GT. Autoignition of toluene reference fuels at high pressures modeled with detailed chemical kinetics. Combust Flame 2007;149:2-24.

[353] Hashimoto K., Koshi M., Miyoshi A., Murakami Y., Oguchi T., Sakai Y., et al Development of gasoline combustion reaction model. SAE Technical Paper 2013-01-0887-10 2013

[354] Biofuels AA. (alcohols and biodiesel) applications as fuels for internal combustion engines. Prog Energy Combust Sci 2007;33:233-71.

[355] Demirbas A. Progress and recent trends in biofuels. Prog Energy Combust Sci 2007;33:1-18.

[356] Salvo A, Geiger FM. Reduction in local ozone levels in urban São Paulo due to a shift from ethanol to gasoline use. Nat Geosci 2014;7:450-8.

[357] Barrett SRH, Speth RL, Eastham SD, Dedoussi IC, Ashok A, Malina R, et al. Impact of the Volkswagen emissions control defeat device on US public health. Environ Res Lett 2015;10:114005-11.

[358] Chossière GP, Malina R, Ashok A. Public health impacts of excess NOx emissions from Volkswagen diesel passenger vehicles in Germany. Environ Res Lett 2017; 12:1-14.

[359] Wang Z, Qi Y, He X, Wang J, Shuai S, Law CK. Analysis of pre-ignition to superknock: hotspot-induced deflagration to detonation. Fuel 2015;144:222-7.

[360] Im HG, Pal P, Wooldridge MS, Mansfield AB. A regime diagram for autoignition of homogeneous reactant mixtures with turbulent velocity and temperature fluctuations. Combust Sci Technol 2015;187:1263-75.

[361] Grogan KP, Goldsborough SS, Ihme M. Ignition regimes in rapid compression machines. Combust Flame 2015: 3071-80.

[362] Bogin GE Jr, Osecky E, Ratcliff MA, Luecke J, He X, Zigler BT, et al. Ignition quality tester (IQT) Investigation of the negative temperature coefficient region of alkane autoignition. Energy Fuels 2013;27:1632-42.

[363] Bogin Jr GE, DeFilippo A, Chen JY, Chin G, Luecke J, Ratcliff MA, et al. Numerica and experimental investigation of n-heptane autoignition in the ignition quality tester (IQT). Energy Fuels 2011;25:5562-72.

[364] Lapuerta M, Hernández JJ, Fernández-Rodríguez D, Cova-Bonillo A. Autoignition of blends of n-butanol and ethanol with diesel or biodiesel fuels in a constantvolume combustion chamber. Energy 2017;118:613-21.

[365] Lapuerta M, Sanz-Argent J, Raine RR. Ignition characteristics of diesel fuel in a constant volume bomb under diesel-like conditions. Effect Operation parameters.. Energy Fuels 2014;28:5445-54.

[366] Wang L, Badra JA, Roberts WL, Fang T. Characteristics of spray from a GDI fuel injector for naphtha and surrogate fuels. Fuel 2017;190:113-28.

[367] Kim K, Kim D, Jung Y, Bae C. Spray and combustion characteristics of gasoline and diesel in a direct injection compression ignition engine. Fuel 2013;109: 616-26.

[368] Naser N, Jaasim M, Atef N, Chung SH, Im HG, Sarathy SM. On the effects of fuel properties and injection timing in partially premixed compression ignition of low octane fuels. Fuel 2017;207:373-88.

[369] Badra J, Viollet Y, Elwardany A, Im HG, Chang J. Physical and chemical effects of low octane gasoline fuels on compression ignition combustion. Appl Energy 2016;183:1-12

[370] Zhen X, Wang Y, Liu D. An overview of the chemical reaction mechanisms for gasoline surrogate fuels. Appl Therm Eng 2017;124:1257-68.

[371] Ren S, Kokjohn SL, Wang Z, Liu H, Wang B, Wang J. A multi-component wide distillation fuel (covering gasoline, jet fuel and diesel fuel) mechanism for combustion and PAH prediction. Fuel 2017;208:447-68.

[372] Badra J, AlRamadan AS, Sarathy SM. Optimization of the octane response of gasoline/ethanol blends. Appl Energy 2017;203:778-93.

[373] Foong TM, Morganti KJ, Brear MJ, Da Silva G, Yang Y, Dryer FL. The octane numbers of ethanol blended with gasoline and its surrogates. Fuel 2014;115:1-13

[374] Yuan H, Yang Y, Brear MJ, Foong TM, Anderson JE. Optimal octane number correlations for mixtures of toluene reference fuels (TRFs) and ethanol. Fuel 2017; 188:408-17.

[375] Anderson JE, DiCicco DM, Ginder JM, Kramer U, Leone TG, Raney-Pablo HE, et al High octane number ethanol-gasoline blends: Quantifying the potential benefits in the United States. Fuel 2012:97:585-94.

[376] Speth RL, Chow EW, Malina R, Barrett SRH, Heywood JB, Green WH. Economic and environmental benefits of higher-octane gasoline. Environ Sci Technol 2014:48:6561-8.

[377] Zhang B, Sarathy SM. Lifecycle optimized ethanol-gasoline blends for turbocharged engines. Appl Energy 2016;181:38-53.

[378] Hao H, Liu F, Liu Z, Zhao F. Compression ignition of low-octane gasoline: life cycle energy consumption and greenhouse gas emissions. Appl Energy 2016;181:391-8 